\author{
Universidade de São Paulo \\ Instituto de Astronomia, Geofísica e Ciências Atmosféricas \\ Departamento de Geofísica
}

\title{
Mantle Anisotropy and Asthenospheric Flow Around Cratons in SE South America
}

\author{
Bruna Chagas de Melo \\ Supervisor: Marcelo Assumpção
}





\begin{abstract}
Seismic anisotropy at continental regions, mainly at stable areas, gives important information about past and present tectonic events, and helps us in understanding patterns of upper mantle flow in a way not achieved by other methods. The measurement of shear wave splitting (SWS), at individual stations, from core refracted phases (such as SKS phases), indicates the amount and orientation of the seismic anisotropy in the upper mantle. Previous studies of SWS in South America concentrated mainly along the Andes and in southeast Brazil. Now we add extra measurements extending to all Brazilian territory, especially in the Pantanal and ParanáChaco basins, as part of the FAPESP "3-Basins Thematic Project". The results from both temporary deployments and from the Brazilian permanent network provide a more complete and robust anisotropy map of the South America stable platform. In general the fast polarization orientations have an average E-W orientation. Significant deviations to ESE-WNW or ENEWSW are observed in many regions. We compare our results with different anisotropy proxies: absolute plate motion given by the hotspot reference frame HS3-NUVEL-1A, a recent model of time dependent upper mantle flow induced by the Nazca plate subduction, global anisotropy from surface wave tomography, and geologic trends. We observe a poor correlation of the anisotropy directions with geological trends, with the exception of a few stations in northern Brazil and a better correlation with the mantle flow model. Therefore, our observed anisotropy is mainly due to upper-mantle flow, with little contribution from frozen lithospheric anisotropy. Also, deviations from the mantle flow model, which includes a thicker lithosphere at the Amazon craton, are mainly due to flow surrounding cratonic nuclei not used in the model: the keel of the São Francisco craton and a possible cratonic nucleus beneath the northern part of the Paraná Basin (called Paranapanema block). Large delay times at the Pantanal Basin may indicate a stronger asthenospheric channel, a more coherent flow, or a thicker asthenosphere. Small delays beneath the northern Paraná Basin and central Amazon craton may indicate thinner anisotropic asthenosphere.
\end{abstract}

Keywords: Seismic Anisotropy; Shear Wave Splitting; Mantle Flow; South America. 


\section{Resumo}

Anisotropia sísmica em regiões continentais, principalmente em áreas estáveis, nos dá informações importantes sobre eventos tectônicos do passado e do presente, e nos ajuda a entender padrões de fluxo do manto superior de forma não alcançada por outros métodos geofísicos. A medida de separação de ondas cisalhantes (SWS), em estações individuais, de fases refratadas no núcleo (fases SKS, por exemplo), indica a intensidade e orientação da anisotropia sísmica no manto superior. Estudos prévios de SWS na América do Sul se concentraram principalmente ao longo dos Andes e no sudeste do Brasil. Agora adicionamos medidas extras que se extendem por todo território Brasileiro e alguns países vizinhos, especialmente nas bacias do Pantanal e do Chaco-Paraná, como parte do "Projeto Temático 3-Bacias" da FAPESP. Os resultados tanto das estações temporárias quanto da rede permanente Brasileira mostram um mapa de anisotropia mais robusto e completo da plataforma estável da América do Sul. Em geral, as direções de polarização rápida tem em média direção L-O. Desvios significantes nas direções LSL-ONO ou LNL-OSO são observadas em muitas regiões. Comparamos nossos resultados com diferentes representantes da anisotropia: movimento absoluto de placa dado pelo sistema de referência de hotspot HS3-NUVEL-1A, um modelo recente dependente do tempo de fluxo do manto superior induzido pela subducção da placa de Nazca, anisotropia global de tomografia de ondas de superfície, e tendências geológicas. Observamos pouca correlação das direções de anisotropia com tendências geológicas, com exceção de algumas estações no norte do Brasil e uma melhor correlação com o modelo de fluxo do manto. Portanto, nossa anisotropia observada é devida principalmente a fluxo do manto superior, com pouca contribuição de anisotropia " congelada" litosférica. Também, desvios do modelo de fluxo do manto, o qual inclui uma litosfera mais espessa no cráton da Amazônia, são devido ao fluxo ao redor de núcleos cratônicos não usados no modelo: a quilha do cráton do São Francisco e um possível núcleo cratônico abaixo da região norte da bacia do Paraná (chamado bloco do Paranapanema). Atrasos de tempo grandes na bacia do Pantanal podem indicar um canal astenosférico mais forte, um fluxo mais coerente ou uma astenosfera mais espessa. Pequenos atrasos abaixo da parte norte da bacia do Paraná e no centro do cráton da Amazônia podem indicar uma astenosfera mais fina.

Palavras Chave: Anisotropia Sísmica; Divisão de Onda Cisalhante; Fluxo do Manto; América do Sul. 


\section{Contents}

Abstract i

Resumo ii

1 Introduction 1

1.1 Thesis Organization. . . . . . . . . . . . . . . . . . 1

1.2 Overview of Project. . . . . . . . . . . . . . . . . . . . 2

1.3 Seismic Anisotropy in the Upper Mantle . . . . . . . . . . . . . . . . . 2

$1.4 \quad$ Shear Wave Splitting . . . . . . . . . . . . . . . . . . . . . . . . . . 4

1.5 Transverse Component Minimization Method $\ldots \ldots \ldots \ldots$

1.5 .1 Two Layer Anisotropy $\ldots \ldots \ldots \ldots$

$\begin{array}{lll}2 & \text { Paper } & 16\end{array}$

3 Additional Results and Discussion $\quad 65$

3.1 Comparison with Different Anisotropy Proxies . . . . . . . . . . . . . 67

3.2 Two Layer Anisotropy $\ldots \ldots \ldots$

$\begin{array}{lll}4 \text { Conclusion } & 73\end{array}$

4.1 Final Conclusions . . . . . . . . . . . . . . . . . . . . . . . . . 73

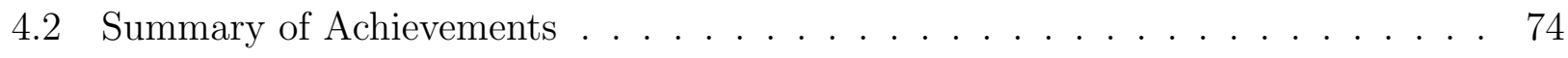

4.3 Future Work . . . . . . . . . . . . . . . . . . . . . . . . . . 74

\begin{tabular}{ll}
\hline A Supplementary Material & 76
\end{tabular}

A.1 Figures . . . . . . . . . . . . . . . . . . . . . . . . . . . . 77 


\section{List of Figures}

1.1 Illustration of the creation of olivine LPO at mid-ocean ridges. The a-axis of the olivine crystals tends to align with the lineation direction, in the foliation plane. Therefore, with the flow directions perpendicular to the ridge direction, maximum P- and S-wave seismic velocities are observed in the spreading directions parallel to the a-axis, and minimum velocities in the ridge direction. . . . . . . . 3

1.2 An olivine crystal showing the different seismic velocities on each direction. The a-axis is equivalent to [100] direction, where both $\mathrm{P}$ and $\mathrm{S}$ velocities are higher compared to the [010] and [001] directions (b and c axes). Figure modified from Stein and Wysession (2002). . . . . . . . . . . . . . . . . . . . 3

1.3 Representation of a shear wave passing through an anisotropic medium. The alignment of anisotropic minerals, as olivine, will cause the waves to split, with the fast component aligned to olivine foliation plane, and a time difference relative to the thickness and intensity of the anisotropic layer. . . . . . . . . . . 5

1.4 Ray paths of a shear wave and a core refracted shear wave. When the teleseismic core refracted shear wave (SKS in this case) crosses the CMB it removes all source side anisotropy. When it encounters an anisotropic medium beneath the station, shear wave splitting will occur. . . . . . . . . . . . . . . . . . 6

1.5 The transverse component minimization method finds the pair of parameters $\phi$ and $\delta t$ that best removes the energy on the transverse component seismogram.

On the first window is shown a typical ellipsoidal XKS wave particle motion that have crossed an anisotropic layer. After application of the method to remove the effect of anisotropy, the corrected particle motion plot is linearized. . . . . . . 7 
1.6 The event analyses window of an SKS wave at station ITAB from the BL network.

a) Normalized radial and transverse seismogram components showing the SKS wave arrival. Purple bars are 50 randomly selected time windows for statistical analyses. b) Particle motion of the original wave showing an ellipsoidal shape. The purple line shows the back-azimuth direction. c) In the energy grid of the splitting parameters, the pair that best minimizes the energy on the transverse component is chosen (blue cross). The black circle is the error estimated with the $95 \%$ confidence level method. d) Particle motion after the application of the method becomes linear, in the direction of the back-azimuth. e) Splitting parameters found and their respective errors. . . . . . . . . . . . . . . . . . . 9

1.7 Distribution of splitting parameters with back-azimuth obtained from AQDB station, BL network. When many measurements do not show large variation with back-azimuth, they can be averaged together. . . . . . . . . . . . . . . 10

1.8 Comparison of a a) the two top graphs are the 1-layer fit of the two anisotropy parameters; with b) bottom graphs show the 2-layer fit of the two anisotropy parameters, all at station PTGB, BL network. Because a large number of events are at the back-azimuthal range from $220^{\circ}$ to $250^{\circ}$, these measurements have a higher contribution to the fit in both cases. . . . . . . . . . . . . . . . . . 11

$3.1 \quad$ All SWS fast directions from this study (black bars) and other published results (gray bars). The bar lengths indicate delay time and good/average qualities of SWS are indicated by thick and thin bars. Red bars are surface wave azimuthal anisotropy directions at $300 \mathrm{~km}$ depth. Colors indicate S-wave velocity anomalies at $150 \mathrm{~km}$ depth from the surface-wave tomography model SL2013Sv. The white arrow indicates the absolute plate motion in the hotspot reference frame HS3NUVEL1A. Colored contours are boundaries of major provinces. Null bars (purple bars) are plotted at stations where few or no measurements were found. Bold numbers denote lithosphere/asthenosphere depth from S-wave receiver functions. 66 
3.2 SWS orientations compared with the main faults mapped at Brazilian territory.

Blue ellipses are the areas where the SWS measurements show a general ESE-

WNE direction. In few stations there is a indicative of agreement of the SWS orientation with the direction of the fault alignment. AC: Amazon Craton. . . . 67

3.3 Upper mantle flow directions (a) and LPO directions computed from TI axis (b), both at $250 \mathrm{~km}$ compared with the observed fast-polarization orientations (black bars) and their respective histograms of the difference between the SWS direction and the model. (c) comparison of the observed SWS fast directions with the predicted SKS, with its respective histogram (Hu, Faccenda, and Liu,

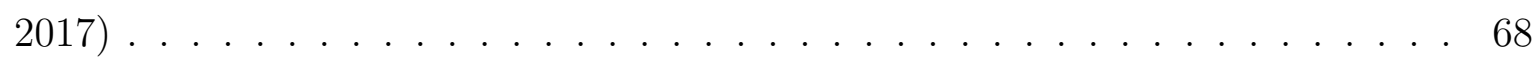

3.4 Two-layer anisotropy results at stations PDRB, PTGB, SALB and VBST plotted with back-azimuth. The curves in green are the 10 best fit models relating the 1 layer apparent parameters to the 2-layer parameters, by the method of Silver and Savage (1994) . . . . . . . . . . . . . . . . . . . . 70

3.5 Stations where a 2-layer inversion was calculated compared with a) velocity directions and b) LPO from TI axis, both at $250 \mathrm{~km}$ depth, and main fault directions in brown. Black bars are anisotropy directions of the lower layer, purple bars are anisotropy directions of the upper layer and green bars are the 1-layer anisotropy directions. AC: Amazon craton; WPS: Western Parana Suture; Pb: Paranapanema block . . . . . . . . . . . . . . . . . . . . 71

A.1 Station names and their respective networks used in this paper. AC: Amazon craton; SFC: São Francisco craton; Pb: Paranapanema Block. . . . . . . . . . . 78 


\section{Chapter 1}

\section{Introduction}

\subsection{Thesis Organization}

This M. Sc. dissertation is formatted into four chapters. Chapter One provides the background information for the project, which includes information on seismic velocity anisotropy, shear wave splitting, the shear wave splitting methodology used herein, and a discussion on two layer anisotropy. Chapter Two is a paper submitted to the Journal of Geophysical International and is currently under revision, to be published shortly. This paper covers the main shear wave splitting results and discussion at the southeast part of stable South America. Because Chapter Two is meant to be a self-containing journal article, some information such as Results and Discussion is stated solely in that chapter. Additional work has been done since the manuscript submission, with more stations analyzed in the northern part of Brazil, and these results will be included in Chapter Three. Chapter Four is a conclusion, of the results from Chapter Two plus the additional results of Chapter Three, plus a summary of the achievements and propositions for future work. An Appendix is supplied, with a table of results, and additional figures. 


\subsection{Overview of Project}

We present shear wave splitting (SWS) results of the southeast stable area of South America, including the Pantanal, Paraná and Chaco-Paraná basins as part of the FAPESP "3-Basins Thematic Project". We used a new package called SplitRacer, by Reiss and Rümpker (2017) to perform seismic anisotropy measurements using the Transverse Component Minimization method (Silver and Chan, 1991). The results obtained herein complete the anisotropy map of South America in areas not sampled before and make it possible to better understand our tectonic history and patterns of upper mantle flow. To do so, our measurements are compared to different anisotropy proxies: absolute plate motion given by the hotspot reference frame HS3NUVEL-1A, upper mantle flow induced by the Nazca plate subduction (Hu, Faccenda, and Liu, 2017), global anisotropy from surface wave tomography (Debayle, Dubuffet, and Durand, 2016) and geologic trends.

\subsection{Seismic Anisotropy in the Upper Mantle}

Seismic anisotropy is the dependence of elastic wave velocity on propagation direction and polarization orientation. One of the most common causes of anisotropy in the mantle is preferred alignment of crystals such as olivine (the most common mineral in the upper mantle) to create lattice preferred orientation (LPO) (Ismail and Mainprice, 1998).

LPO textures are created when crystals within a polycrystalline aggregate are preferentially aligned by an externally imposed deformation mechanism (e.g. Figure 1.1) (Li, Di Leo, and Ribe, 2014). Dislocation creep is commonly presumed to be the dominant mechanism for LPO fabric (Long and Silver, 2009; Savage1999SeismicSplitting), although additional deformation mechanisms such as grain boundary sliding, dislocation glide, and diffusion creep may also play a role in causing upper mantle anisotropy (Li, Di Leo, and Ribe, 2014).

In an anisotropic medium with LPO, a seismic wave will travel faster parallel to the a-axis of the olivine and slower if it is perpendicular to that axis (Figure 1.2. Since olivine is one 


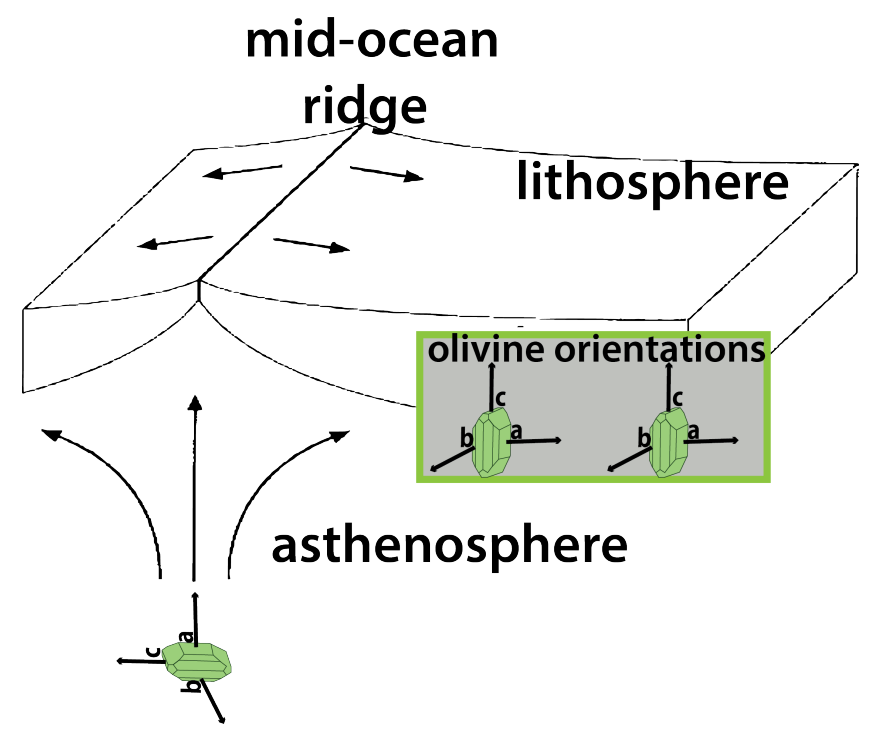

Figure 1.1: Illustration of the creation of olivine LPO at mid-ocean ridges. The a-axis of the olivine crystals tends to align with the lineation direction, in the foliation plane. Therefore, with the flow directions perpendicular to the ridge direction, maximum $\mathrm{P}$ - and $\mathrm{S}$-wave seismic velocities are observed in the spreading directions parallel to the a-axis, and minimum velocities in the ridge direction.

of the main minerals in the upper mantle, and xenolith studies show that for typical mantle conditions it contributes the most to seismic anisotropy (Zhang and Karato, 1995), it is usually assumed that olivine LPO is the primary source of observed anisotropy (Silver and Chan, 1991; Zhang and Karato, 1995; Silver, 1996). LPO can provide information regarding strain and deformation processes in the upper mantle.

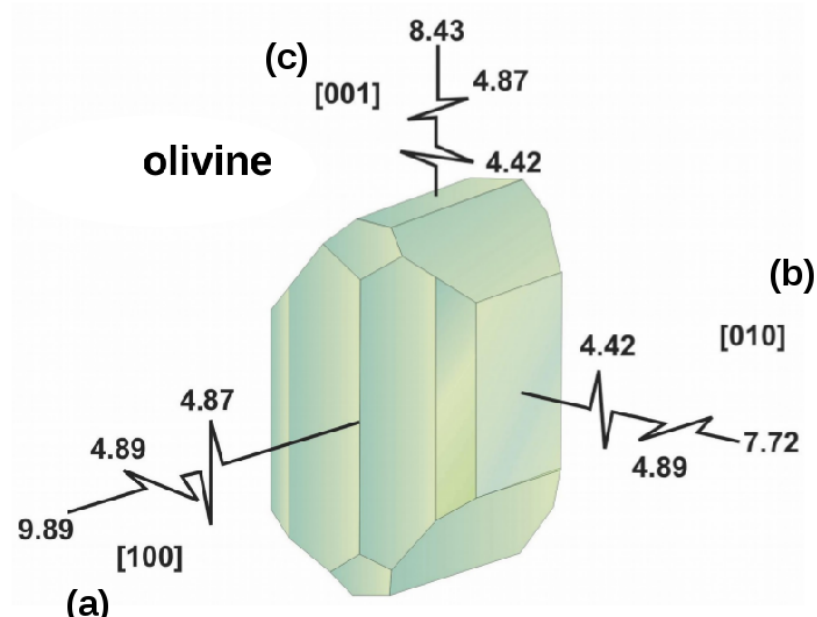

Figure 1.2: An olivine crystal showing the different seismic velocities on each direction. The a-axis is equivalent to [100] direction, where both $\mathrm{P}$ and $\mathrm{S}$ velocities are higher compared to the [010] and [001] directions (b and c axes). Figure modified from Stein and Wysession (2002). 
The observed SWS can be due to anisotropy in the lithospheric mantle (called "frozen" anisotropy), due to past tectonic processes (Silver and Chan, 1991; Silver, 1996), or in the asthenosphere due to present mantle flow (Vinnik et al., 1992). It is now believed that both lithospheric and asthenospheric anisotropies can be present in the same region (Martha Savage, 1999; Silver and Savage, 1994).

Although not studied here, seismic anisotropy can also be observed in other regions within the Earth, such as the transition zone (Karato, 1998), the lower mantle, the D" layer (Kendall and Silver, 1996), and the inner core (Morelli, Dziewonski, and Woodhouse, 1986). Anisotropy in the upper crust can also be formed by the process of shape preferred orientation of cracks (due to stresses) (Crampin, 1987), or preferred mineral alignment in metamorphic fabric (e.g. Nascimento, Bezerra, and Takeya (2004)). The contribution of crustal anisotropy to SKS splitting is usually very small $(\leq 0.1 \mathrm{~s})$, and is usually ignored in studies of mantle anisotropy.

\subsection{Shear Wave Splitting}

The most common method to measure the effect of anisotropy is shear wave splitting (SWS). This phenomenon is analogous to optical birefringence and occurs when a seismic shear wave encounters an anisotropic medium (e.g., LPO fabric of olivine) (Martha Savage, 1999). Upon encountering an anisotropic medium, the shear wave is split into two orthogonally polarized waves traveling at different velocities, one faster and one slower, orthogonal wave Figure 1.3 (Silver, 1996; Long and Silver, 2009). The splitting is characterized by two parameters:

$$
\begin{array}{r}
\phi=\text { fast orientation } \\
\delta t=\text { delay time }
\end{array}
$$

which refer to the polarization orientation of the first-arriving "fast" split shear wave and the time difference between the two polarized shear waves, respectively. The fast axis orientation 
is sensitive to the geometry of the anisotropic fabric and the split time is proportional to the thickness and intensity of the anisotropic layer (Silver and Chan, 1991). A null measurement is one where splitting cannot be detected for one of four reasons: there is no splitting or the polarization of the XKS wave is parallel or perpendicular to the orientation of the olivine foliation plane. A different and more complex type of anisotropy, such as orientations varying with depth, or tilted fast axes of the olivine crystals (Baptiste and Tommasi, 2014).

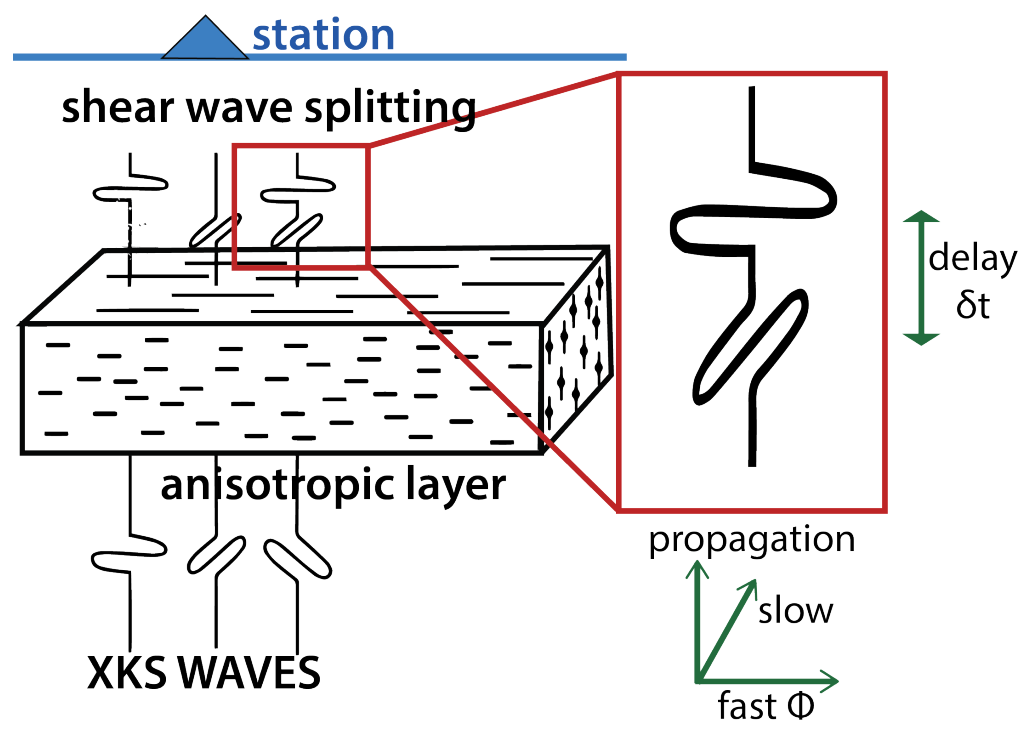

Figure 1.3: Representation of a shear wave passing through an anisotropic medium. The alignment of anisotropic minerals, as olivine, will cause the waves to split, with the fast component aligned to olivine foliation plane, and a time difference relative to the thickness and intensity of the anisotropic layer.

To perform shear wave splitting analysis we use core-refracted seismic wave phases as SKS, SKKS, and PKS (hereafter named as XKS, Figure 1.4). Teleseismic XKS are used in SWS analyses because they are radially polarized when they are converted from a compressional (P) wave to a vertical shear (SV) wave at the core-mantle boundary (CMB). This radial polarization at the CMB removes all source-side effects and therefore, all measured anisotropy comes from the path of the receiver side (Silver and Chan, 1991; Long and Silver, 2009). Moreover, XKS phases travel in a nearly vertical direction through the mantle, which simplifies the analysis but makes it difficult to resolve the depth at which the measured anisotropy is occurring (Long and Silver, 2009). 


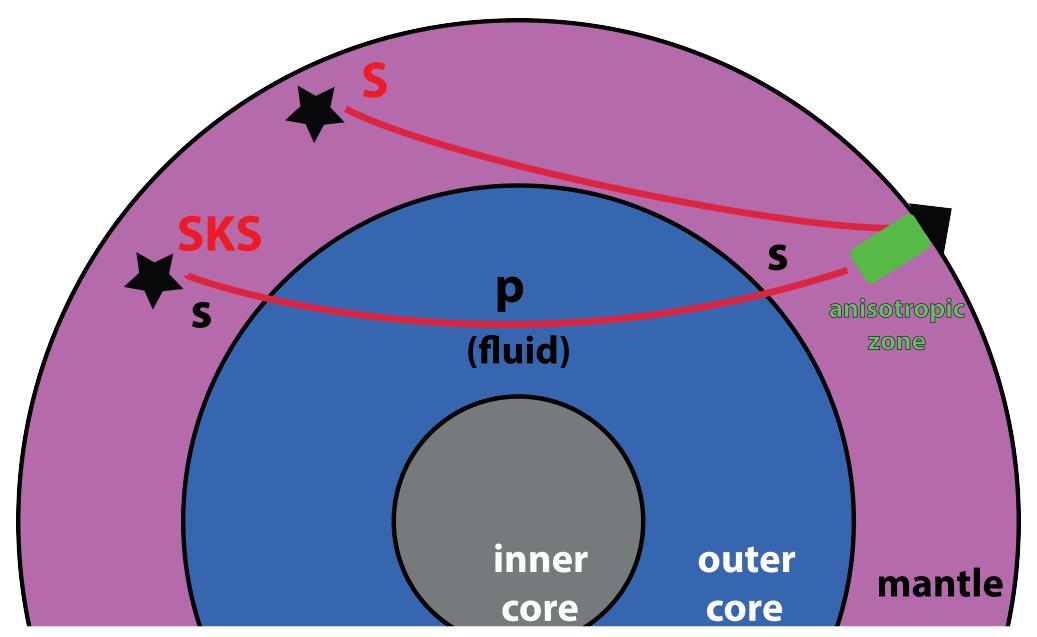

Figure 1.4: Ray paths of a shear wave and a core refracted shear wave. When the teleseismic core refracted shear wave (SKS in this case) crosses the CMB it removes all source side anisotropy. When it encounters an anisotropic medium beneath the station, shear wave splitting will occur.

\subsection{Transverse Component Minimization Method}

Due to conversion from $\mathrm{P}$ to $\mathrm{SV}$ wave at the $\mathrm{CMB}$, in the absence of an anisotropic layer, the XKS is assumed to arrive at the seismic station with energy only in the radial component. The transverse component minimization method, introduced by Silver and Chan (1991), attempts to reverse the effects of splitting by finding the pair of anisotropy parameters that best minimizes the energy on the transverse component (that is assumed to be propagating in a near vertical direction upwards from the source to the station) using an inverse splitting operator Figure 1.5.

In order to carry out the Silver and Chan (1991) method we require observations of shear waves as inputs. In an isotropic, homogeneous medium a shear wave can be written as a vector function:

$$
\mathbf{u}(\omega)=\mathbf{A}(\omega) \exp \left[-i \omega T_{o}\right]
$$


where, as specified by Walsh, Arnold, and Savage (2013):

$$
\begin{gathered}
\omega=\text { angular frequency } \\
\mathbf{u}(\omega)=\text { isotropic shear wave vector } \\
\mathbf{A}(\omega)=w(\omega) \hat{\mathbf{A}}(\omega) \text { complex amplitude vector } \\
w(\omega)=\|\mathbf{A}(\omega)\| \text { norm of the amplitude with angular frequency } \omega \\
T_{0}=\text { time at which the wave arrives at the surface }
\end{gathered}
$$

To represent the propagation coordinates $(\mathrm{P})$, a right handed set of orthogonal vectors $[\hat{\mathbf{p}} \hat{\mathbf{b}} \hat{\mathbf{a}}]$

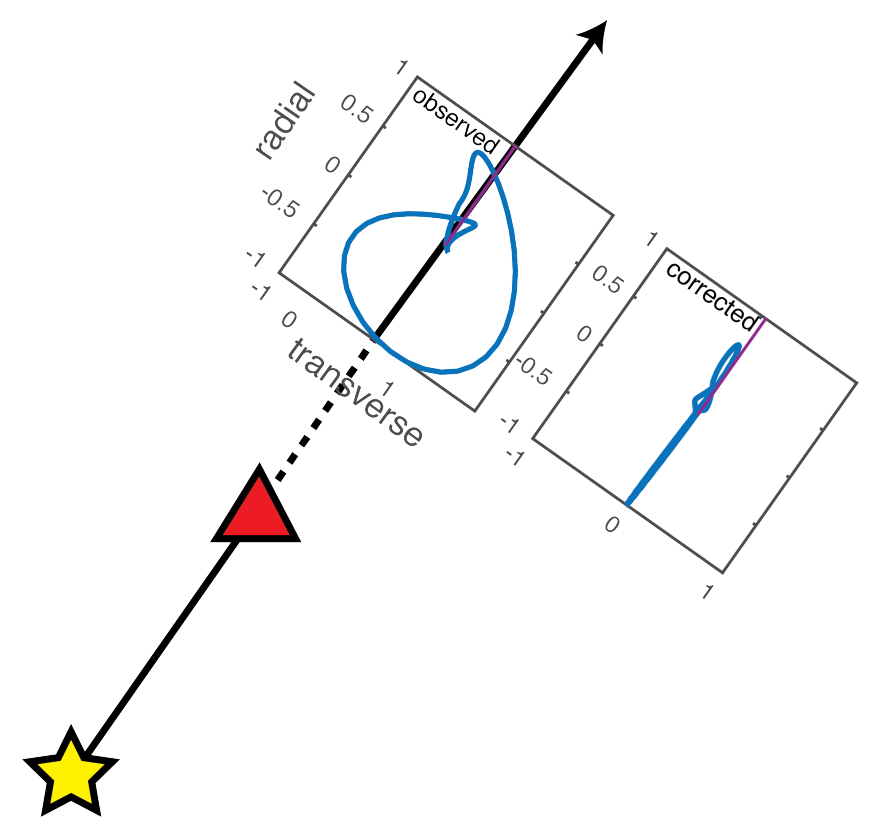

Figure 1.5: The transverse component minimization method finds the pair of parameters $\phi$ and $\delta t$ that best removes the energy on the transverse component seismogram. On the first window is shown a typical ellipsoidal XKS wave particle motion that have crossed an anisotropic layer. After application of the method to remove the effect of anisotropy, the corrected particle motion plot is linearized.

are defined. The three orthogonal vectors that define this coordinate system are

$$
\hat{\mathbf{b}}=\text { propagation vector }
$$

$\hat{\mathbf{p}}=$ polarisation vector pointing in the direction of shear wave displacement

$$
\hat{\mathbf{a}}=\hat{\mathbf{b}} \times \hat{\mathbf{p}}
$$


Silver and Chan (1991) assume that waves (for all frequencies $\omega$ ) displace in the same direction

$\hat{\mathbf{p}}$. Therefore the complex amplitude vector $\mathbf{A}(\omega)$ can be approximated by replacing $\hat{\mathbf{A}}(\omega)$ with $\hat{\mathbf{p}}$ for all $\omega$. Therefore Equation 1.3 is rewritten as:

$$
\mathbf{u}(\omega)=w(\omega) \exp \left[-i \omega T_{o}\right] \hat{\mathbf{p}}
$$

The splitting due to anisotropy is modeled as the geometrical operations of projecting $\hat{\mathbf{p}}$ onto the fast and slow polarization directions fast $\hat{\mathbf{f}}$ and slow $\hat{\mathbf{s}}$, and then time shift these two components by $\delta t / 2$ (earlier) and $-\delta t / 2$ (later) respectively. The process of producing a split shear wave can be represented as the application of the splitting operator:

$$
\Gamma \equiv \exp [i \omega \delta t / 2] \hat{\mathbf{f f}}+\exp [-i \omega \delta t / 2] \hat{\mathbf{s s}}
$$

to the wave equation, with the resulting split waveform:

$$
\mathbf{u}_{s}(\omega)=w(\omega) \exp \left[-i \omega T_{o}\right] \Gamma(\phi, \delta t) \hat{\mathbf{p}}
$$

where $\phi$ is the angle between $\hat{\mathbf{f}}$ and $\hat{\mathbf{p}}$. Defining the tensor

$$
\delta T=\delta t / 2(\hat{\mathrm{ff}}-\hat{\mathbf{s}})
$$

$\Gamma$ can be more compactly written as

$$
\Gamma=\exp [i \omega \delta T(\phi, \delta t)]
$$

in analogy with the isotropic case Equation 1.4.

We want to estimate the parameters $\phi$ and $\delta t$. To do so, we perform a grid search over all possible pairs of $\phi$ and $\delta t$ and choose the pair that most nearly returns Equation 1.6 into the form Equation 1.4 by reversing the geometrical operations, that is, search for the inverse operator $\Gamma^{-1}$. This operator is unitary, therefore the inverse is the complex conjugate $\Gamma^{*}$. The method assumes a single layer of anisotropy and that two of the three symmetry axes lie in the 

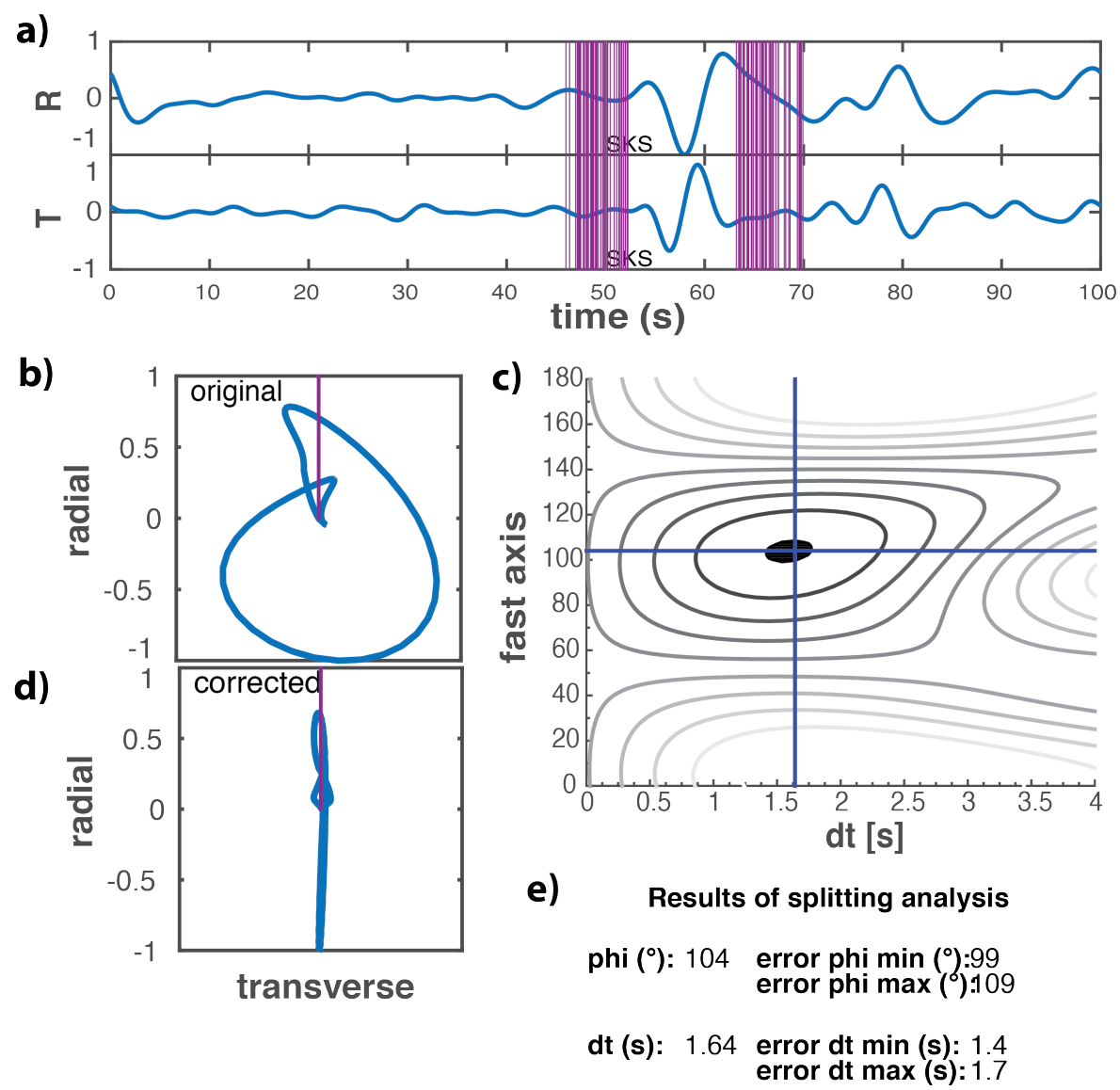

Figure 1.6: The event analyses window of an SKS wave at station ITAB from the BL network. a) Normalized radial and transverse seismogram components showing the SKS wave arrival. Purple bars are 50 randomly selected time windows for statistical analyses. b) Particle motion of the original wave showing an ellipsoidal shape. The purple line shows the back-azimuth direction. c) In the energy grid of the splitting parameters, the pair that best minimizes the energy on the transverse component is chosen (blue cross). The black circle is the error estimated with the $95 \%$ confidence level method. d) Particle motion after the application of the method becomes linear, in the direction of the back-azimuth. e) Splitting parameters found and their respective errors.

horizontal plane. Error estimations are made with the $95 \%$ confidence test. The application of this method has been made with the aid of the SplitRacer package by (Reiss and Rümpker, 2017). Figure 1.6 shows an example of SWS analyses.

\subsubsection{Two Layer Anisotropy}

When using the Transverse Component Minimization method, it is assumed that there is a single homogeneous layer of anisotropy under the receiver (Silver and Chan, 1991). In this way, the anisotropy parameters $\phi$ and $\delta t$ have no variation with incident angle and back-azimuth, 
and many measurements can be averaged together, e.g. Figure 1.7.
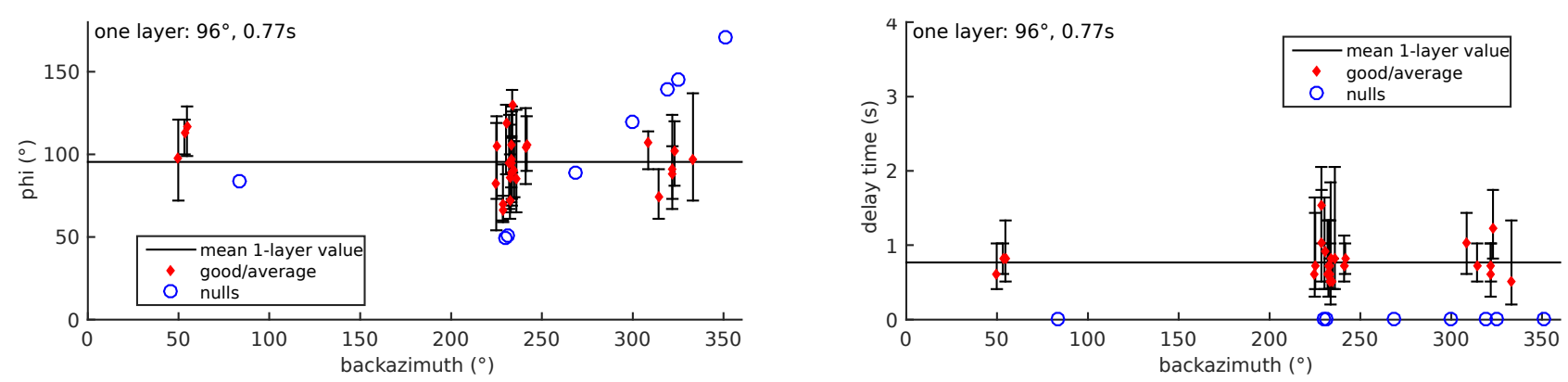

Figure 1.7: Distribution of splitting parameters with back-azimuth obtained from AQDB station, BL network. When many measurements do not show large variation with back-azimuth, they can be averaged together.

However, in some cases these assumptions do not represent the reality, and the parameters may have a dependence with back-azimuth. For example, dipping symmetry will have $2 \pi$ periodicity with back-azimuth, and if two anisotropic layers are present, the splitting parameters will have a $\pi / 2$ periodicity with back-azimuth. Silver and Savage (1994) have shown that the splitting parameters obtained assuming a one layer anisotropy (here referred as apparent splitting parameters) are still meaningful, and that there are simple trigonometric functions to relate them to the 2-layer parameters $\phi_{1}, \delta t_{1}, \phi_{2}$ and $\delta t_{2}$. Silver and Savage (1994) define the parameters: $\alpha_{1,2}=2 \phi_{1,2}$, where $\phi_{1,2}$ is the angle between the initial polarization (back-azimuth) $\phi_{p}$ and the fast polarization orientation of the layer $(1,2)$, and $\theta_{1,2}=\omega \delta t_{1,2} / 2$. Now they define $a_{p}, a_{p \perp}, C_{c}$ e $C_{s}$ by:

$$
\begin{gathered}
a_{p}=\cos \theta_{1} \cos \theta_{2}-\sin \theta_{1} \sin \theta_{2} \cos \left(\alpha_{2}-\alpha_{1}\right) \\
a_{p \perp}=-\sin \theta_{1} \sin \theta_{2} \sin \left(\alpha_{2}-\alpha_{1}\right) \\
C_{c}=\cos \theta_{1} \sin \theta_{2} \cos \alpha_{2}+\cos \theta_{2} \sin \theta_{1} \cos \alpha_{1} \\
C_{s}=\cos \theta_{1} \sin \theta_{2} \sin \alpha_{2}+\cos \theta_{2} \sin \theta_{1} \sin \alpha_{1}
\end{gathered}
$$


and express the apparent splitting parameters $\phi_{a}$ e $\delta t_{a}$ as:

$$
\begin{gathered}
\tan \phi_{a}=\frac{a_{p \perp}^{2}+C_{s}^{2}}{a_{p \perp} a_{p}+C_{s} C_{c}} \\
\tan \delta t_{a}=\frac{a_{p \perp}}{C_{s} \cos \alpha_{a}-C_{c} \sin \alpha_{a}}=\frac{C_{s}}{a_{p} \sin \alpha_{a}-a_{p \perp} \cos \alpha_{a}}
\end{gathered}
$$

This group of equations provide the direct method of using the 2-layer parameters to find the 1 layer apparent parameters. The SplitRacer (Reiss and Rümpker, 2017) package used in this work to calculate the 1 layer anisotropy parameters also provides the tools to perform the inversion and to find the best fit of the 2-layer anisotropy parameters based on this method of Silver and Savage (1994) (Figure 1.8).
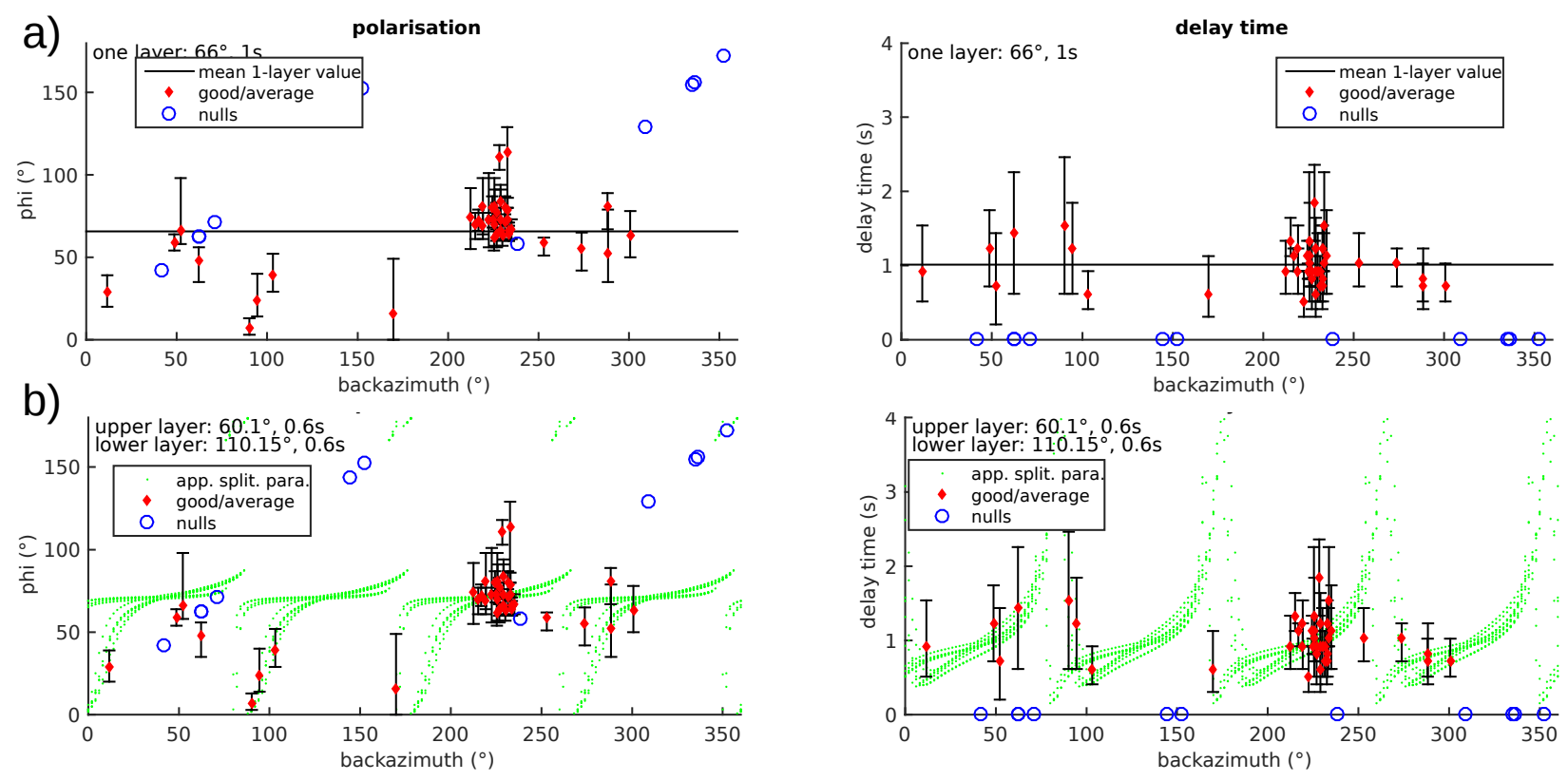

Figure 1.8: Comparison of a a) the two top graphs are the 1-layer fit of the two anisotropy parameters; with b) bottom graphs show the 2-layer fit of the two anisotropy parameters, all at station PTGB, BL network. Because a large number of events are at the back-azimuthal range from $220^{\circ}$ to $250^{\circ}$, these measurements have a higher contribution to the fit in both cases.

There are many situations where more than one layer is present, and in a stable continental region, it is common to exist both fossil anisotropy in the lithosphere, as well as anisotropy associated with upper mantle flow in the asthenosphere (Silver and Chan, 1991; Silver and Savage, 1994). 
Among the stations analyzed in this study there are many that exhibit signs of a more complex form of anisotropy in the form of disperse measurements that can not be well fitted by one single value of $\phi$ and $\delta t$ (such as station PTGB in Figure 1.8). Some attempts have been made to find a 2-layer anisotropy case, and they will be discussed in Chapter 3. For most cases, due to poor back-azimuthal distribution of the events, a clear 2-layer case could not be identified and a single layer of anisotropy fitted the data well. 


\section{Bibliography}

Baptiste, V. and A. Tommasi (2014). "Petrophysical constraints on the seismic properties of the Kaapvaal craton mantle root". In: Solid Earth. ISSN: 18699510. DOI: $10.5194 /$ se-545-2014.

Crampin, S. (1987). "Geological and industrial implications of extensive-dilatancy anisotropy". In: Nature. ISSN: 0028-0836. DOI: 10.1038/328491a0.

Debayle, E., F. Dubuffet, and S. Durand (2016). "An automatically updated S-wave model of the upper mantle and the depth extent of azimuthal anisotropy". In: Geophysical Research Letters. ISSN: 19448007. DOI: 10.1002/2015GL067329.

Hu, J., M. Faccenda, and L. Liu (2017). "Subduction-controlled mantle flow and seismic anisotropy in South America". In: Earth and Planetary Science Letters. ISSN: 0012821X. DOI: $10.1016 / \mathrm{j}$. epsl.2017.04.027.

Ismaïl, W. B. and D. Mainprice (1998). "An olivine fabric database: An overview of upper mantle fabrics and seismic anisotropy". In: Tectonophysics. ISSN: 00401951. DOI: 10.1016/ S0040-1951(98)00141-3.

Karato, S. (1998). "Seismic Anisotropy in the Deep Mantle, Boundary Layers and the Geometry of Mantle Convection". In: Pure and Applied Geophysics. ISSN: 0033-4553. DOI: 10.1007/ s000240050130.

Kendall, J.-M. and P. G. Silver (1996). "Constraints from seismic anisotropy on the nature of the lowermost mantle". In: Nature 381, p. 409. URL: http://dx.doi.org/10.1038/ 381409a0\%2010.1038/381409a0.

Li, Z.-H., J. F. Di Leo, and N. M. Ribe (2014). "Subduction-induced mantle flow, finite strain, and seismic anisotropy: Numerical modeling". In: Journal of Geophysical Research: Solid 
Earth 119.6, pp. 5052-5076. ISSN: 21699313. DOI: 10.1002/2014JB010996. URL: http : //doi.wiley.com/10.1002/2014JB010996.

Long, M. D. and P. G. Silver (2009). Shear wave splitting and mantle anisotropy: Measurements, interpretations, and new directions. DOI: 10.1007/s10712-009-9075-1.

Martha Savage (1999). "Seismic anisotropy and mantle deformation: What have we learned from shear wave splitting?" In: Reviews of Geophysics. DOI: 10.1029/98RG02075.

Morelli, A., A. M. Dziewonski, and J. H. Woodhouse (1986). "Anisotropy of the inner core inferred from PKIKP travel times". In: Geophysical Research Letters 13.13, pp. 1545-1548. DOI: 10.1029/GL013i013p01545, URL: http://doi .wiley.com/10.1029/GL013i013p01545.

Nascimento, A. F. do, F. H. Bezerra, and M. K. Takeya (2004). "Ductile Precambrian fabric control of seismic anisotropy in the Aç u dam area, northeastern Brazil". In: Journal of Geophysical Research B: Solid Earth. ISSN: 01480227. DOI: 10.1029/2004JB003120.

Reiss, M. C. and G. Rümpker (2017). "SplitRacer: MATLAB Code and GUI for Semiautomated Analysis and Interpretation of Teleseismic Shear-Wave Splitting". In: Seismological Research Letters. ISSN: 0895-0695. DOI: 10.1785/0220160191.

Silver, P. G. (1996). "Seismic Anisotropy Beneath the Continents: Probing the Depths of Geology". In: Annual Review of Earth and Planetary Sciences. DOI: 10.1146/annurev.earth. 24.1 .385 .

Silver, P. G. and W. W. Chan (1991). "Shear wave splitting and subcontinental mantle deformation". In: Journal of Geophysical Research. ISSN: 0148-0227. DOI: 10.1029/91JB00899.

Silver, P. G. and M. K. Savage (1994). "The Interpretation of Shear Wave Splitting Parameters In the Presence of Two Anisotropic Layers". In: Geophysical Journal International. DoI: 10.1111/j.1365-246X.1994.tb04027.x.

Stein and Wysession (2002). An Introduction to Seismology, Earthquakes and Earth StructureWiley (2002). John Wiley and Sons.

Vinnik, L. P. et al. (1992). "Global patterns of azimuthal anisotropy and deformations in the con tinen t a1 mantle". In: Geophys. I. Znt 111, pp. 433-447.

Walsh, E., R. Arnold, and M. K. Savage (2013). "Silver and Chan revisited". In: Journal of Geophysical Research: Solid Earth. ISSN: 21699356. DOI: 10.1002/jgrb.50386. 
Zhang, S. and S. Karato (1995). "Lattice preferred orientation of olivine aggregates deformed in simple shear". In: Nature. DOI: 10.1038/375774a0. 


\section{Chapter 2}

\section{Paper}

This chapter consists of a manuscript submitted to the Journal of Geophysical International on the 17th of October of 2017. On December 22nd, 2017, moderate revision was asked by the Editor following recommendations of two reviewers. Accordingly, this manuscript version contains all modifications asked by the reviewers, with some additional maps and information. All changes to the original manuscript are highlighted in blue and the side notes explain which alterations were made. 


\title{
Mantle Anisotropy and Asthenospheric Flow Around Cratons in Southeastern South America
}

\author{
Bruna Chagas de Melo, Marcelo Assumpção, and the "3-Basins" Project \\ Team \\ Centro de Sismologia, Departamento de Geofísica, Instituto de Geofísica, Astronomia, e \\ Ciências Atmosféricas, Universidade de São Paulo, São Paulo, Brazil.
}

\begin{abstract}
Upper mantle seismic anisotropy is one of the most important means to study dynamics of the Earth's interior. It has been extensively used to infer past and present mantle dynamics and continental evolution. Seismic anisotropy in the upper mantle can be measured by the method of shear wave splitting (SWS) of core refracted phases, such as SKS. Previous studies of SWS in South America concentrated mainly along the Andes and in southeast Brazil. Now we add extra measurements in the area of the Pantanal and Chaco-Paraná basins, as part of the FAPESP "3-Basins" thematic project. With the splitting results of 47 new stations, we have a more complete and robust anisotropy map of the South America stable platform. On average, over most of the mid plate continent, the fast polarizations have an average $\mathrm{E}-\mathrm{W}$ orientation, which is close to the absolute plate motion given by the hotspot reference model HS3-NUVEL-1A (median deviation of $15.7^{\circ}$ ). However, recent models of subduction induced mantle flow beneath South America provide a better explanation for the fast orientations (median deviation of $\approx 12^{\circ}$ ). Nevertheless, detailed analyses of the fast orientations indicate an additional component of mantle flow deviating from the cratonic blocks, at the São Francisco and Amazon cratons, and beneath the Paraná basin (called Paranapanema block). Large delay times may indicate a strong asthenospheric channel, a more coherent flow, or a thicker asthenosphere, between the Paranapanema block and the Amazon craton. Similarly, small delay times may indicate thinner anisotropic asthenosphere beneath the Paranapanema block.
\end{abstract}

Keywords: Anisotropy, Shear Wave Splitting, Asthenospheric Flow 


\section{Introduction}

The study of seismic anisotropy beneath continents, particularly in stable areas, yields important constraints on past and present tectonic processes, and helps understanding patterns of sub-lithospheric mantle flow, in a way that cannot be achieved by other geophysical methods. Shear wave splitting is now a standard method for studying seismic anisotropy in the upper mantle, consisting of local measurements at individual stations. The resulting splitting parameters are usually interpreted as due to preferred mineral alignment, which could reflect mantle flow directions related to present-day plate motions and/or "fossil" deformation preserved in the lithospheric mantle since the last major ${ }^{\mathrm{c} 1}$ tectonic event ${ }^{\mathrm{c} 2}$.

Seismic anisotropy is the dependence of wave speed on the direction of seismic polarization and wave propagation. A shear wave propagating through an anisotropic medium is split into two orthogonal quasi-shear waves, one traveling faster than the other (Silver, 1996). The polarization orientation of the fast component is usually named fast polarization orientation $(\phi)$ of anisotropy. The two waves travel at different speeds; therefore, a delay time $(\delta t)$ is observed between the "fast" and "slow" components when they arrive at the station. The amount of delay time depends on the thickness of the anisotropic layer and/or the strength of anisotropy. When there is a delay time between the fast and slow components of core refracted phases, such as SKS, SKKS and PKS phases (here nominated XKS), they will exhibit some energy on the tangential component producing an elliptical particle motion. Analyses of the fast polarization orientation $(\phi)$ and delay time $(\delta t)$ provide simple measurements that characterize seismic anisotropy directly beneath the receiving seismic station.

Fast polarization directions measured by shear wave splitting (SWS) are related to lattice preferred orientation (LPO) of anisotropic minerals (especially olivine), caused by shear deformation in the mantle (Silver, 1996). Studies of mantle xenoliths show that anisotropy can be as high as $7 \%$ (Ismall and Mainprice, 1998). Deformation through dislocation creep (crystalline dislocations within grains) is needed to cause preferred mineral orientation, and it occurs with high stress, large grain size, or both (Savage, 1999).

${ }^{c 3}$ Some authors such as Silver and Chan (1991) and Silver (1996) argued that the fast polarization orientation in stable continents correlate better with c1 erogeny

c2 changed orogeny to tectonic event as requested by reviewer 1

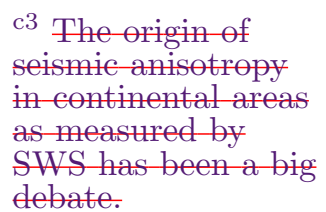

c3 The origin of seismic anisotropy in continental areas SWS has been a big debate. 
${ }^{c 4}$ crustal structural trends, implying that "frozen" anisotropy imprinted by past lithospheric deformation is the main source of anisotropy. ${ }^{c 5}$ It is also believed that anisotropy is formed by the alignment of fast propagation orientations with current, or geologically recent, mantle flow (Vinnik et al., 1992; Fouch et al., 2000; Becker et al., 2014). Becker et al. $(2014){ }^{{ }^{c 6}}$ explores two different scenarios: $1 \longdiv { \text { the comparison of azimuthal anisotropy directions } }$ with absolute plate motion (APM) models, under the assumption that the mantle at some larger depth is relatively stationary, such that surface velocities are directly related to the asthenosphere, and 2) the comparison with mantle flow, which he argues to be a plausible, global back-ground model of azimuthal anisotropy for oceanic plates and their underlying asthenosphere. ${ }^{c 7}$ Specially in continental areas, some studies show contribution from lithosphere thickness variation, inducing flow around cratonic roots (Fouch et al. 2000; Assumpção et al., 2006; Becker et al., 2012). ${ }^{\text {c8 }}$

Initial studies in SWS in Southeast Brazil indicated strong correlation of fast orientations with geological trends (James and Assumpção, 1996; Heintz et al. 2003). However, later studies in a larger region (Assumpção et al., 2006); (Assumpção et al., 2011) tended to favor upper mantle flow around cratonic roots, with fossil anisotropy restricted to few localized areas. Here we expanded the shear wave splitting measurements further to the west with newly installed stations (Figure 1) to have a more complete regional pattern.

Our results reveal that the São Francisco and Amazon cratons, and an anomalous high velocity block in the Paraná basin, interpreted as a cratonic nucleus (Mantovani et al., 2005), modulate the anisotropy orientation by diverting mantle flow.

\section{Geological Setting}

\subsection{Paraná Basin}

The Paraná basin of southern Brazil (Figure 1 - contour in brown) is a typical Paleozoic intracratonic basin and hosts one of the largest igneous provinces of the world c1 the Cretaceous Serra Geral Formation c2 Milani and De Wit, 2008). The central and northern parts of the basin have been studied by passive seismology in the past 20 years, but little is known of the upper mantle structure in the west of the basin, especially in Paraguay, NE Argentina, and beneath the Chaco Basin. In some areas, the lithosphere could be up to $200 \mathrm{~km}$ thick, as revealed by the compilation of Steinberger and Becker (2016). Julià et al. (2008) used receiver function and Rayleigh-wave c4 tectonic structures in the erust

c5 A common interpretation is that shear deformation due to relative motion of the lithosphere with respect to the asthenosphere orients the olivine a-axis and therefore eauses the fast directions, $\phi$ to be eriented parallel to the plate motion. Other models sugrest that olivine tPO could be induced by larger-scale flow in the asthenosphere. The fast direction would coincide with the direction of How but might differ from the direction of plate motion if the plate is decoupled from the How beneath it.

c6 Text added.

c7 Text added.

c8 This paragraph was changed to add the suggestion of the reviewer 1 , which was to add some detail as explored by Becker et al, (2014).

c1 Text added.

c2 added the age of the tectonic province as requested by reviewer 2 
dispersion to confirm that the basin sediments are underlain by a predominantly cratonic nucleus (Mantovani et al., 2005; Cordani, 1984), and mafic underplating only occurred under selected sites, possibly channeled between fragmented cratonic roots as seen in the model of Milani and Ramos (2017).

Previous measurements of SWS in this area are scarce (Assumpção et al., 2011), and show a trend of small delays with a general E-W fast direction, which has been mainly correlated with the absolute plate motion directions in the HS3-NUVEL-1A frame (Gripp and Gordon, 2002).

\subsection{Pantanal Basin}

The Pantanal basin (Figure 1 - Pt) is a shallow ( 400m), Quaternary basin between the deep intracratonic Paraná basin and the sub-Andean basins (Assine and Soares, 2004). Both regional (Feng et al., 2007) and global (Schaeffer and Lebedev, 2013) tomography models show a strong S-wave lowvelocity anomaly in the upper mantle (100-300 km depth), concentrated at the basin and continuing to the NE in the Tocantins Province. Ussami et al. (1999) proposed that the formation and subsidence of the basin resulted from extensional flexural stresses due to the Andean load, in a migrating foreland bulge. However, seismicity in the Pantanal basin is characterized by shallow, reverse faulting events (Dias et al., 2016), which makes subsidence due to flexural extension unlikely. Studies of SWS may help better understand the upper mantle dynamics in this area and ${ }^{\mathrm{c} 1 \mathrm{c} 2}$ shed light on the formation mechanism of this Quaternary Basin.

Again, previous measurements (Assumpção et al., 2011) in this area have poor coverage, due to a lack of stations. Assumpção et al. (2006, 2011) analyzed stations AQDB and PP1B ${ }^{c 3}$ (see Fig. S1, at the Supplementary Material, for station names and locations) ${ }^{\mathrm{c} 4}$, as they were the only ones in the area at the time. ${ }^{\mathrm{c} 5}$ The few measurements were compared with flow parallel to APM as well with flow ${ }^{\text {c6 }}$ surrounding the positive S-wave anomaly in the Paraná basin.

c1 eentribute to

c2 removed contribute to as suggested by reviewer 1

c3 Text added.

c4 A supplementary figure with all station names and locations is provided at the Supplementary Material, as suggested by reviewer 2 .

c5 and have shown a deviation from the proposed APM model

c6 Changed this phrase for better clarity. 


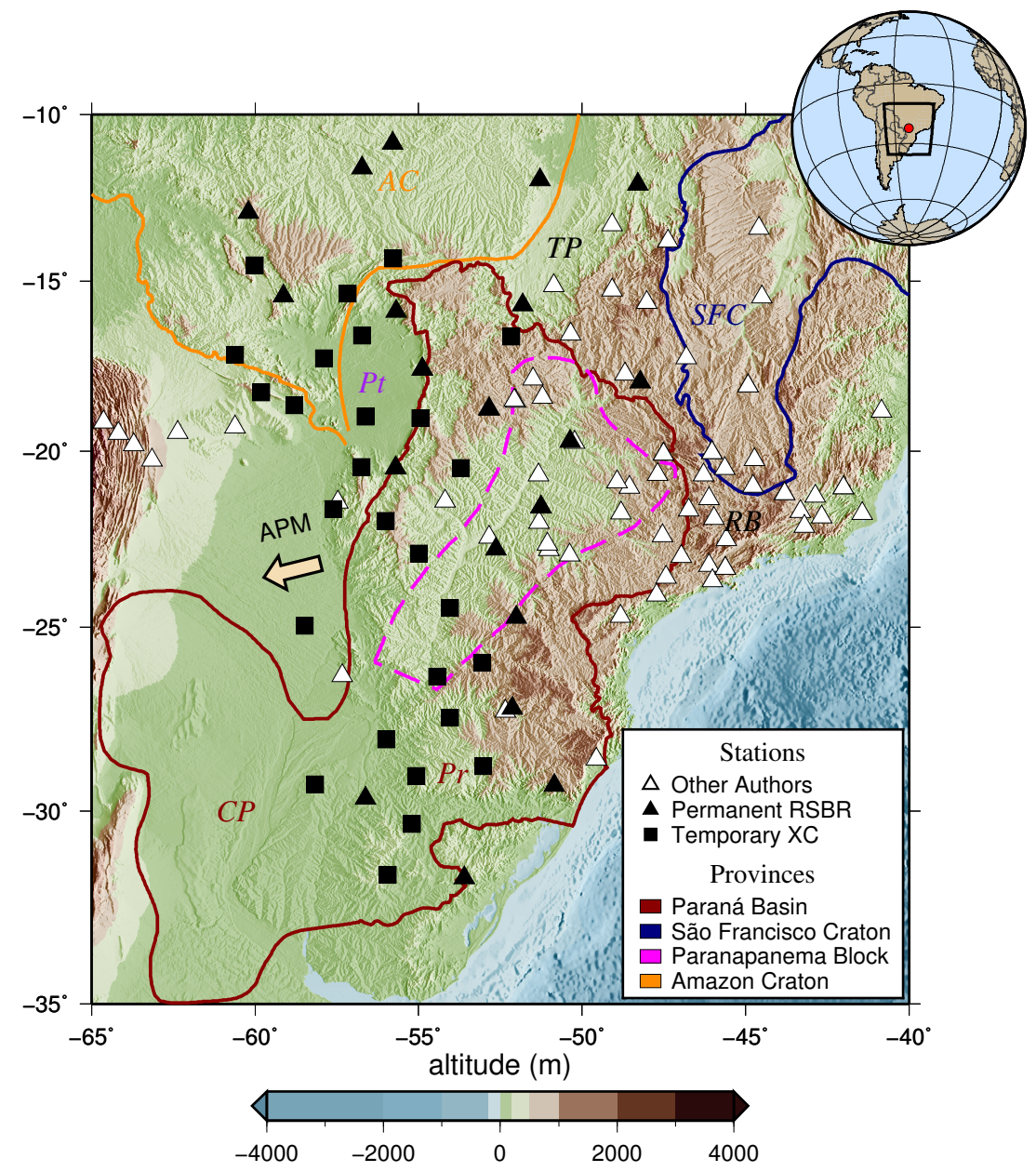

Figure 1: Stations with the new and old measurements of SWS in southeastern South America (shown in black and white fill). The colored contours show the main geological provinces here discussed. Labels on the map are: SFC - São Francisco craton; CP - ChacoParaná basin (western part of the basin); Pr - Paraná basin (eastern part of the basin), Pt - Pantanal basin; TP - Tocantins foldbelt province; RB - Ribeira foldbelt; AC - Amazon craton. The yellow arrow is the absolute plate motion direction in the HS3-NUVEL-1A frame. 


\section{Data and Method}

A 3-year experiment (called "3-Basins" experiment, for short) deployed 35 temporary stations, with an average station spacing of $400 \mathrm{~km}$, to study the crust and upper mantle structure beneath the Pantanal, Paraná and ChacoParaná Basins (Figure 1). Here we show the first SWS results from this experiment together with data from the permanent Brazilian Seismographic Network (RSBR) ( ${ }^{\mathrm{c} 1}$ see Fig. S1), analyzed between January 2011 and May $2017^{\text {c2 }}$ (Tables S1 and S2). We examined core refracted phases (XKS), with distances $\geq 85^{\circ}$ and magnitude $\geq 5.6$. For earthquakes deeper than $100 \mathrm{~km}$, this magnitude is the limit to acceptable signal-to-noise ratio (SNR). Events with poor SNR $(<2)$ were discarded. Seismograms were bandpass filtered between 0.03 and $0.3 \mathrm{~Hz}$, with the exception of stations with low SNR and stations that showed evidences of complex anisotropy, ${ }^{\mathrm{c} 3}$ for which we also examined the effect of small-scale changes in anisotropy at higher frequencies, with a bandpass filter from 0.15 to $0.5 \mathrm{~Hz}^{\mathrm{c} 4}$

To determine the two anisotropy parameters: fast-polarization orientation $(\phi)$ and delay time $(\delta t)$ we used a Matlab based software: the SplitRacer package (Reiss and Rümpker, 2017). Shear wave splitting (SWS) is analyzed hased on the c5transverse-component eneroy minimization method of Silver and Chan (1991). To apply this method, we must know the initial polarization of the wave, which is always assumed for core-phases to correspond to the station back-azimuth. ${ }^{c 6}$ The package also has a misalignment check tool, ${ }^{\text {c7 }}$ based on the difference between the orientation of the ellipse drawn by the XKS particle motion and the back-azimuth ( ${ }^{\mathrm{c} 8}$ Fig. S2). ${ }^{\mathrm{c} 9}$ After manual selection of the events, we compared the misalignment angles calculated by the package, based on the XKS particle motions, with misalignment measured by P-wave particle motions by Bianchi $(2015),{ }^{c 10}$ and they were equivalent. When the average value of misalignment was higher than $10^{\circ}$, the correction was applied. ${ }^{\mathrm{c} 11}$

Figure 2 shows an example of splitting analysis for an event recorded at station ITAB. The SplitRacer package uses a grid search for the splitting parameters $(\phi)$ and $(\delta t)$ carried out to minimize the energy on the transverse component, after removing the anisotropy effect. This is done within a time window initially chosen around the phase and is repeated for 50 random window variations (Figure 2,a,b). The results for each time window are then plotted in histograms (Figure 2-c), which are used to calculate mean splitting parameters and to check the consistency of the results. Errors are

c1 Text added. c2 Text added.

c3 where the bandpass was adapted.

${ }^{c 4}$ Added specification about how the filter parameters were adapted for complex waveforms, as suggested by reviewer 2.

c5 Text added.

${ }^{c 6}$ After manual selection of the events,

${ }^{c 7}$ a misalignment check is performed, c8 Text added.

c9 The results matched the misalignment measured with $\mathrm{P}$-wave particle motions. A eorrection was then applied to the misaligned stations. c10 Text added. c11 Added more specifications on the misalignment check performed, and the reference for the $\mathrm{p}$-wave polarization measurements, as suggested by reviewer 2 . 
calculated with $95 \%$ confidence levels from the F-test as in Silver and Chan (1991) (Figure 2f,g). Based on clear phase arrivals, particle motion plots, histogram distribution, error and percentage of transverse energy reduction, we classify the results as good, average, poor or null.

After application of the inverse splitting operator on the XKS phase, the elliptical particle motion should become linear (Figure 2-e), and the histogram should show one clear peak for each parameter. If the anisotropy correction does not lead to linearization of the particle motion, the event is classified as poor and not used in the analyses. When the wave arrives at the anisotropic layer with polarization perpendicular or parallel to the fast-axis direction, the wave is not split, and thus, arrives without transverse energy. These measurements are called nulls, and they can also represent complex anisotropic structures as discussed by Bastow et al. (2015). When there is a clear phase arrival, but no energy on the transverse component and both the particle motions from before and after the inversion are linear, the event is classified as null. In this case, the energy grid shows $95 \%$ confidence levels usually along the whole delay-time axis, at two narrow values of fast orientations, corresponding to the back-azimuth and its perpendicular direction. c1 c2 To investigate whether a one layer model of anisotropy is suitable, single station measurements ${ }^{\mathrm{c} 3}$ are inspected for azimuthal dependency, e.g. Figure 3-a,b,c. For example, a two-layer case with different anisotropic properties will have splitting parameters with a $\frac{\pi}{2}$ periodicity as a function of back azimuth (Savage, 1999). ${ }^{\text {c4 However, for stations localized in }}$ South America we have a restricted back-azimuthal coverage of events, which makes it difficult to observe this periodicity, or other forms of complex anisotropy. Figure $4{ }^{5}$ shows the map of event location and the polar histograms of the event azimuthal coverage of some stations at different locations. The main source of usable events for SWS splitting analysis comes from the Fiji islands, and covers back-azimuths from $215^{\circ}$ to $245^{\circ}$. In fewer cases, there are events from Alaska $\left(290^{\circ}\right.$ to $\left.340^{\circ}\right)$, and from the Mediterranean $\left(40^{\circ}\right.$ to $\left.60^{\circ}\right)$. At some stations (Fig. S20), it seems that the anisotropy is more complex than a single layer model, and the 2-layer model could fit the data better. Yet, it has not been observed in this study any case where a two layers of anisotropy can be considered conclusively. At stations with a larger variability of the parameters with back-azimuth, a simple mean of all events was calculated (Table S1.) ${ }^{\mathrm{c} 6}$ At the stations where the one layer model fitted well the data (Table S2), we applied a joint splitting analysis consisting of using all waveforms ${ }^{\mathrm{c} 7}$, and simultaneously minimizing the transverse energy

${ }^{c 1}$ We added more information about the back-azimuthal coverage in the text, as well as a figure showing some examples of back-azimuthal distribution. We also added the graphs of the anisotropy parameters versus back-azimuth of all stations at the Supplementary Data.

c2 Single

c3 at one station

c4 If azimuthal variations are not significant, a single layer of anisotropy is assumed.

c5 Text added.

c6 When this is the ease

c7 at a given station 
on all of them, resulting in a more robust pair of splitting parameters (Figure 3-d,e,f). The corrected transverse components are concatenated so that the sum of the energy on all transverse components is used in the grid search for the splitting parameters. This approach significantly reduces the influence of noise and increases the robustness of the splitting results, avoiding over-interpretation of single-phase results (Reiss and Rümpker, 2017). The application of the inverse splitting parameters should lead to a linearization of the particle motions of all waveforms, and then a single layer of anisotropy explains the observations. ${ }^{\mathrm{c} 8}$ c1

c8 Nevertheless, it is possible that due to a poor

distribution of back-azimuths, a wo-layer case or other anisotropic complexities exist, but are not detected.

c1 Changed the blue color at the pie chart of Figure 3 to red, to facilitate the visualization of the labels, as suggested by reviewer 2 . 

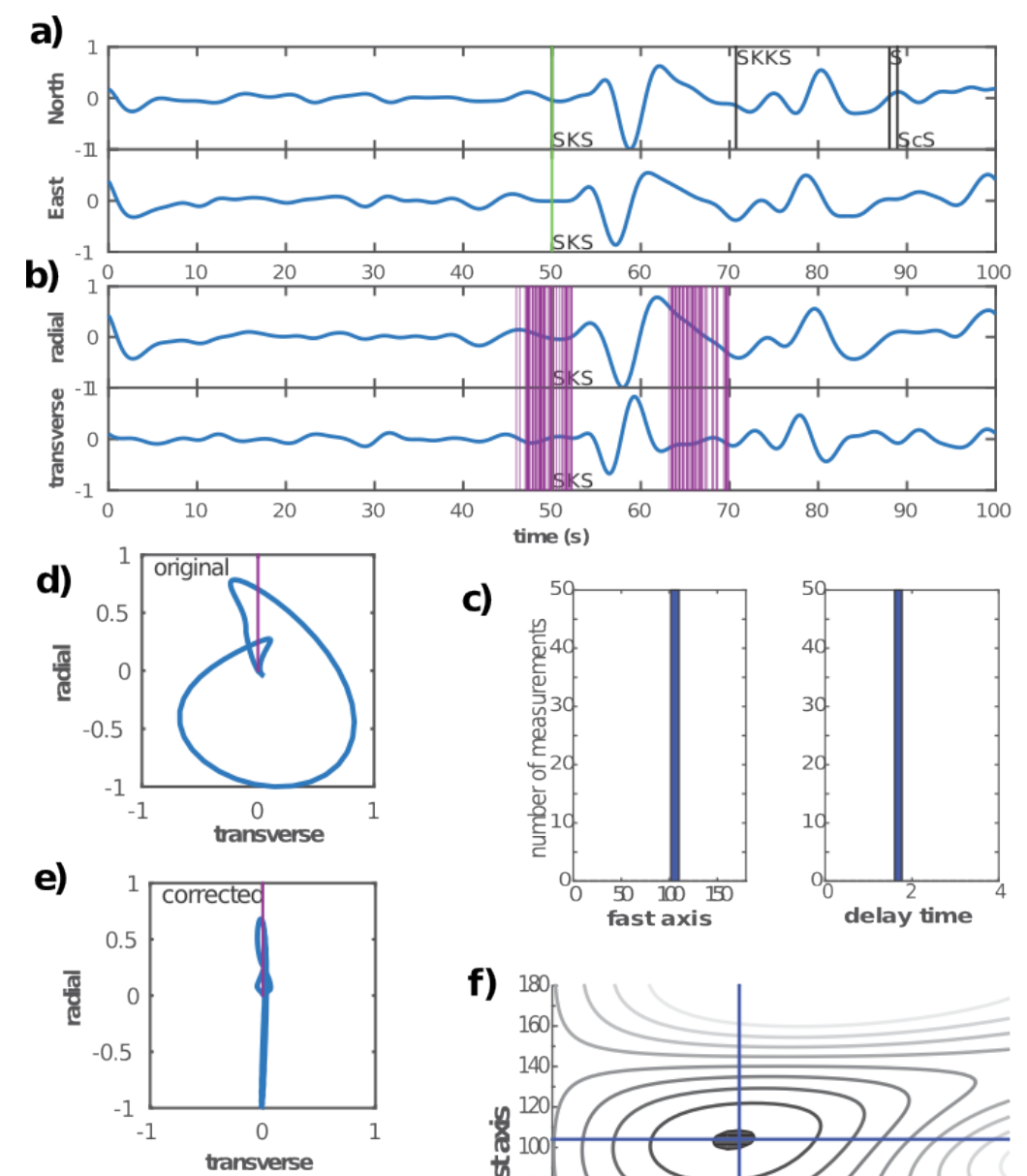

\section{g) Results of splitting analysis phi $\left({ }^{\circ}\right): 104 \begin{aligned} & \text { error phi } \min \left(\left(^{\circ}\right): 99\right. \\ & \text { error phi } \max \left(\left(^{\circ}\right): 109\right.\end{aligned}$ \\ dt (s): 1.64 error $d t \min (s): 1.4$ error dt max (s): 1.7 \\ energy reduction (\%) 99}

c)
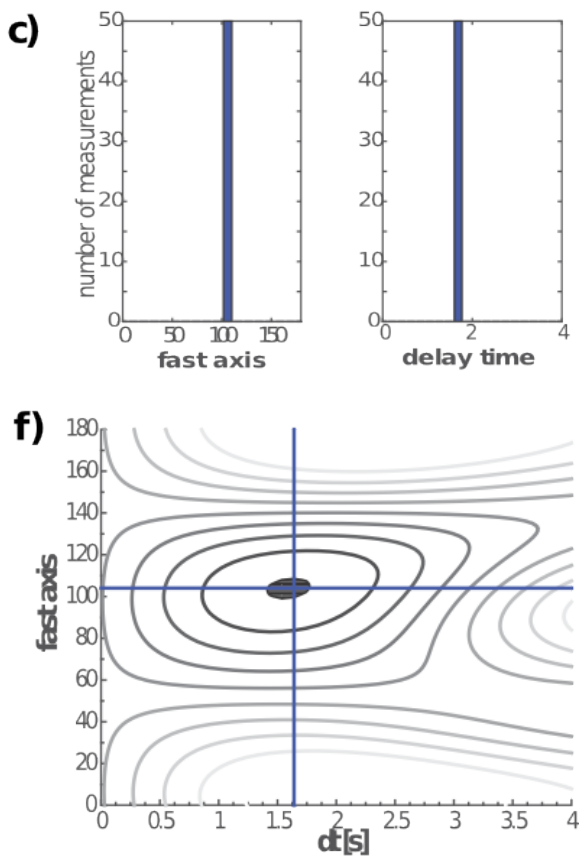

Figure 2: Analysis of an SKS phase at the station ITAB from the RSBR network. a) Normalized original North and East components. b) Normalized radial and transverse components. The purple lines are 50 randomly selected time windows. c) Histograms of fast axis $(\phi)$ and delay time results from the 50 different time windows. d) Original particle motion. The purple bar is the back-azimuth. e) Particle motion after correction. f) Energy grid of the corrected transverse component. The black contour level refers to the $95 \%$ confidence level. The blue cross marks the pair of splitting parameters which best minimizes the energy on the transverse component. g) Results of the splitting parameters with errors, and the energy reduction rate. 

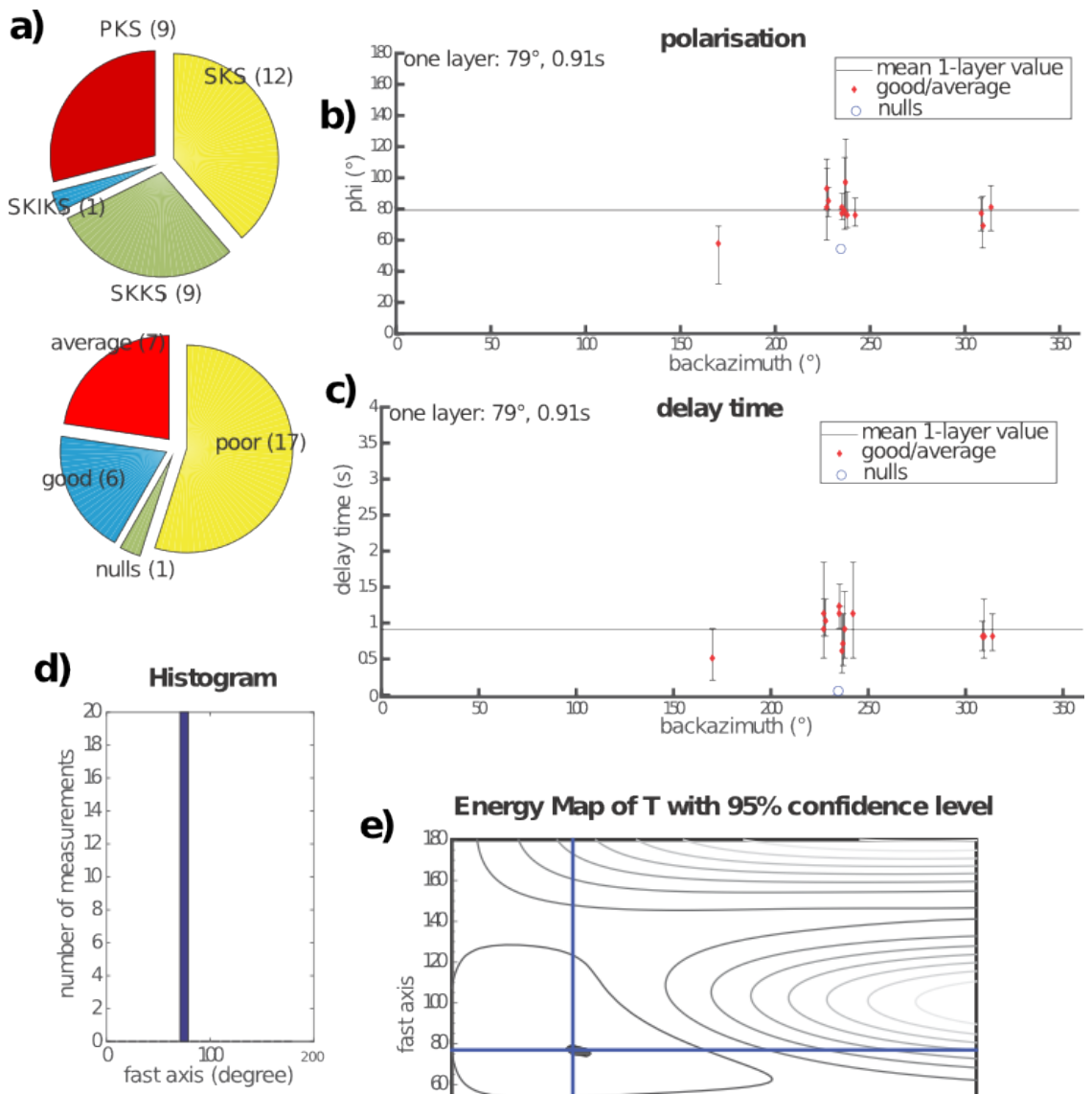

e) Energy Map of T with $95 \%$ confidence level

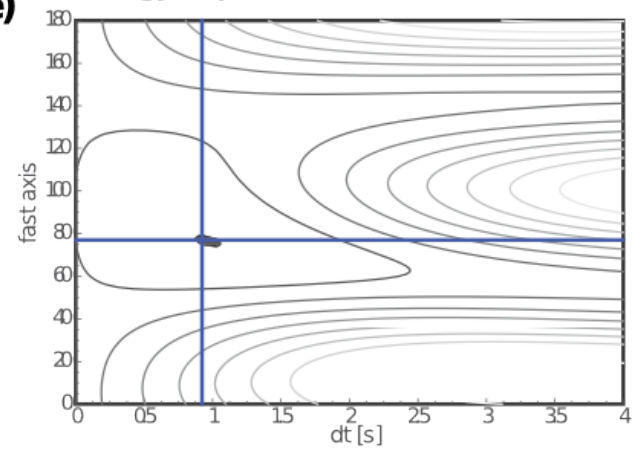

\section{f) Results of splitting analysis}

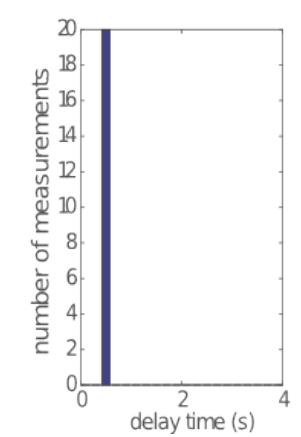
phi $\left({ }^{\circ}\right): \quad 77$
dt (s): 0.92
error $\left({ }^{\circ}\right)$ : 73-78
error (s): 0.92-1
filter (s): 3-30
mean energy
reduction (\%): 76.3

Figure 3: Compilation of the events analyzed at station PP1B. a) Pie charts showing distribution of phases used and classification of the events. b) Polarization of fast-direction measurements plotted against back-azimuth. The black line represents the mean value, written at the top of the graph. c) Delay times and their respective back-azimuths. d) Histogram of the joint-inversion of all events of this station. e) Energy map of the jointinversion. f) Results given by the joint-inversion. 


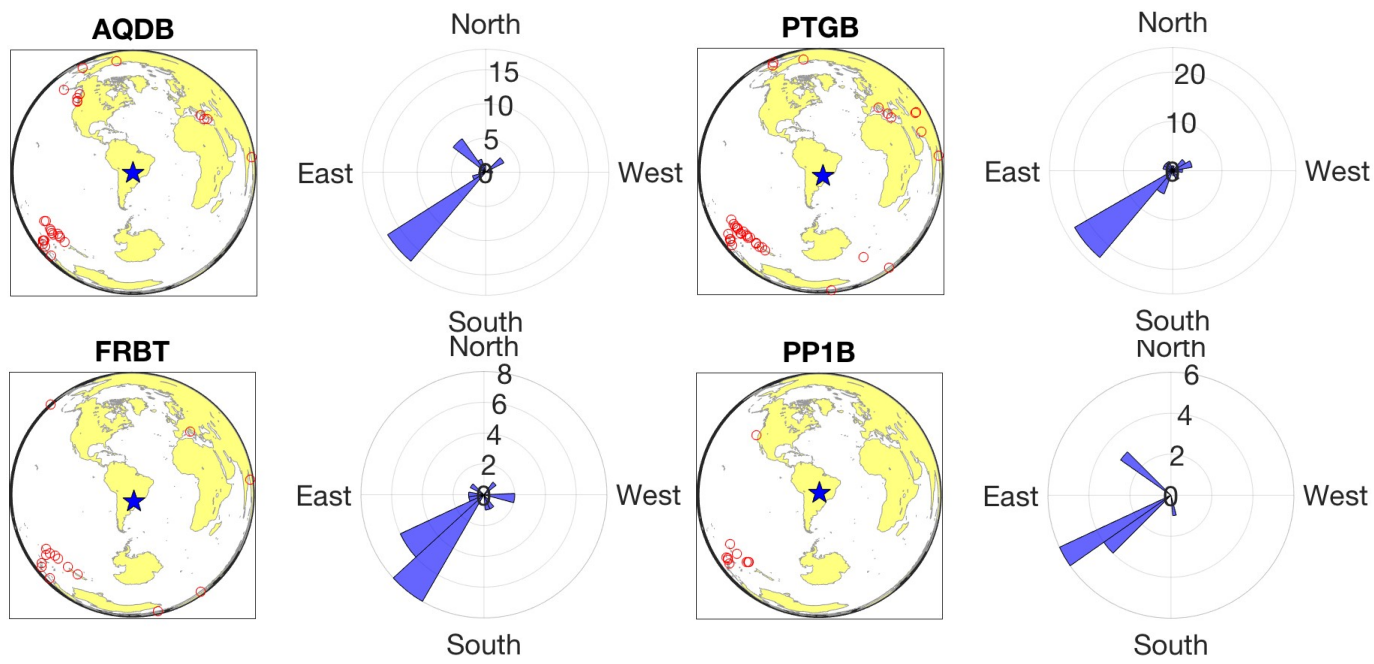

Figure 4: Maps of event distribution per station. The blue star is the location of the station and the red circles are the events used in the SWS analyses. The respective polar histograms are the back-azimuthal coverage of events at stations AQDB, FRBT, PP1B, SALV

\section{Results and Discussion}

The 45 new SWS measurements from both temporary and permanent stations are presented in Figure $5{ }^{\mathrm{c} 1}$ (Table S1 and S2), together with previous compilations for the stable part of South America (Assumpção et al., 2006)assumpcao2011. The gap in XKS measurements between the Andes and SE Brazil is now partly filled, and we provide a more complete and robust anisotropy map of the South America stable platform. A general trend can be recognized, where most fast orientations tend to be oriented E-W, roughly parallel to the absolute plate motion in the hot-spot reference frame HS3-NUVEL1A (Gripp and Gordon (2002)). However, regional variations can be observed: ESE-WNW orientations and small delays just south of the Amazon craton, large delays and mostly ENE-WSW orientations in the Pantanal basin, small delays and E-W fast orientations in the northern part of the Paraná Basin, and ESE-WNW in the southern part of the Paraná basin.

\subsection{Comparison with Surface Wave Azimuthal Global Anisotropy}

${ }^{c 2}{ }^{c 3}$ Shear wave splitting measurements have excellent lateral resolution, but no resolution with depth. Here we investigate the origin of upper mantle anisotropy by comparison with the surface wave azimuthal global anisotropy

${ }^{c 1}$ Text added.

${ }^{\mathrm{c} 2}$ We add global surface wave anisotropy directions at Figure 5 , and a section to discuss this comparison as suggested by reviewer 1 .

c3 Text added. 


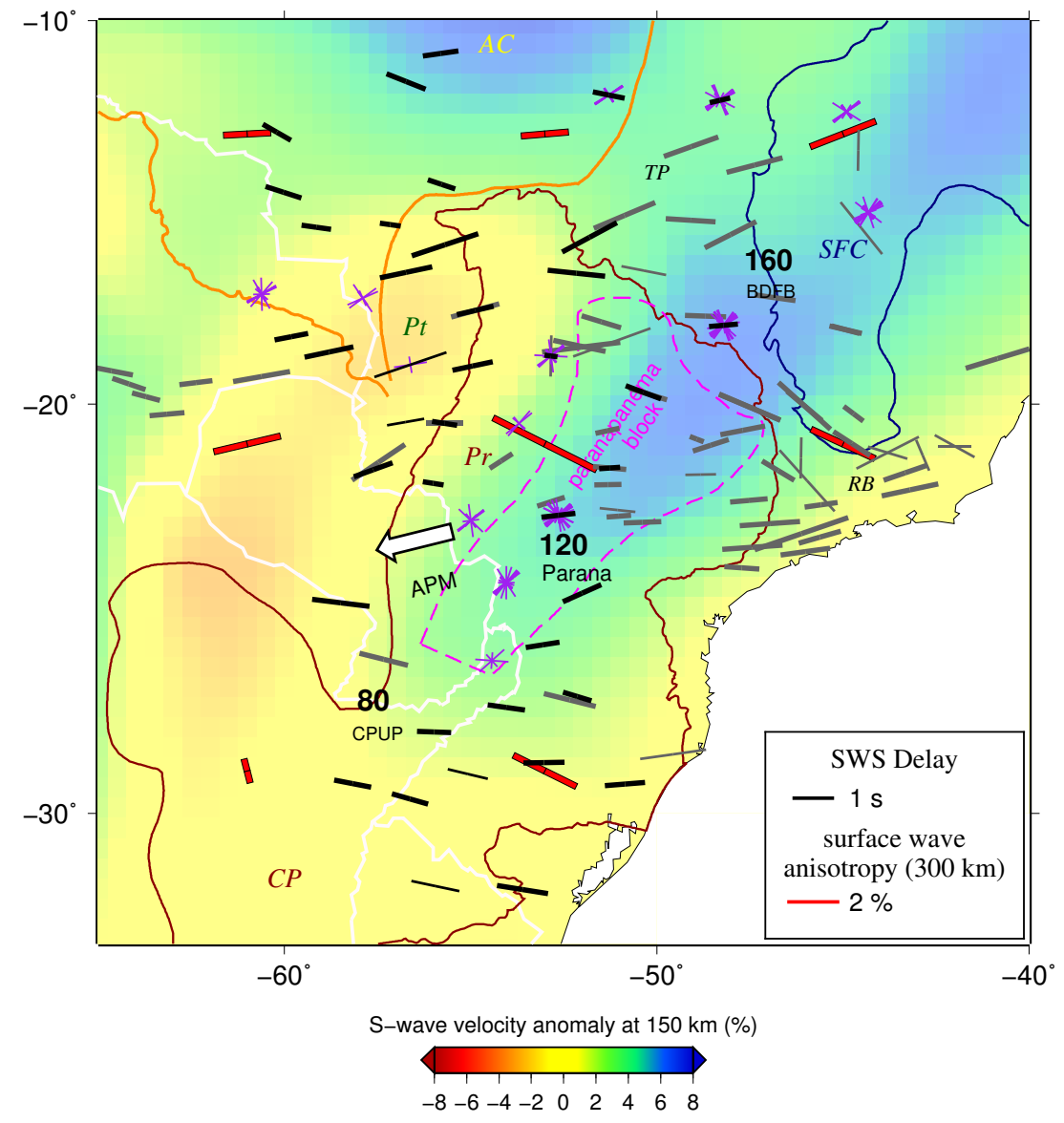

Figure 5: SWS fast directions from this paper are black bars and other published results (gray bars). The bar lengths indicate delay time and good (5 or events events used) /average qualities of SWS are indicated by thick and thin bars. Red bars are surface wave azimuthal anisotropy directions at $300 \mathrm{~km}$ depth from Debayle et al. (2016). Colors indicate S-wave velocity anomalies at $150 \mathrm{~km}$ depth from the surface-wave tomography model SL2013 (Schaeffer and Lebedev, 2013). The white arrow indicate the absolute plate motion in the hotspot reference frame HS3-NUVEL1A (Gripp and Gordon, 2002). Colored contours are the major provinces boundaries. Null bars (as purple bars) are plotted at stations where few or no measurements were found. Bold numbers denote lithosphere/asthenosphere depth from S-wave receiver functions Heit et al. (2007).

directions from the model of Debayle et al. (2016). ${ }^{c 4} \mathrm{~A}$ qualitative comparison has been made at different upper mantle depths (Figure S22), and we observed that the SWS anisotropy directions correlate better with the surface wave anisotropy directions at $300 \mathrm{~km}$ depth(Figure 5 ). ${ }^{\mathrm{c} 5}$ Surface wave anisotropy from global models have low lateral resolution, therefore the influ-

c5 Text added.

c4 Text added. 
ence of regional lithospheric topography is hardly observed. There is a overall E-W trend, which match our orientations, specially at the northern Parana basin, at the Pantanal basin and at the Amazon craton. Moreover, the directions at the keel of the SFC have the same SW trend. At the southern ChacoParana basin the SWS orientations have a slight ESE rotation, tending to the NW-SE orientation shown by the surface wave anisotropy directions. The fact that our measurements correlate better with surface wave anisotropy at 300 $\mathrm{km}$ depth, lead us to believe that the main source of anisotropy in SE South America comes from asthenospheric mantle flow and that the lithospheric, frozen anisotropy has little to no contribution.

\subsection{Comparison with Geologic Trends}

${ }^{c 2}{ }^{c} \mathrm{In}$ Figure $6{ }^{4}$ we see the main geologic provinces of the study area and basement fault directions. In addition, a recent study of crustal structure with gravity and geological data by Dragone et al. $(2017)^{\mathrm{c} 5}$ proposed a N-S trending suture zone between the Pantanal and Paraná basins from $15^{\circ} \mathrm{W}$ to $30^{\circ} \mathrm{W}$, called Western Paraná Suture (WPS, green contour in ??).

${ }^{\mathrm{c} 6}$ In the Pantanal basin and the northern Paraná basin ??-b ${ }^{\mathrm{c} 7}$ there is a main ENE-SWS alignment, which correlates with the fault directions at the most part of the northern Paraná basin, but do not with the basement fault direction under the Pantanal basin, which is N-S. Also, the WPS has $\mathrm{N-S}$ alignment in this region. In Figure 6 -c $)^{\mathrm{c} 8}$ the anisotropy directions have a general E-W to ESE-WNW directions, in agreement with the direction of the WPS. However this is inconclusive as the general trend of the entire area is in the E-W direction. Moreover, there is no correlation with the fold belt directions under the basin, which are NE. Although effects of frozen anisotropy in the lithospheric mantle had been suggested in some parts of SE Brazil (James and Assumpção, 1996; Heintz et al., 2003; Assumpção et al., 2011), we note the fast polarization orientations do not correlate with the main geological trends. ${ }^{\text {c9 }}$

${ }^{c 1}$ There has been a modification in the order of the items discussed here, to better accommodate the new topics. We now discus the frozen anisotropy before the comparison with the tomography features, to make clearer the reason why we discard these effects in our interpretation.

c2 We also add a figure of geologic trends, and discuss in more detail the existence of frozen anisotropy, as suggested by reviewer 2 .

c3 Text added.

c4 Text added.

c5 Text added.

c6 Text added.

c7 Text added.

c8 Text added.

c9, with the exception of few measurements at the Ribeira belt, south of the Sao Franciseo craton (SFC). 

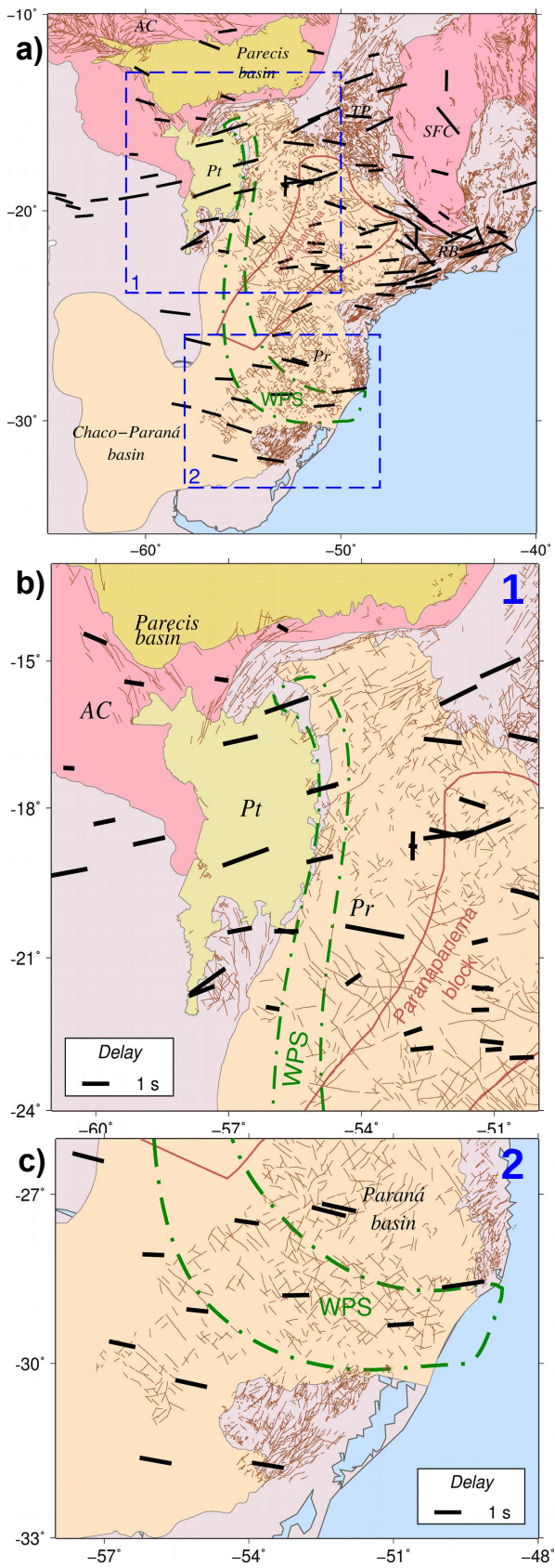

Figure 6: Main geologic provinces in South America. AC: Amazon craton; SFC: São Francisco craton; TP: Tocantins Province: Pt: Pantanal basin; RB: Ribeira Belt; WPS: West Paraná Suture (Dragone et al., 2017). Brown lines are basement faults mapped by CPRM (Brazilian Geological Survey), and the dashed squares are the areas with more measuments selected for comparison of the SWS directions with the fault trends. a) Geology of the study region. The dashed squares 1 and 2 are shown in more detail at b) and c), respectively. b) Mainly the ENE-WSW directions observed at the Pantanal and northern Paraná basin. c) E-W directions ơfserved at the southern Paraná basin. 


\subsection{Comparison with Lithospheric Depths}

We now discuss possible relations between the fast SWS orientation with a thick lithospheric block beneath the northern part of the Paraná basin. The positive and negative S-wave anomalies derived from the surface-wave tomography, shown in Figure 5 (Schaeffer and Lebedev, 2013) are a qualitative indication of the depth of the lithosphere. As we wish to check if variations in the lithospheric thickness are influencing the flow directions in the asthenosphere, we compare our results with the tomography anomalies at $150 \mathrm{~km}$ depth and with the lithosphere-asthenosphere boundary at a few stations obtained with S-wave receiver function (Heit et al., 2007). ${ }^{c 1} \mathrm{We}$ find that the thickest lithosphere $(160 \mathrm{~km})$ at station BDFB corresponds to $+5 \% \mathrm{~S}$-wave anomaly at $150 \mathrm{~km}$ depth. The thin part of the lithosphere $(\leq$ $80 \mathrm{~km}$ at CPUP) is associated with an S-wave anomaly value of only $1 \%$. In the Paraná Basin, a stack of 10 temporary stations showed an average lithosphere-asthenosphere boundary of $120 \mathrm{~km}$ depth, which is consistent with about $4.5 \% \mathrm{~S}$-wave anomalies. This means that the $\mathrm{S}$-wave velocity anomaly at $150 \mathrm{~km}$ depth can be used as a rough proxy for the lithospheric thickness. We have three separate main deep lithospheric roots: one at the southern part of the Amazon craton, one at the São Francisco craton, and one in the NE part of the Paraná basin. The positive anomaly in the tomography in the Paraná basin corresponds roughly to the cratonic block defined by Cordani (1984), based on radiometric dates and geological evidences. Mantovani et al. (2005) used gravity data to delimit this cratonic block, calling it Paranapanema block (Figure 5-in dashed pink). ${ }^{\mathrm{c} 2}$ Considering that the positive anomalies correspond to thicker lithospheres, we observe an ENE-WSW trend of the SWS orientations from the Pantanal basin to the Tocantins Province, north of the thick lithosphere of the Paranapanema block. Likewise, there is an ESE-WNW orientation group south of the Paranapanema thick lithosphere. Therefore, we consider that ${ }^{\mathrm{c} 3}$ the main contribution to the fast polarization orientations comes from asthenospheric flow and flow modulation due to lithosphere thickness variation at cratonic keels, especially around the SFC (Assumpção et al., 2006), and the Amazon cratons. The suggested flow surrounding the Paranapanema block in the Paraná basin, as will be shown below.

\subsection{Comparison with Mantle Flow}

The SKS splitting observed at the surface is the compound effect of the passage of the shear wave through a complex series of anisotropic layers in the
${ }^{\mathrm{c} 1}$ Labels of stations CPUP and BDFB are added to the tomography map at Figure 5, as asked by the editor. Also a map of all stations used is added to the Supplementary Material.

\section{c2 Text added.}

c3 frozen anisotropy plays a miner role in the observed SWS, and 
upper mantle. Comparing the fast orientation with any single parameter can be an over-simplification of heterogeneous and complex structure. However, it is useful to compare the fast orientations with some simple proxies for the anisotropy effect in an attempt to get insight into the main contribution to the observed shear wave splitting.

In this section we compare our SWS results with three different proxies of anisotropy: absolute plate motion with respect to the deep mantle (hot spot reference frame NUVEL1A-HS3), convection velocity ${ }^{c 1}$ and computed LPO, with respect to the overriding South American plate from the model of $\mathrm{Hu}$ et al. (2017).

${ }^{c 3}$ The model of Hu et al. (2017) calculates ${ }^{c 4}$ time-dependent upper mantle flow driven by the evolution of the Nazca plate subduction since the MidCretaceous. Conrad et al. (2007), Assumpção et al. (2011) and Miller and Becker (2012) had already compared their results with mantle flow models. However, these studies only utilized instantaneous mantle flow models. A time-dependent flow is needed to better predict seismic anisotropy, due to the long term response of anisotropic minerals to the cumulative strain (Ribe, 1992). This recent convection model depends on the subduction history and slab geometry and should better represent the real Earth, compared to models based on tomography images or parameterized slab geometry $(\mathrm{Hu}$ et al., 2017). ${ }^{55}$ To compute the strain-induced LPO directions of the mineral aggregates, the model calculates transverse isotropy, i.e. TI axis from full elastic tensors. TI axis of upper mantle aggregates approximately coincides with the direction of maximum stretching and fastest seismic velocity, and when sub-horizontal, define the orientation of the XKS wave fast component and maximum SWS is expected (Faccenda and Capitanio, 2013). ${ }^{\mathrm{c} 6}$ Moreover, it uses the kinematic model D-Rex of Kaminski et al. $(2004)^{\text {c7 }}$ which includes plastic deformation, dynamic recrystallization and grain boundary sliding, and incorporates these deformation mechanisms to compute LPO using the constrained mantle flow history. ${ }^{\mathrm{c} 8}$

${ }^{c 9}$ The model of $\mathrm{Hu}$ et al. $(2017)^{\mathrm{c} 10}$ also considers that the continent has a constant thickness of $100 \mathrm{~km}$ and only includes a variation of lithospheric depth for the Amazon craton, with a thickness of $250 \mathrm{~km}$. We compare SWS directions with the mantle velocity and LPO directions at different depths; $150 \mathrm{~km}, 200 \mathrm{~km}, 250 \mathrm{~km}$ and $300 \mathrm{~km}$ (Fig. S22). Both models do not show large variation of the directions with depths at the continental stable region, with all directions close to E-W, on average. For having a better correlation with our measurements across the entire study area (Fig. S23), the

\section{c1 Text added.}

c2 We add that the models of $\mathrm{Hu}$ et al. (2017), are using the overriding South American plate as reference frame, as suggestion by reviewer 2 .

c3 Text added. c4 Text added.

c5 Text added.

c6 Text added.

c7 Text added.

c8 We add more detailed information about how $\mathrm{Hu}$ et al., (2017) calculate the LPO directions shown in Figure 7 , as suggested by reviewer 2 .

c9 Text added. c10 Text added. 
directions at $250 \mathrm{~km}$ depth were chosen for comparison. Figure 7 shows the present velocity directions and the computed LPO orientations, both at 250 $\mathrm{km}$ depth, compared with the observed SWS results. ${ }^{\mathrm{c} 11}$
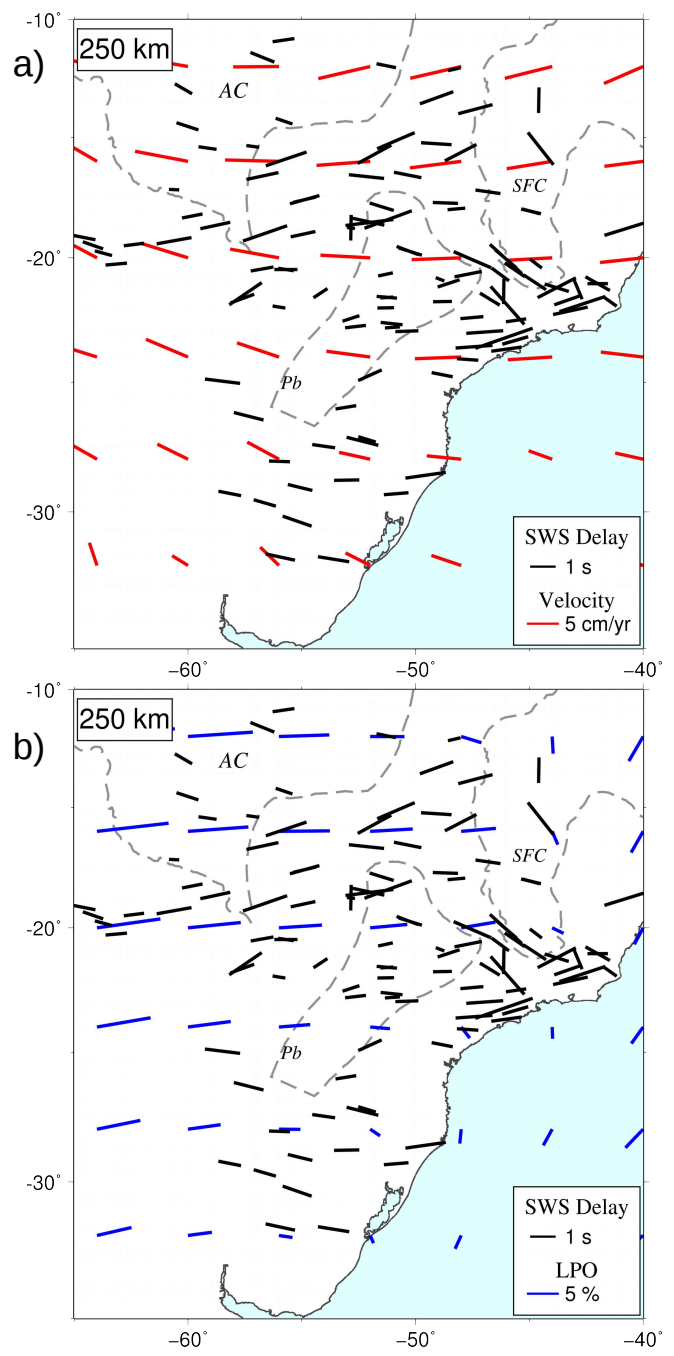

Figure 7: a) Upper mantle flow directions and LPO directions computed from TI axis, both at $250 \mathrm{~km}$ compared with the observed fast-polarization orientations.

We compare the APM, mantle velocity and LPO directions with the SWS results in the histograms of Figure 8 . The median misfit values are $15.7^{\circ}$, $11.8^{\circ}$ and $11.9^{\circ}$ respectively. This clearly shows that the slab-induced mantle flow model is a significant improvement in explaining SWS, compared with 
a)

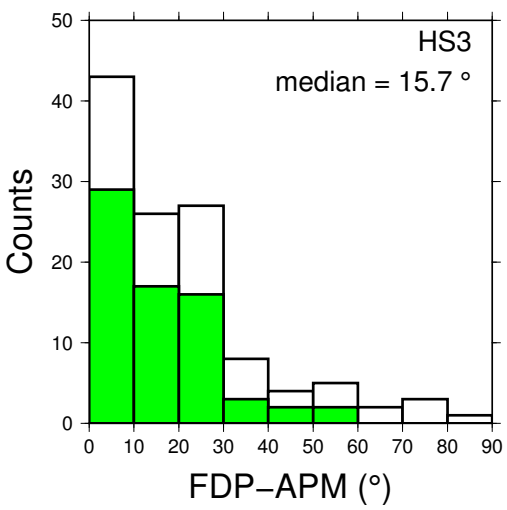

b)

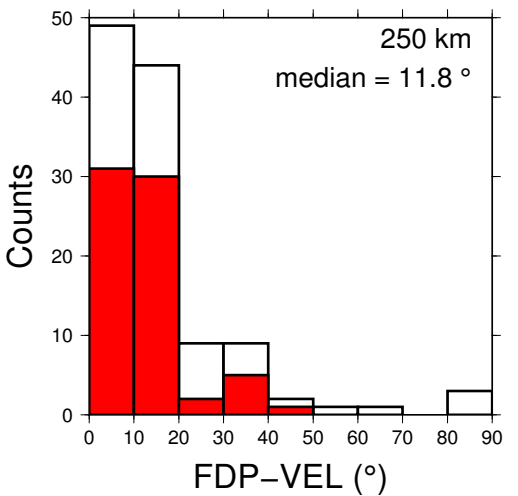

c)

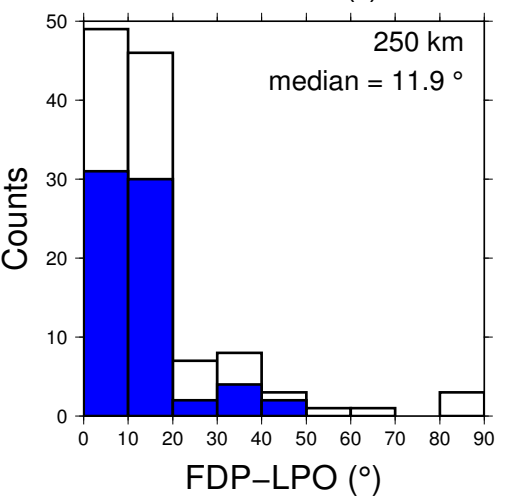

Figure 8: Histograms of the comparison of all station fast polarization orientation $(\phi)$ with the: a) absolute plate motion (APM) given by the HS3-NUVEL-1A model (Gripp and Gordon, 2002); b) mantle flow orientations from the model of $\mathrm{Hu}$ et al. (2017) at 250 $\mathrm{km}$ depth; c) LPO orientations from the model of (Hu et al., 2017) also at $250 \mathrm{~km}$ depth. Colored columns are more reliable values with measurements from 5 or more events, and white columns are all measurements. 
the simplistic APM. Our measurements also agree with mantle flow around the Amazon craton, as predicted by the model of $\mathrm{Hu}$ et al. (2017), as seen in Figure 5. Further south, however, especially in the Pantanal Basin, the observed SWS fast orientations tend to be ENE-WSW, deviating from the general ESE-WNW predicted orientations in Figure 7. We propose that the observed ENE-WSW orientation may be due to flow surrounding the Paranapanema block. ${ }^{c 1}$ In order to visualize the deviation of the fast orientations from the Paranapanema block, we calculate the difference between the LPO model directions and our results. Values within a $\pm 10^{\circ}$ difference are taken as in good agreement with the proposed model and are plotted in gray in Figure 9. The measurements with a difference higher than $10^{\circ}$ clockwise, are plotted in red and the measurements with a difference more than $10^{\circ}$ anticlockwise are plotted in blue. South of the Paraná deep lithospheric block the fast orientation tend to deviate away (clockwise) from it. To the northwest, especially in the Pantanal basin, the fast orientations deviate anticlockwise, with respect with the model of $\mathrm{Hu}$ et al. (2017). We propose that these deviations show mantle flow deflected by the deep structures below the Paranapanema block, as we can see in Figure 9. All the three main structures (Amazon and São Francisco cratons and the Paranapanema block) seem to be diverting the flow in between them. Assumpção et al. (2006) proposed that the anisotropy orientations indicate flow around the keel of the São Francisco craton. Here, we add that the Paranapanema block also deviates mantle flow.

The geometry of the Paranapanema block is not known in detail. Different geological and geophysical models have been proposed (Cordani, 1984; Mantovani et al., 2005; Milani and Ramos, 2017). Different studies of surface wave tomography tend to show large velocities beneath the northern part of the Paraná basin, but with different geometries. The regional tomography of Feng et al. (2007) shows two high velocities in the northern part of the Paraná basin and a separate high velocity keel in the southern part of the São Francisco craton Figure 9.b. The proposal of Assumpção et al. (2006) of mantle flow around SFC was based on this keel. The global tomography model SL2013sv (Schaeffer and Lebedev, 2013) Figure 9. a, on the other hand, does not have resolution to separate these two keels.

We also observe different areas of large and small delays. Large delay times are observed in the Pantanal basin and may indicate a strong asthenospheric channel, a more coherent flow, or a thicker asthenosphere. Further to the northeast, large delays seem to predominate between the São Fran-

c1 The images are now plotted with the same reference values, and the assumptions made are still valid. Only the high velocity anomaly of the northern Parana basin -figure 10b- is not as evident as before, but it is seem in a light green shade, as suggested by reviewer 1 . 
cisco ad Amazon cratons. Small delays are generally observed beneath areas with thick lithosphere, such as the Amazon craton, and the Paranapanema block. This may indicate thinner anisotropic asthenosphere, consistent with the model of $\mathrm{Hu}$ et al. (2017) ${ }^{\mathrm{c} 1}$, or a different and more complex type of anisotropy, such as orientations varying with depth, or tilted fast axes of the olivine crystals (Baptiste and Tommasi, 2014)..$^{c 2}$

The SFC geometry used in the mantle flow calculation of $\mathrm{Hu}$ et al. (2017), did not significantly change the estimated SWS orientations. For this reason, the model version used in Figure 8, Figure 7 and Figure 9 does not include the SFC. We propose that the addition of a deep keel in southern part of the SFC and the Paranapanema block should improve the fit to the observed orientations. 

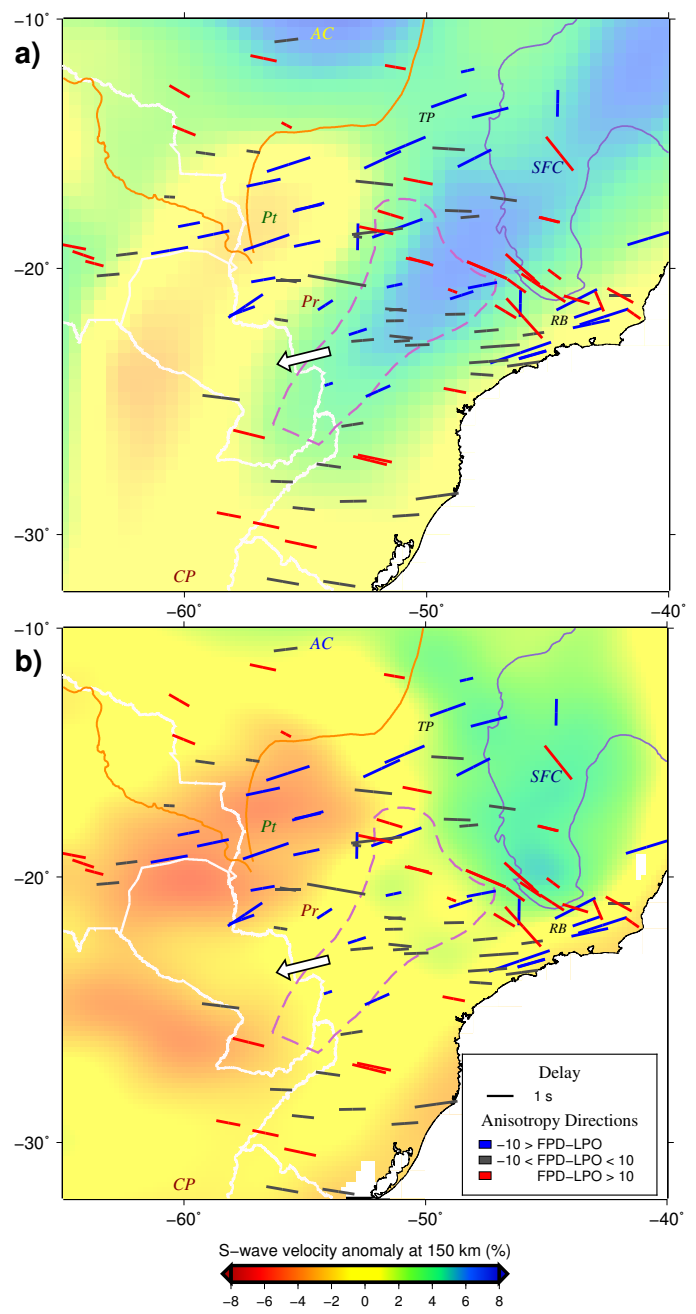

Figure 9: Same as Figure 5, with bar colors showing the difference from the LPO model of Hu et al. (2017). SWS observations which deviate more than $10^{\circ}$ clockwise from the LPO directions are plotted as red bars. Deviations more than $10^{\circ}$ anticlockwise are shown as blue bars. Colors indicate S-wave velocity anomalies at $150 \mathrm{~km}$ depth from two different tomography models: a) SL2013Sv global model of Schaeffer and Lebedev (2013), b) the regional model of Feng et al. (2007).

\section{Conclusions}

In this work we present new measurements of shear wave splitting in the Paraná and Pantanal basins, SE Brazil, in ${ }^{\mathrm{c} 1}$ an area not well sampled before. In general, considering the previous and new results in the continental midplate South America, the fast polarization orientations have an average E- 
W trend, previously related with the absolute plate motion directions (HS3NUVEL1A). Our results show that the subduction-induced, time dependent flow model of $\mathrm{Hu}$ et al. (2017) provides a much better explanation for the SWS observations, which is seen using two proxies: convection velocity and LPO at $250 \mathrm{~km}$ depth. The observed orientations are also consistent with the flow around the Amazon craton, predicted by their model. ${ }^{c 2}{ }^{c 3}$ Our measurements are consistent with the proposition of cratonic block under the Parana basin, the Paranapanema block, proposed previously, diverting flow around it.

\section{Acknowledgements}

We are thankful to the support and attention from M. Reiss with the SplitRacer package, L. Liu and J. Hu for providing the mantle flow model. Work supported by the FAPESP "3-Basin" grant 2013/24215-6, CAPES M.Sc. scholarship and CNPq research grant 30.6547/2013-9. We thank the "3Basins Project Team" which made possible the production of our dataset: Felipe Neves, Luís Galhardo, José Roberto Barbosa, Cleusa Barbosa (USP, field work); Bruno Collaço, Jackson Calhau (USP, field work and data management); Marcelo Bianchi, Emilia Brasilio (USP, data management and data quality); Paulo Azevedo, Marcelo Rocha (UnB, Brazil); Tiago Silva, Edna Facincani (UFMS, Brazil); Gonzalo Fernandez, Felipe Condori (OSC, Bolivia); Gerardo Sánchez, Luis Andujar (INPRES, Argentina); Rafael Fugarazzo, Moisés Gadea, Vincent Figueres (UNA, Paraguay); Leda Sánchez, Enrique Latorres, Hernán Castro, Martín Rodríguez, Anahí Curbelo (UDELAR, Uruguay). Figures were prepared using the GMT software package (Wessel and Smith, 1998).

\section{References}

Assine, M. L. and P. C. Soares

2004. Quaternary of the Pantanal, west-central Brazil. Quaternary International, 114(1):23-34.

Assumpção, M., M. Guarido, S. van der Lee, and J. C. Dourado 2011. Upper-mantle seismic anisotropy from SKS splitting in the South American stable platform: A test of asthenospheric flow models beneath the lithosphere. Lithosphere, 3(2):173-180. c2 We also support the existence of a eratonic block under the Parana basin, the

Paranapanema block, which diverts mantle flow. The small delay times observed in the Paranapanema block seem to be typical of other cratonic areas. c3 Text added. 
Assumpção, M., M. Heintz, A. Vauchez, and M. E. Silva 2006. Upper mantle anisotropy in SE and Central Brazil from SKS splitting: evidence of asthenospheric flow around a cratonic keel. Earth and Planetary Science Letters, 250(1):224-240.

Baptiste, V. and A. Tommasi

2014. Petrophysical constraints on the seismic properties of the kaapvaal craton mantle root. Solid Earth, 5(1):45.

Bastow, I. D., J. Julia, A. do Nascimento, R. Fuck, T. Buckthorp, and J. McClellan 2015. Upper mantle anisotropy of the Borborema Province, NE Brazil: Implications for intra-plate deformation and sub-cratonic asthenospheric flow. Tectonophysics, 657:81-93.

Becker, T., S. Lebedev, and M. Long 2012. On the relationship between azimuthal anisotropy from shear wave splitting and surface wave tomography. Journal of Geophysical Research: Solid Earth, 117(B1).

Becker, T. W., C. P. Conrad, A. J. Schaeffer, and S. Lebedev 2014. Origin of azimuthal seismic anisotropy in oceanic plates and mantle. Earth and Planetary Science Letters, 401:236-250.

Bianchi, M.

2015. RSBR automatic sensor orientation analysis by P-wave incidence direction.

Conrad, C. P., M. D. Behn, and P. G. Silver 2007. Global mantle flow and the development of seismic anisotropy: differences between the oceanic and continental upper mantle. Journal of Geophysical Research: Solid Earth, 112(B7).

Cordani, U. G. 1984. Estudio preliminar de integraçao do Pré-Cambriano com os eventos tectônicos das bacias sedimentares Brasileiras, volume 15. Petrobrás, Centro de Pesquisas e Desenvolvimento Leopoldo A. Miguez de Mello, Setor de Informação Técnica e Propriedade Industrial.

Debayle, E., F. Dubuffet, and S. Durand

2016. An automatically updated s-wave model of the upper mantle and 
the depth extent of azimuthal anisotropy. Geophysical Research Letters, 43(2):674-682.

Dias, F., M. Assumpção, E. Facincani, G. França, M. Assine, P. AC Filho, and R. Gamarra 2016. The 2009 earthquake, magnitude $4.8 \mathrm{mb}$, in the Pantanal wetlands, west-central Brazil. Anais da Academia Brasileira de Ciências.

Dragone, G. N., N. Ussami, M. E. Gimenez, F. G. L. Klinger, and C. A. M. Chaves 2017. Western Paraná suture/shear zone and the limits of Rio Apa, Rio Tebicuary and Rio de la Plata cratons from gravity data. Precambrian Research, 291:162-177.

Faccenda, M. and F. Capitanio 2013. Seismic anisotropy around subduction zones: Insights from threedimensional modeling of upper mantle deformation and SKS splitting calculations. Geochemistry, Geophysics, Geosystems, 14(1):243-262.

Feng, M., S. Van der Lee, and M. Assumpção 2007. Upper mantle structure of South America from joint inversion of waveforms and fundamental mode group velocities of Rayleigh waves. Journal of Geophysical Research: Solid Earth, 112(B4).

Fouch, M. J., K. M. Fischer, E. Parmentier, M. E. Wysession, and T. J. Clarke 2000. Shear wave splitting, continental keels, and patterns of mantle flow. Journal of Geophysical Research: Solid Earth, 105(B3):6255-6275.

Gripp, A. E. and R. G. Gordon 2002. Young tracks of hotspots and current plate velocities. Geophysical Journal International, 150(2):321-361.

Heintz, M., A. Vauchez, M. Assumpção, G. Barruol, and M. Egydio-Silva 2003. Shear wave splitting in SE Brazil: an effect of active or fossil upper mantle flow, or both? Earth and Planetary Science Letters, 211(1):79-95.

Heit, B., F. Sodoudi, X. Yuan, M. Bianchi, and R. Kind 2007. An S receiver function analysis of the lithospheric structure in South America. Geophysical Research Letters, 34(14). 
Hu, J., M. Faccenda, and L. Liu 2017. Subduction-controlled mantle flow and seismic anisotropy in South America. Earth and Planetary Science Letters, 470:13-24.

Ismall, W. B. and D. Mainprice 1998. An olivine fabric database: an overview of upper mantle fabrics and seismic anisotropy. Tectonophysics, 296(1):145-157.

James, D. E. and M. Assumpção 1996. Tectonic implications of S-wave anisotropy beneath SE Brazil. Geophysical Journal International, 126(1):1-10.

Julià, J., M. Assumpção, and M. Rocha 2008. Deep crustal structure of the Paraná Basin from receiver functions and Rayleigh-wave dispersion: Evidence for a fragmented cratonic root. Journal of Geophysical Research: Solid Earth, 113(B8).

Kaminski, E., N. M. Ribe, and J. T. Browaeys 2004. D-rex, a program for calculation of seismic anisotropy due to crystal lattice preferred orientation in the convective upper mantle. Geophysical Journal International, 158(2):744-752.

Mantovani, M., M. Quintas, W. Shukowsky, and B. Brito Neves 2005. Delimitation of the Paranapanema Proterozoic block: a geophysical contribution. Episodes-Newsmagazine of the International Union of Geological Sciences, 28(1):18-22.

Milani, E. J. and M. De Wit 2008. Correlations between the classic Paraná and Cape-Karoo sequences of South America and Southern Africa and their basin infills flanking the gondwanides: Du Toit revisited. Geological Society, London, Special Publications, 294(1):319-342.

Milani, E. J. and V. A. Ramos 2017. Orogenias paleozóicas no domínio sul-ocidental do Gondwana e os ciclos de subsidência da Bacia do Paraná. Revista Brasileira de Geociências, 28(4):473-484.

Miller, M. S. and T. W. Becker

2012. Mantle flow deflected by interactions between subducted slabs and cratonic keels. Nature Geoscience, 5(10):726-730. 
Reiss, M. C. and G. Rümpker 2017. Splitracer: Matlab Code and GUI for Semiautomated Analysis and Interpretation of Teleseismic Shear-Wave Splitting. Seismological Research Letters, 88(2A):392-409.

Ribe, N. M. 1992. On the relation between seismic anisotropy and finite strain. Journal of Geophysical Research: Solid Earth, 97(B6):8737-8747.

Savage, M. 1999. Seismic anisotropy and mantle deformation: what have we learned from shear wave splitting? Reviews of Geophysics, 37(1):65-106.

Schaeffer, A. and S. Lebedev 2013. Global shear speed structure of the upper mantle and transition zone. Geophysical Journal International, 194(1):417-449.

Silver, P. G. 1996. Seismic anisotropy beneath the continents: Probing the depths of geology. Annual review of earth and planetary sciences, 24(1):385-432.

Silver, P. G. and W. W. Chan 1991. Shear wave splitting and subcontinental mantle deformation. Journal of Geophysical Research: Solid Earth, 96(B10):16429-16454.

Steinberger, B. and T. W. Becker 2016. A comparison of lithospheric thickness models. Tectonophysics.

Ussami, N., S. Shiraiwa, and J. M. L. Dominguez 1999. Basement reactivation in a sub-andean foreland flexural bulge: The Pantanal wetland, SW Brazil. Tectonics, 18(1):25-39.

Vinnik, L., L. Makeyeva, A. Milev, and A. Y. Usenko 1992. Global patterns of azimuthal anisotropy and deformations in the continental mantle. Geophysical Journal International, 111(3):433-447.

Wessel, P. and W. H. Smith 1998. New, improved version of generic mapping tools released. Eos, Transactions American Geophysical Union, 79(47):579-579. 


\title{
Mantle Anisotropy and Asthenospheric Flow Around Cratons in Southeastern South America
}

\author{
Supplementary Material
}

Bruna Chagas de Melo, Marcelo Assumpção

March 2, 2018

\section{Tables}

Table S 1: New XKS splitting results calculated with the average of all individual results. $\phi$ are fast polarization orientations and $\mathrm{d} \phi$ are the errors; $\delta t$ is splitting delay time and $\mathrm{d} \delta t$ are the errors; $\mathrm{N}$ number of measurements; null values represent stations where only null measurements were available. $\mathrm{BR}$ and BL networks are part of the Brazilian Seismographic Network (RSBR). XC is the temporary deployment of the "3 Basins" project.

\begin{tabular}{ccccccccc}
\hline \hline Net & Sta & Lat $\left(^{\circ}\right)$ & Lon $\left(^{\circ}\right)$ & $\phi\left(^{\circ}\right)$ & $d \phi\left(^{\circ}\right)$ & $\delta \mathbf{t}$ & $d \delta \mathbf{t}$ & $\mathbf{N}$ \\
\hline BL & CLDB & -10.87 & -55.80 & 81.8 & 8.4 & 0.86 & 0.21 & 81 \\
BL & CNLB & -29.31 & -50.85 & 85.4 & 11.8 & 0.98 & 0.24 & 115 \\
BL & ITAB & -27.23 & -52.13 & 107.0 & 0.0 & 0.72 & 0.00 & 31 \\
BL & ITRB & -19.70 & -50.36 & 110.6 & 17.3 & 0.90 & 0.29 & 40 \\
BL & PLTB & -31.76 & -53.60 & 99.1 & 11.1 & 1.24 & 0.29 & 53 \\
BL & PTGB & -24.72 & -52.01 & 65.8 & 20.9 & 1.01 & 0.29 & 77 \\
BL & TRCB & -22.79 & -52.64 & 83.5 & 21.2 & 0.83 & 0.32 & 26 \\
BR & ARAG & -15.71 & -51.81 & 61.6 & 32.4 & 1.50 & 0.48 & 15 \\
BR & IPMB & -17.98 & -48.21 & 85.0 & 16.6 & 0.69 & 0.24 & 23 \\
BR & PDRB & -11.61 & -56.73 & 111.8 & 12.7 & 1.01 & 0.30 & 17 \\
BR & SALB & -15.90 & -55.69 & 71.5 & 23.3 & 1.69 & 0.56 & 29 \\
BR & SNDB & -11.97 & -51.29 & 101.4 & 27.3 & 0.79 & 0.35 & 5 \\
BR & VILB & -12.95 & -60.20 & 120.0 & 37.1 & 0.79 & 0.24 & 13 \\
BR & PTLB & -15.45 & -59.14 & 98.0 & 3.0 & 0.72 & 0.00 & 9 \\
XC & AMBA & -22.93 & -54.99 & null & null & null & null & 10 \\
XC & CCRS & -17.29 & -57.89 & null & null & null & null & 3 \\
XC & EDMB & -26.36 & -54.43 & null & null & null & null & 2 \\
XC & NBRS & -14.32 & -55.78 & 108.6 & 15.0 & 0.69 & 0.24 & 4 \\
XC & PANT & -18.99 & -56.62 & 71.0 & 0.0 & 1.85 & 0.00 & 2 \\
XC & RODS & -30.35 & -55.20 & 109.0 & 1.0 & 1.20 & 0.16 & 3 \\
XC & TBOT & -31.68 & -55.94 & 102.0 & 2.8 & 1.18 & 0.22 & 2 \\
XC & UNIS & -29.07 & -55.07 & 102 & 8.5 & 0.99 & 0.25 & 6 \\
XC & VBST & -14.53 & -60.02 & 108.0 & 30.1 & 0.92 & 0.47 & 10 \\
\hline \hline
\end{tabular}


Table S 2: New XKS splitting results calculated with the joined minimization of all waveforms (under the assumption of 1 layer). $\phi$ are fast polarization orientations and $\mathrm{d} \phi$ are the errors; $\delta t$ is splitting delay time and $\mathrm{d} \delta t$ are the errors; $\mathrm{N}$ number of measurements; null values represent stations where only null measurements were available. BR and BL networks are part of the Brazilian Seismographic Network (RSBR). XC is the temporary deployment of the "3 Basins" project.

\begin{tabular}{ccccccccc}
\hline \hline Net & Sta & Lat $\left(^{\circ}\right)$ & Lon $\left(^{\circ}\right)$ & $\phi\left(^{\circ}\right)$ & $d \phi\left(^{\circ}\right)$ & $\delta \mathbf{t}$ & $d \delta \mathbf{t}$ & $\mathbf{N}$ \\
\hline BL & AQDB & -20.48 & -55.70 & 99.0 & 5.0 & 0.62 & 0.00 & 26 \\
BL & C2SB & -18.77 & -52.84 & 97.0 & 8.0 & 0.31 & 0.00 & 11 \\
BL & ITQB & -29.66 & -56.63 & 106.0 & 4.5 & 0.92 & 0.05 & 30 \\
BL & PCMB & -21.61 & -51.26 & 86.0 & 5.0 & 0.51 & 0.05 & 22 \\
BL & PEXB & -12.11 & -48.30 & 77.0 & 4.5 & 0.51 & 0.05 & 17 \\
BL & PP1b & -17.60 & -54.88 & 77.0 & 2.5 & 0.92 & 0.04 & 22 \\
XC & ALGR & -28.80 & -53.03 & 89.0 & 4.5 & 1.00 & 0.09 & 9 \\
XC & ANTJ & -22.00 & -56.00 & 99.0 & 8.5 & 0.51 & 0.10 & 4 \\
XC & AZCA & -28.08 & -55.98 & 92.0 & 6.0 & 0.82 & 0.15 & 7 \\
XC & BBLB & -18.67 & -58.80 & 78.0 & 3.0 & 1.20 & 0.20 & 11 \\
XC & BBRB & -18.28 & -59.81 & 79.0 & 4.5 & 0.82 & 0.15 & 9 \\
XC & BBSD & -17.19 & -60.61 & 93.0 & 10.0 & 0.41 & 0.10 & 3 \\
XC & BDQN & -20.45 & -56.75 & 80.0 & 13.0 & 0.92 & 0.60 & 2 \\
XC & CRSM & -27.49 & -54.04 & 98.0 & 6.0 & 0.92 & 0.09 & 7 \\
XC & DVLD & -16.64 & -52.16 & 96.0 & 5.0 & 1.40 & 0.15 & 8 \\
XC & ESFA & -24.96 & -58.49 & 97.0 & 8.0 & 1.40 & 0.25 & 5 \\
XC & FRBT & -25.98 & -53.06 & 81.0 & 4.0 & 0.82 & 0.10 & 17 \\
XC & MECA & -29.30 & -58.17 & 101.0 & 3.0 & 0.92 & 0.05 & 4 \\
XC & MURT & -21.66 & -57.61 & 70.0 & 4.0 & 1.00 & 0.20 & 6 \\
XC & POCN & -16.62 & -56.73 & 78.0 & 4.5 & 1.30 & 0.25 & 4 \\
XC & PTET & -15.38 & -57.16 & 98.0 & 9.0 & 0.51 & 0.10 & 5 \\
XC & RVDE & -19.03 & -54.94 & 78.0 & 5.0 & 1.00 & 0.10 & 5 \\
\hline \hline
\end{tabular}




\section{Figures}

\section{$2.1 \quad$ Station names and locations}

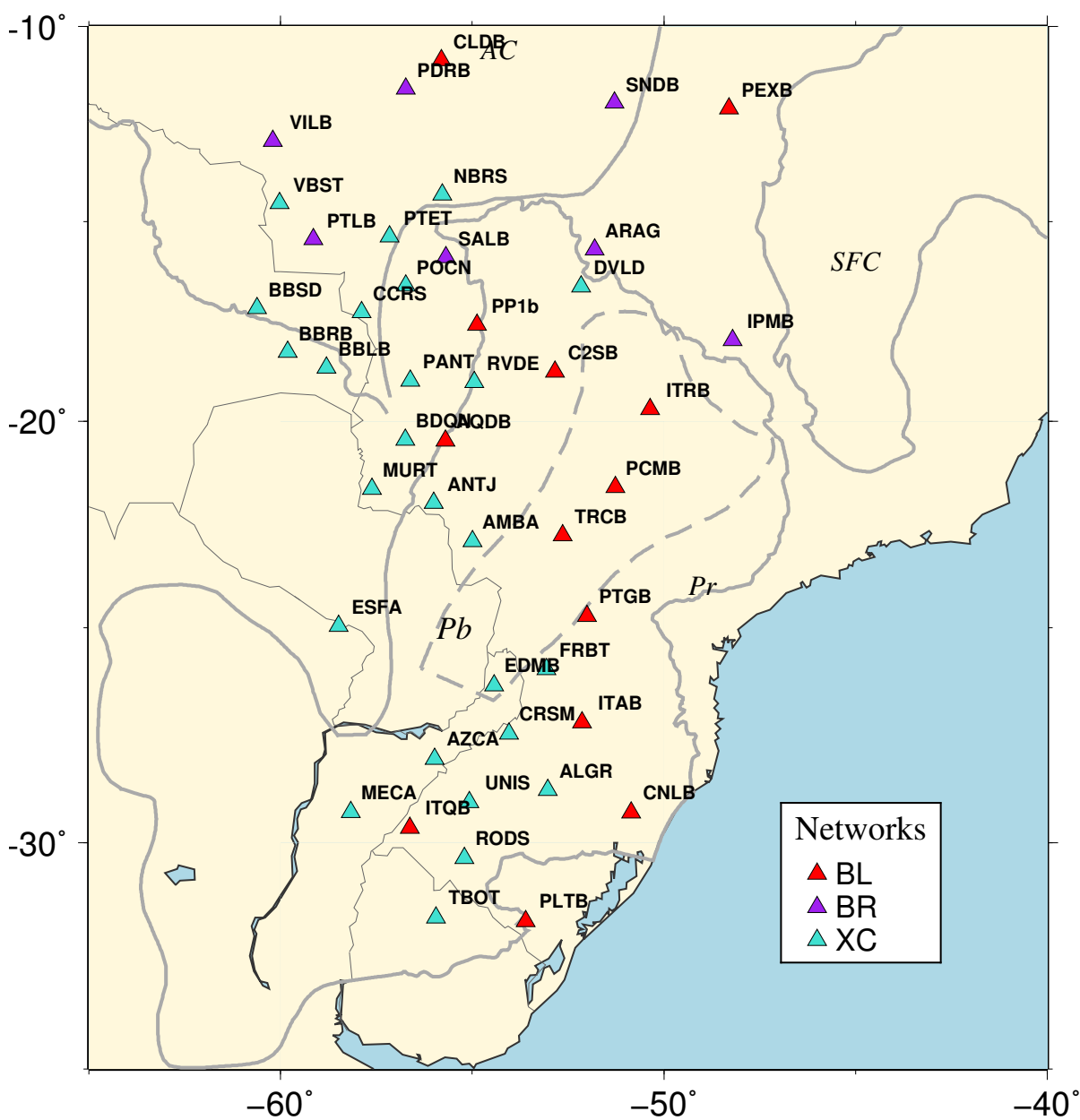

Fig. S 1: Station names and their respective networks used in this paper. AC: Amazon craton; SFC: São Francisco craton; Pb: Paranapanema Block; Pr: Paraná Basin.

\subsection{Misalignment Check}




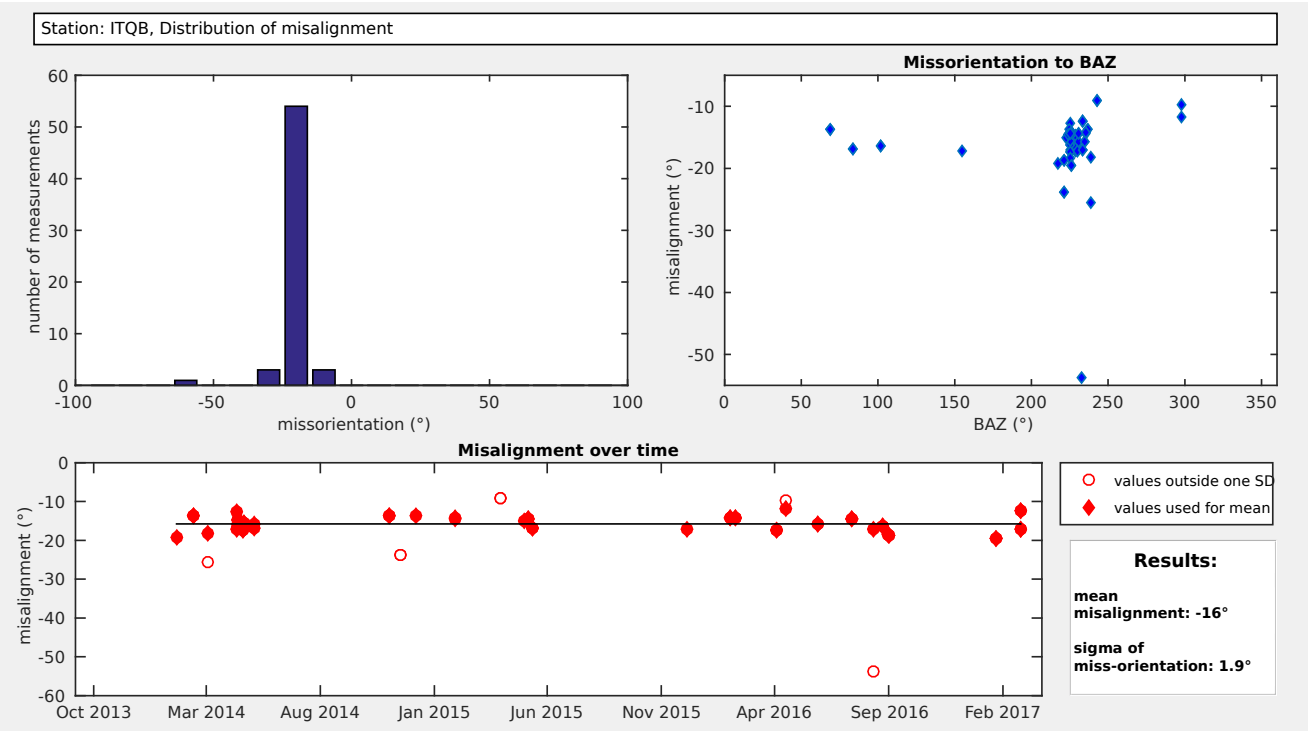

Fig. S 2: Misalignment check at station ITQB. This measure is made based on the difference between the orientation of the ellipse drawn by the XKS particle motion and the back-azimuth. This station showed a mean misalignment of $-16^{\circ}$ which matched the misalignment measured with $\mathrm{P}$-wave particle motions by Bianchi, 2016. For misalignments larger than $\pm 10^{\circ}$ the correction was applied.

\subsection{All measurements per station: Averaged for 1 layer}

This plot helps the reader to visualize where 1 layer or other form of complex anisotropy should be considered. Despite the large variation of the anisotropy parameters with back-azimuth at some stations (see stations ITRB and PTGB, for example) we considered that the 1 layer assumption fitted well the data, and that there is not enough evidence of a 2 layer case. Where only null measurements where found, no anisotropy parameter is calculated. For all these stations, there is not sufficient data to assume if these are "null" stations with no anisotropy on the wave path. 


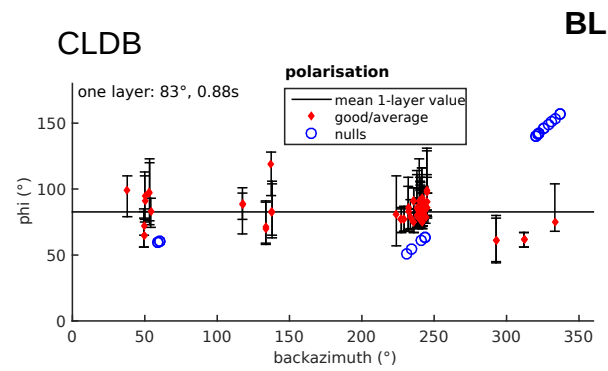

BL Network

CNLB
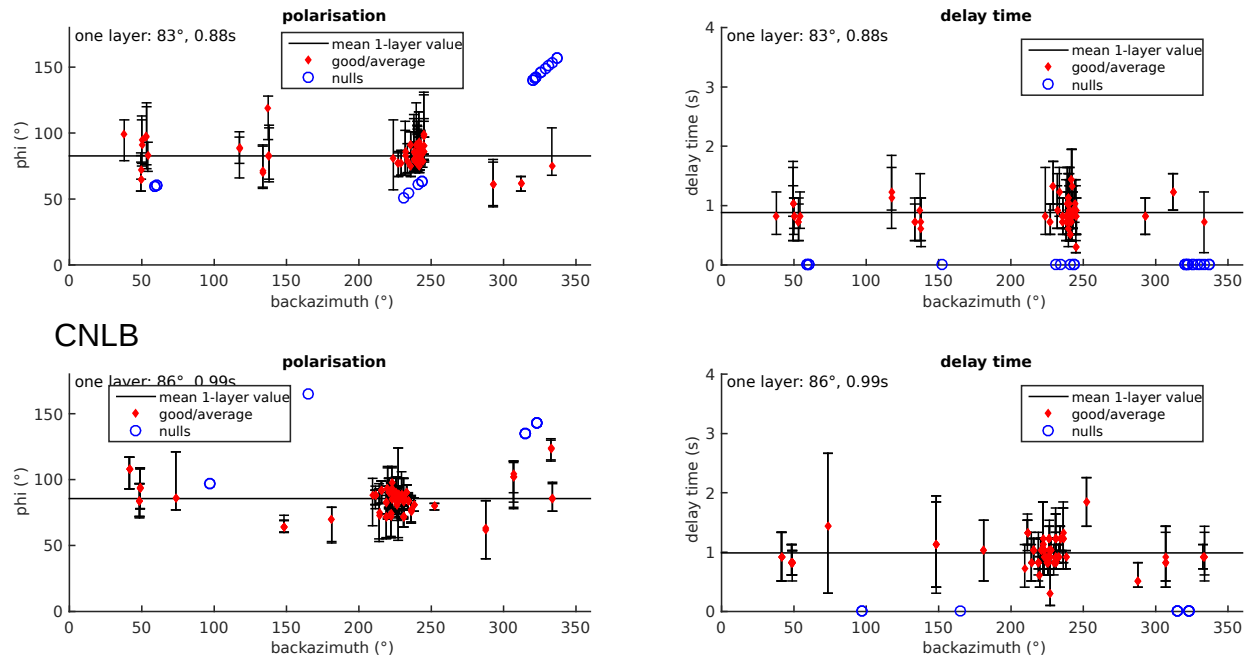

ITAB
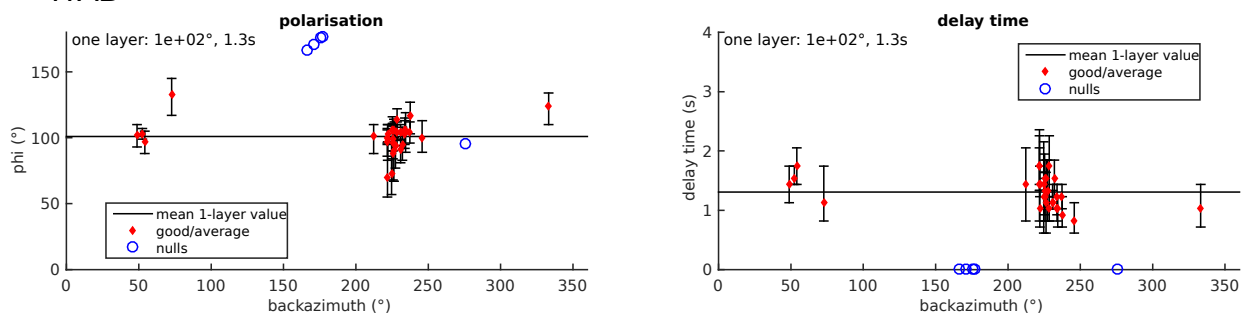

Fig. S 3: Individual measurements plotted with back-azimuth for stations CLDB, CNLB and ITAB (BL network from the RSBR). The calculated anisotropy parameters at these stations are the mean of all measurements of $\phi$ and $\delta t$. 


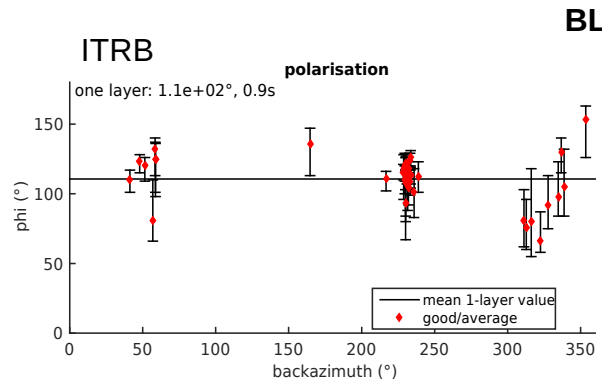

\section{BL Network}
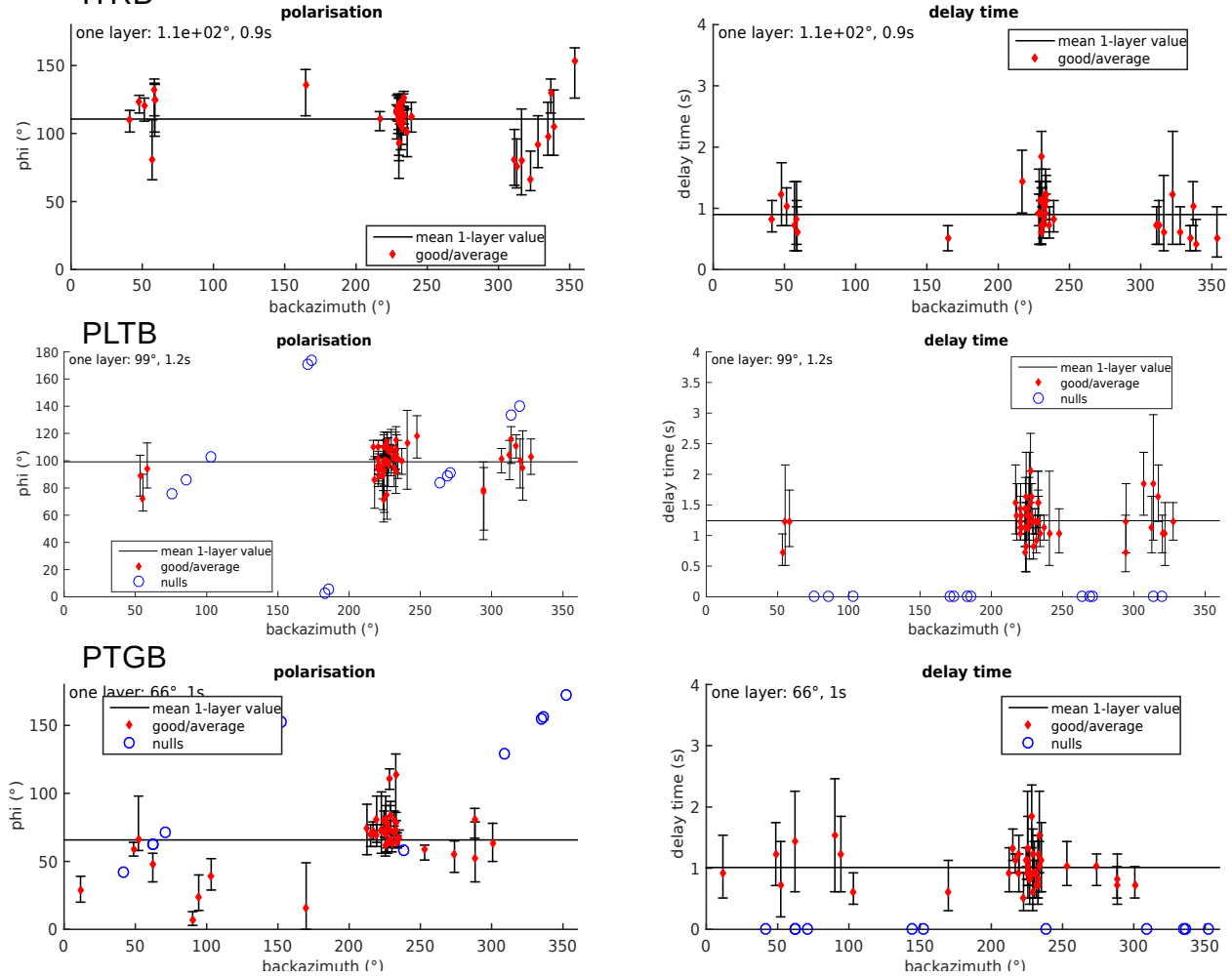

Fig. S 4: Individual measurements plotted with back-azimuth for stations ITRB, PLTB and PTGB (BL network from the RSBR). The calculated anisotropy parameters at these stations are the mean of all measurements of $\phi$ and $\delta t$. 

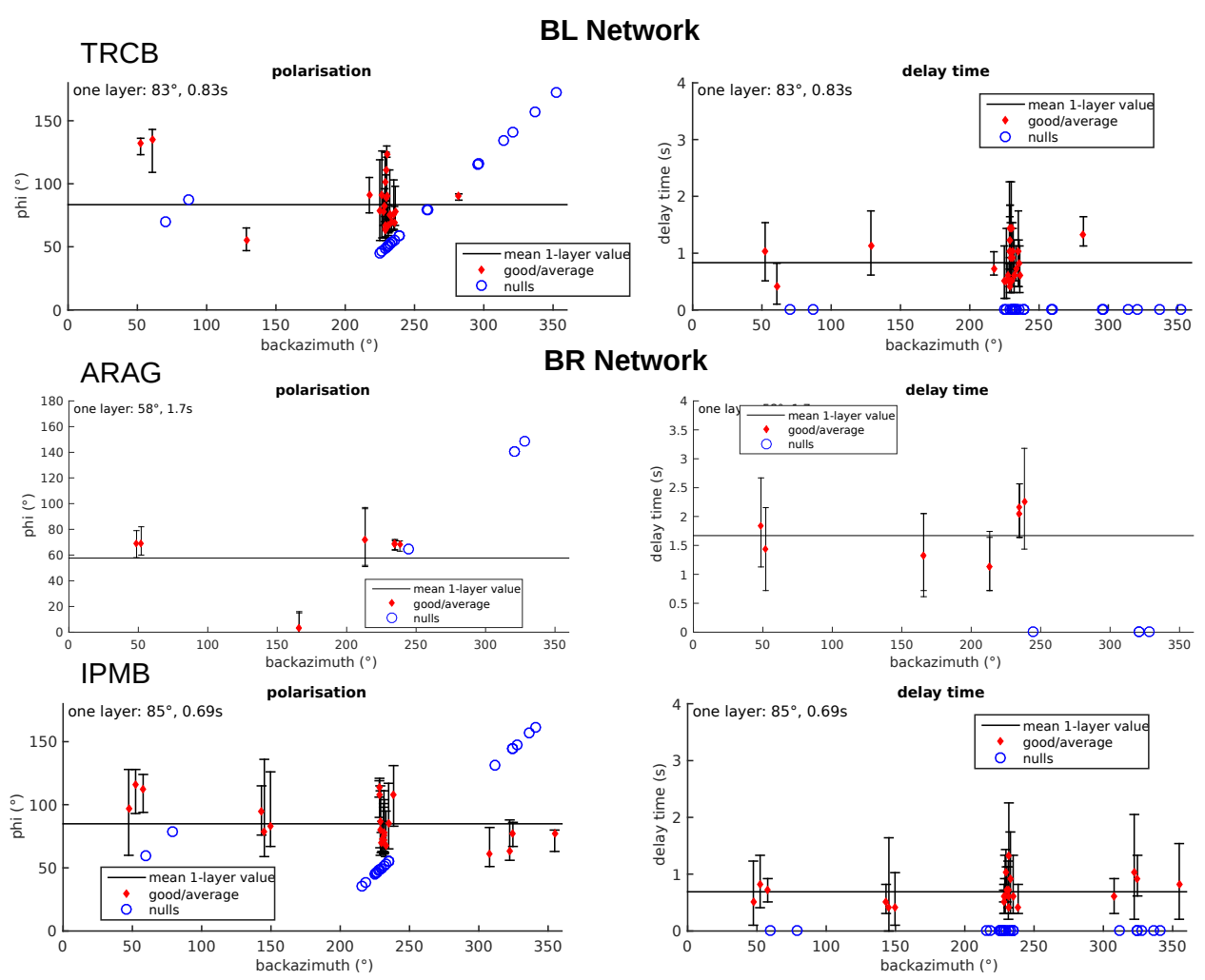

Fig. S 5: Individual measurements plotted with back-azimuth for stations TRCB, ARAG and IPMB (BL and BR networks from the RSBR). The calculated anisotropy parameters at these stations are the mean of all measurements of $\phi$ and $\delta t$. 


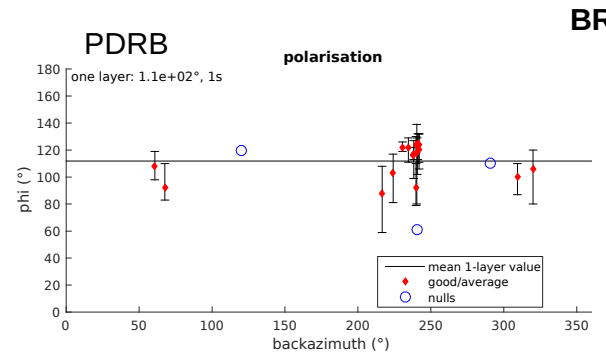

BR Network
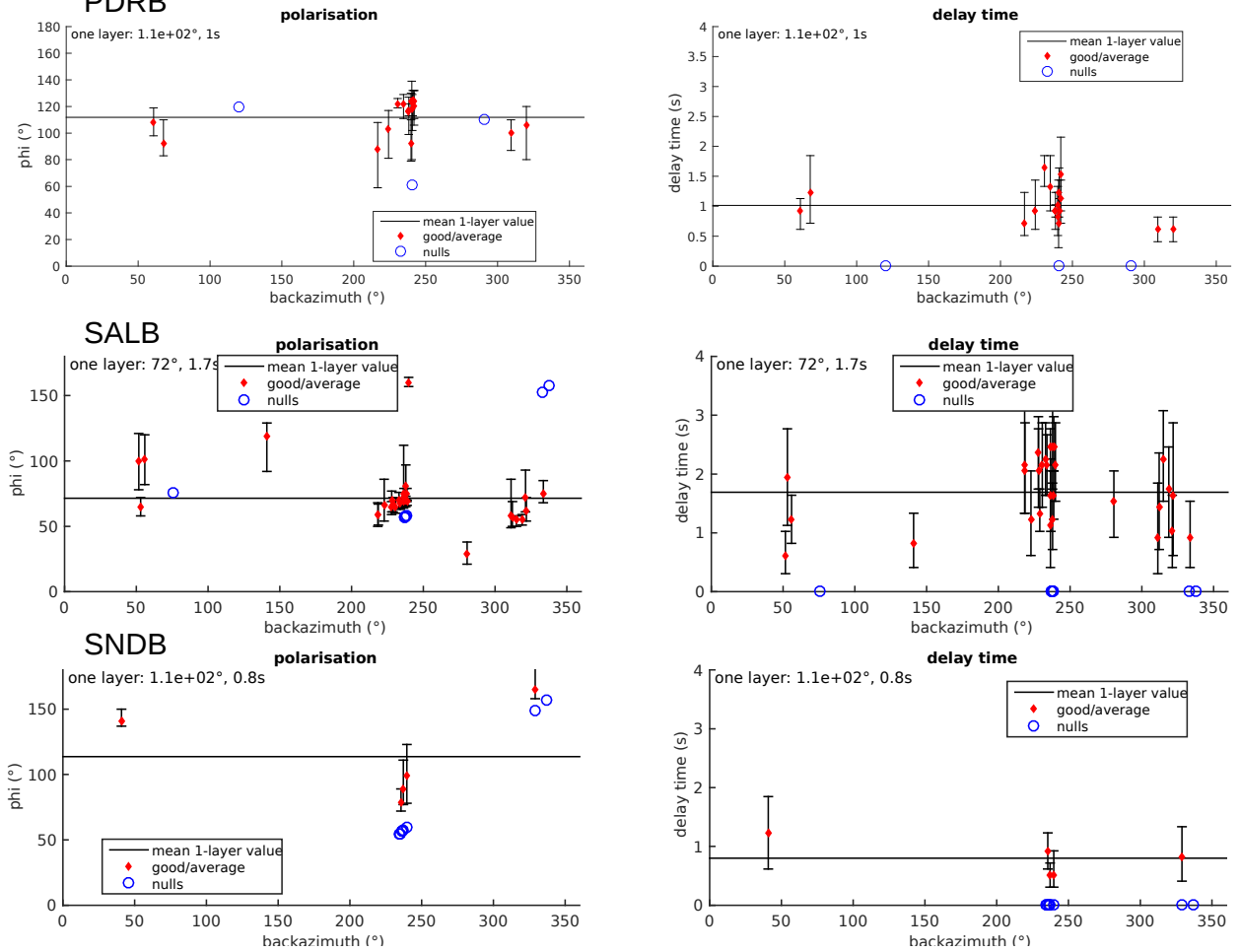

Fig. S 6: Individual measurements plotted with back-azimuth for stations PDRB, SALB and SNDB (BR network from the RSBR). The calculated anisotropy parameters at these stations are the mean of all measurements of $\phi$ and $\delta t$. 


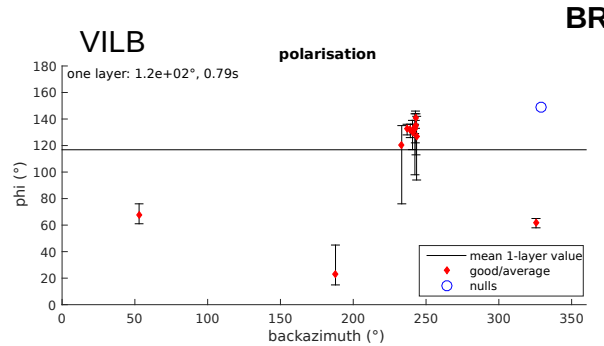

BR Network
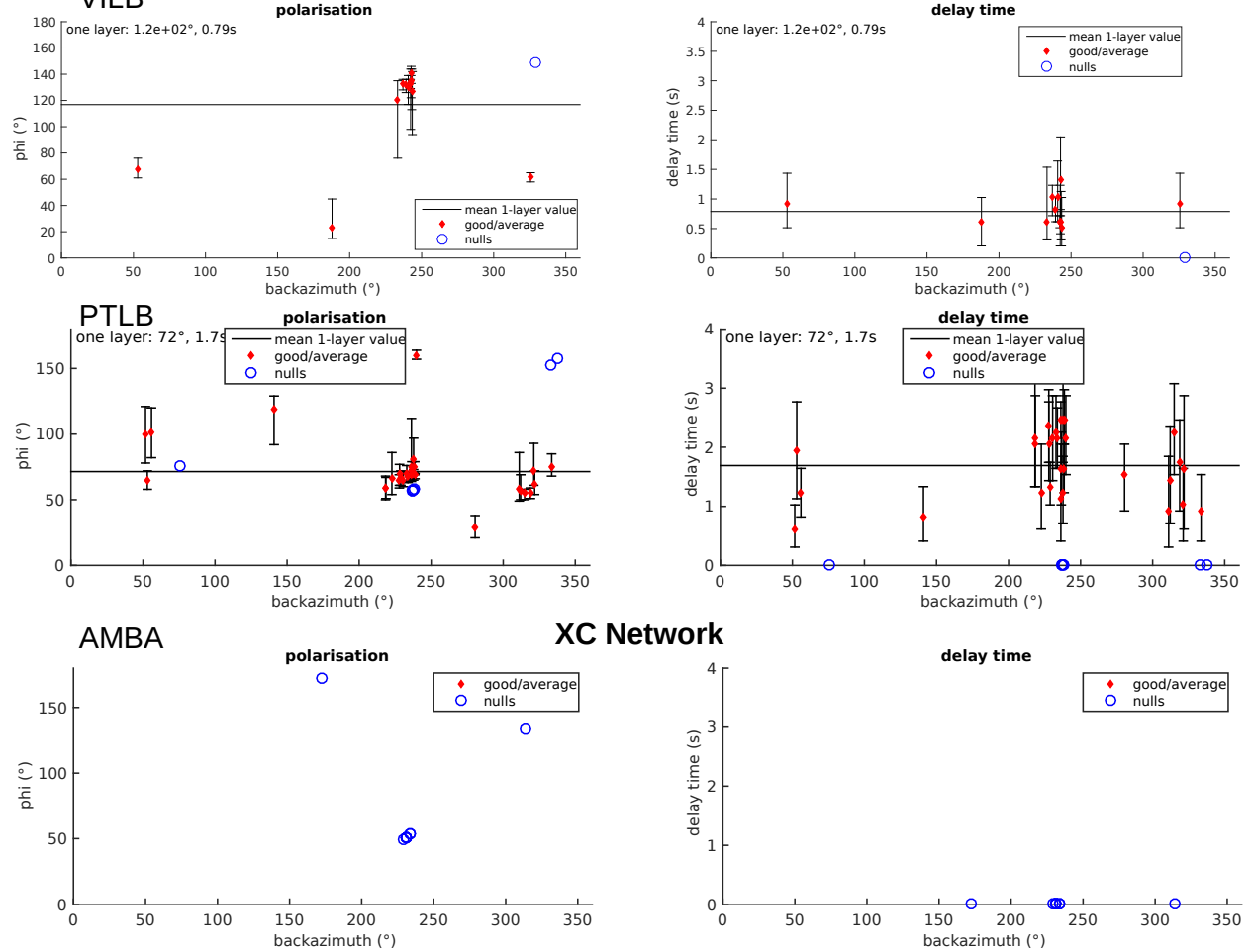

Fig. S 7: Individual measurements plotted with back-azimuth for stations VILB and PTLB (BR network from the RSBR) and station AMBA (XC network from the FAPESP "3-Basin Thematic Project"). The calculated anisotropy parameters at these stations are the mean of all measurements of $\phi$ and $\delta t$. 


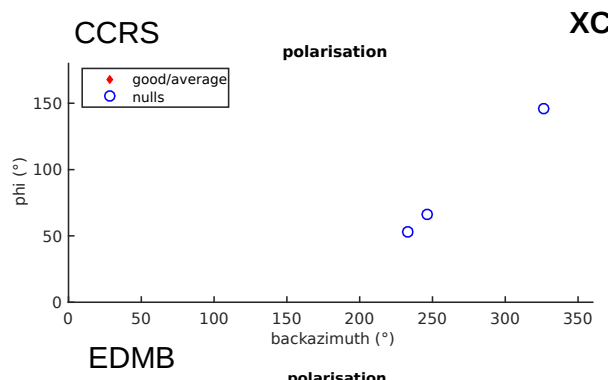

XC Network
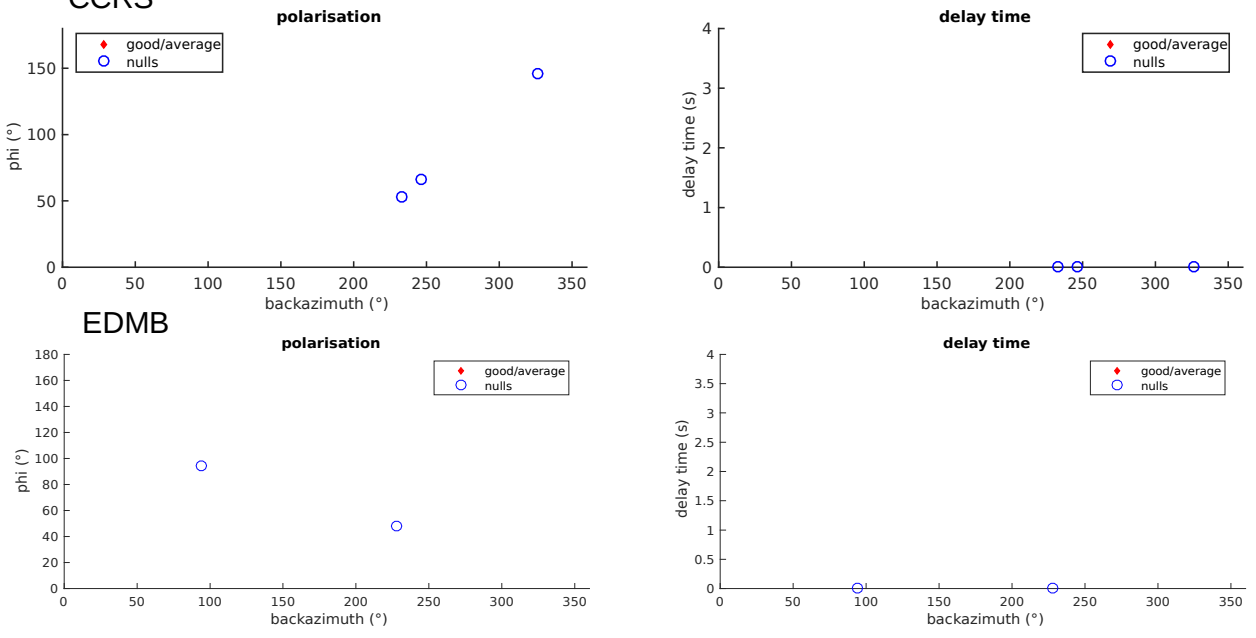

NBRS
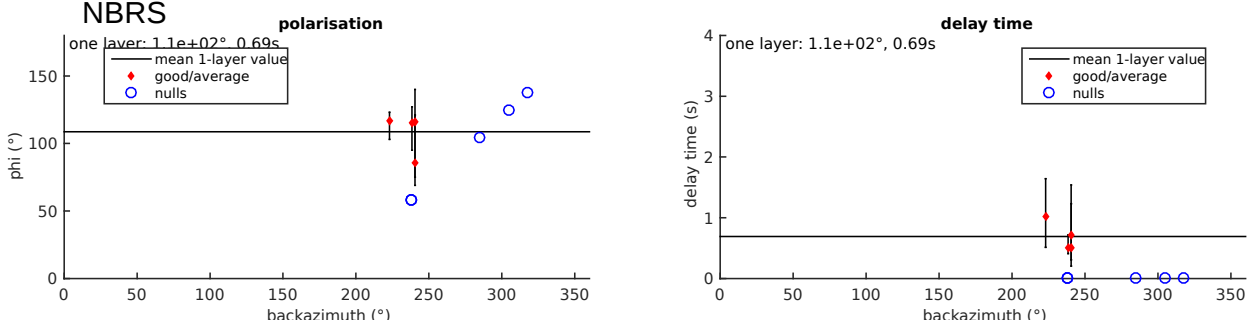

Fig. S 8: Individual measurements plotted with back-azimuth for stations CCRS, EDMB and NBRS (XC network from the FAPESP "3-Basin Thematic Project"). The calculated anisotropy parameters at these stations are the mean of all measurements of $\phi$ and $\delta t$. 


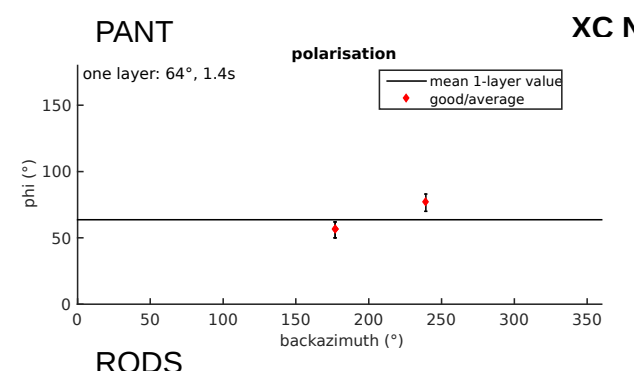

XC Network
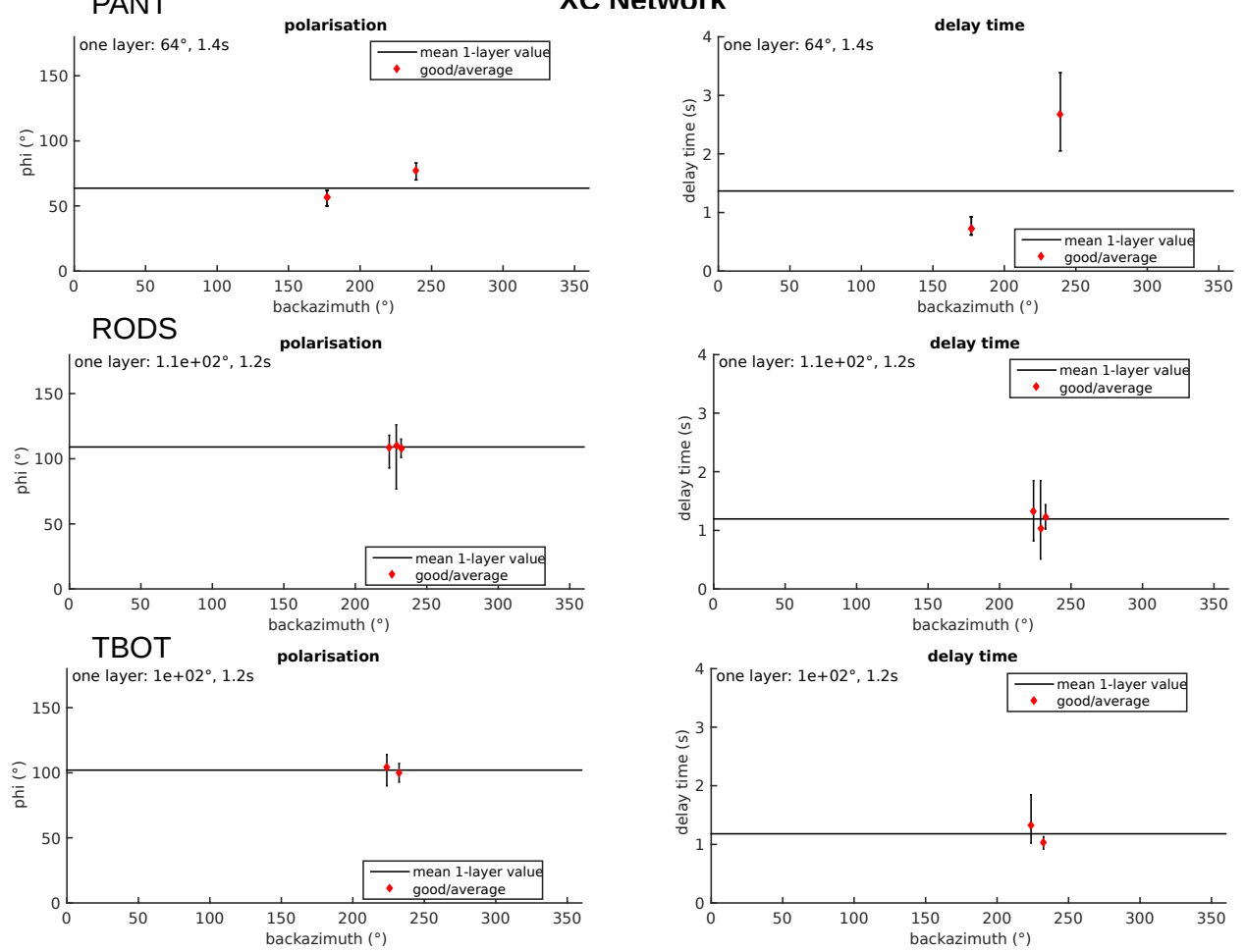

Fig. S 9: Individual measurements plotted with back-azimuth for stations PANT, RODS and TBOT (XC network from the FAPESP "3-Basin Thematic Project"). The calculated anisotropy parameters at these stations are the mean of all measurements of $\phi$ and $\delta t$. 

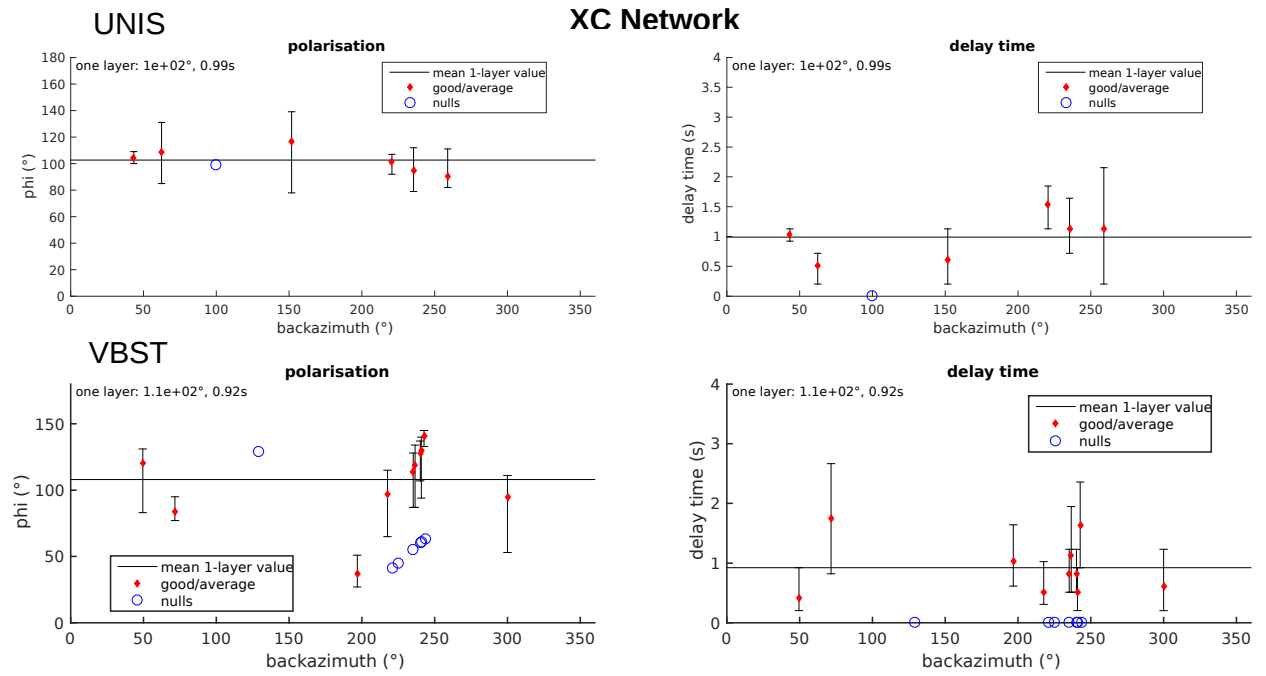

Fig. S 10: Individual measurements plotted with back-azimuth for stations UNIS and VBST (XC network from the FAPESP "3-Basin Thematic Project"). The calculated anisotropy parameters at these stations are the mean of all measurements of $\phi$ and $\delta t$. 


\subsection{All measurements per station: Joint Waveform Inver- sion for 1 layer}

At these stations, a smaller variability of the parameters with back-azimuth is observed, and a joint waveform inversion for one layer was performed.
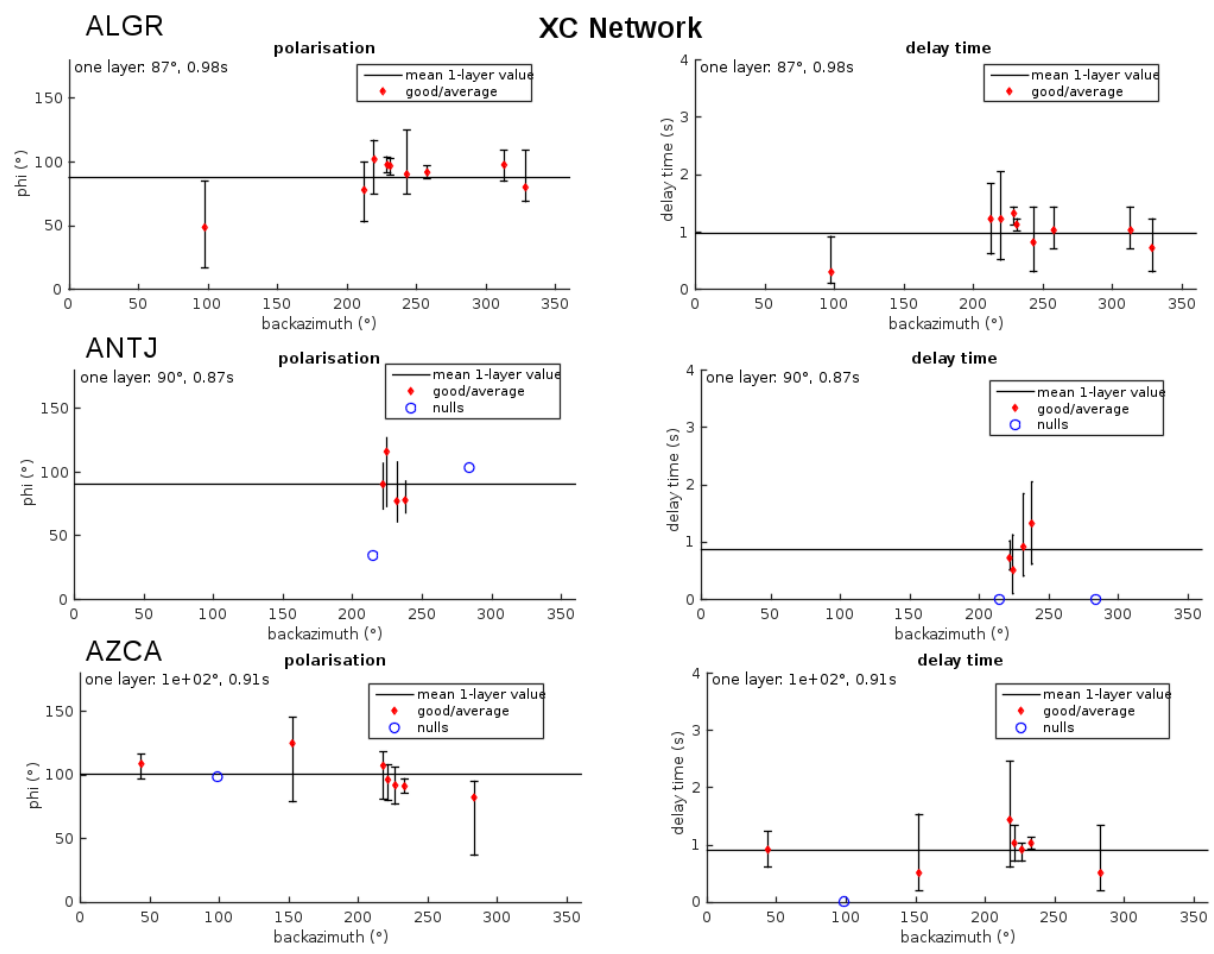

Fig. S 11: Individual measurements plotted with back-azimuth for stations ALGR, ANTJ and AZCA (XC network from the FAPESP "3-Basin Thematic Project").

\subsection{2 layer anisotropy}




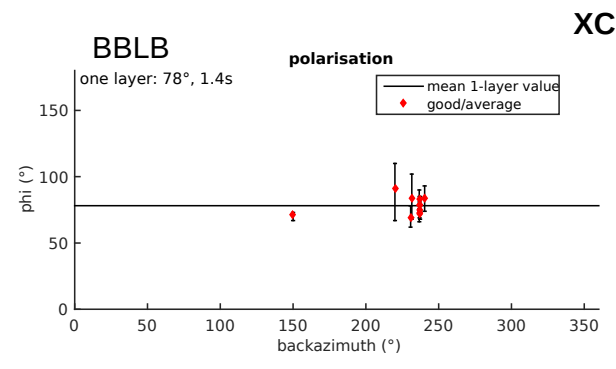

XC Network
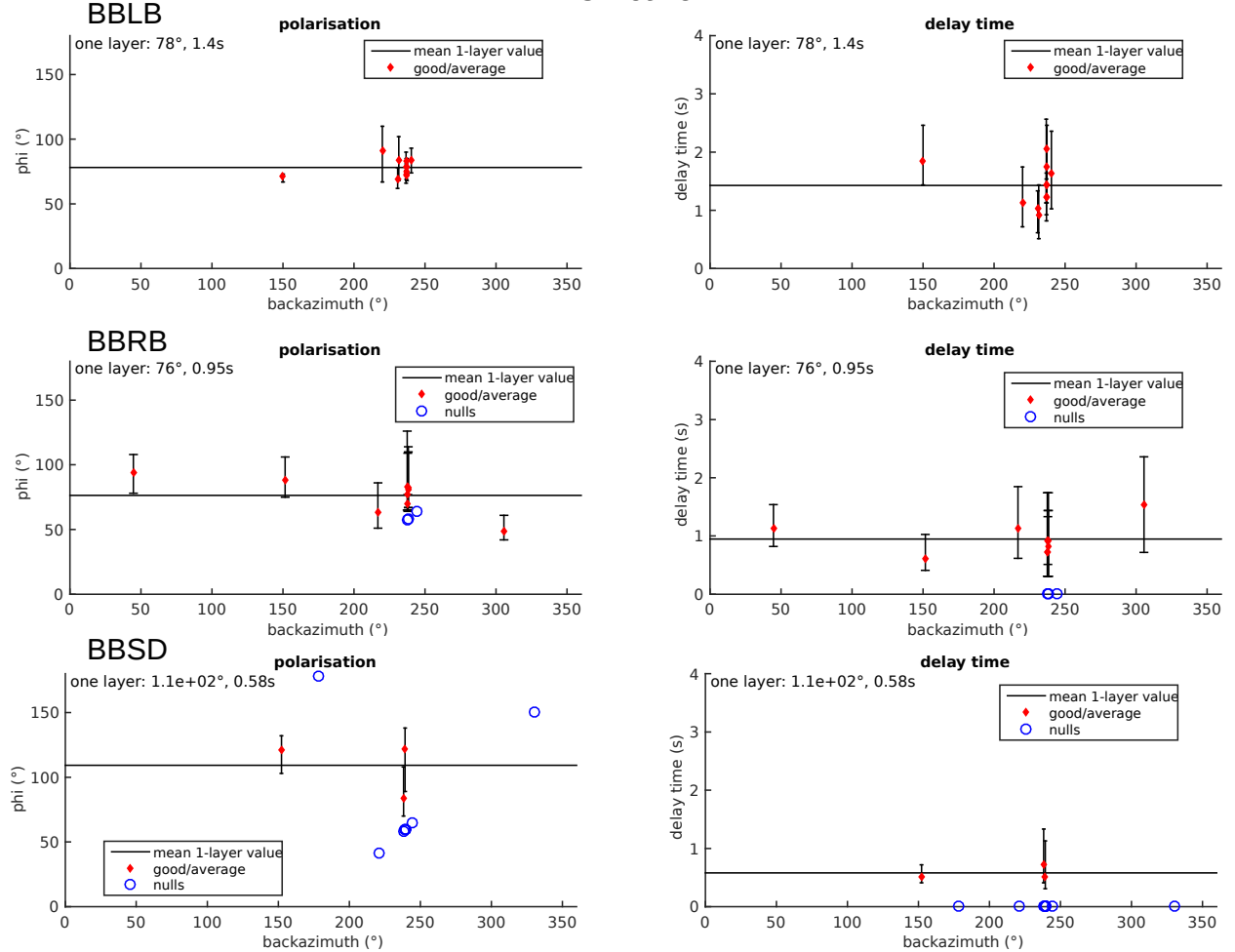

Fig. S 12: Individual measurements plotted with back-azimuth for stations BBLB, BBRB and BBSD (XC network from the FAPESP "3-Basin Thematic Project"). 


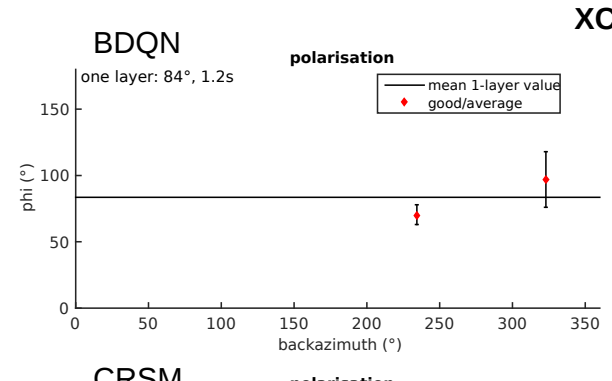

XC Network
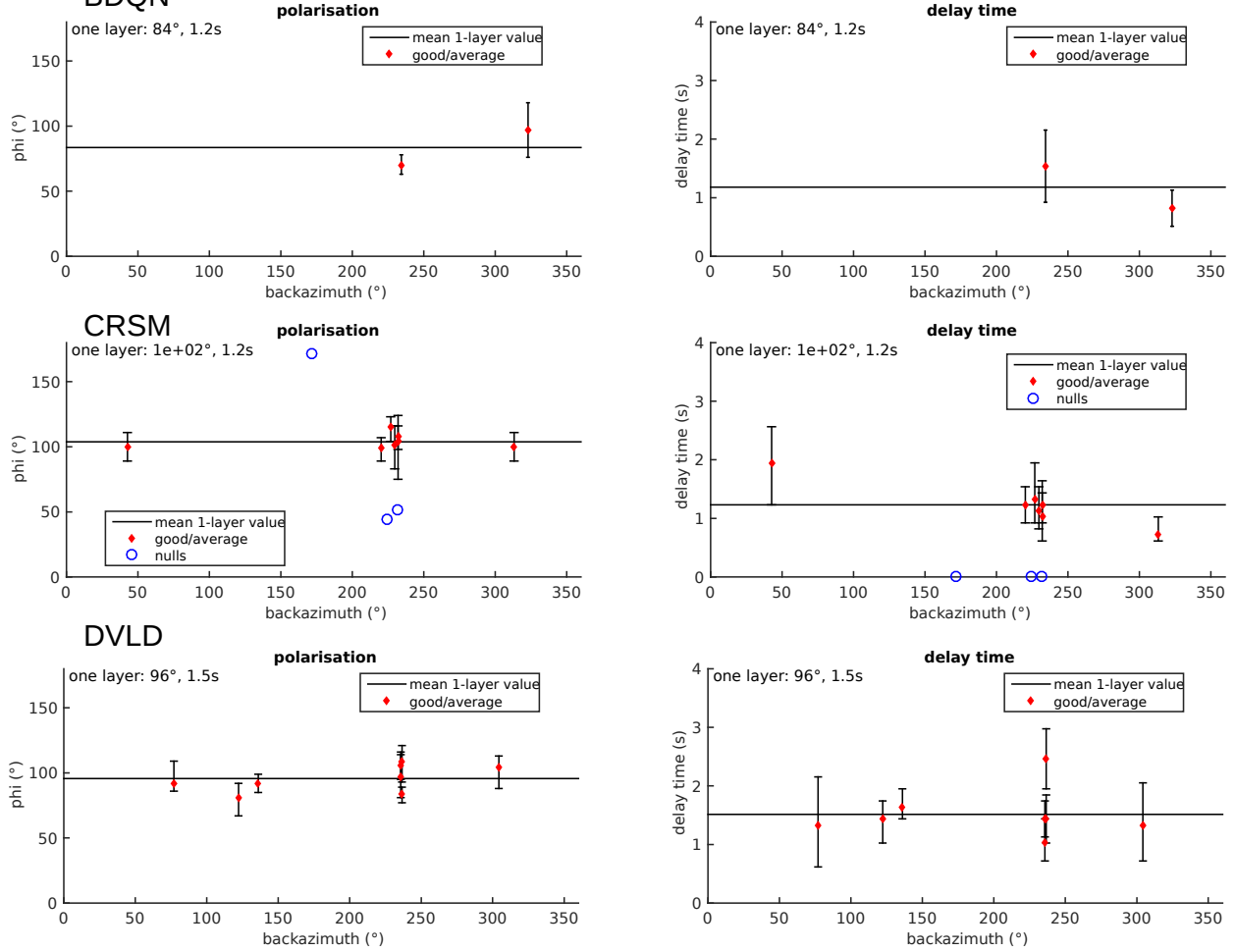

Fig. S 13: Individual measurements plotted with back-azimuth for stations BDQN, CRSM and DVLD (XC network from the FAPESP "3-Basin Thematic Project"). 


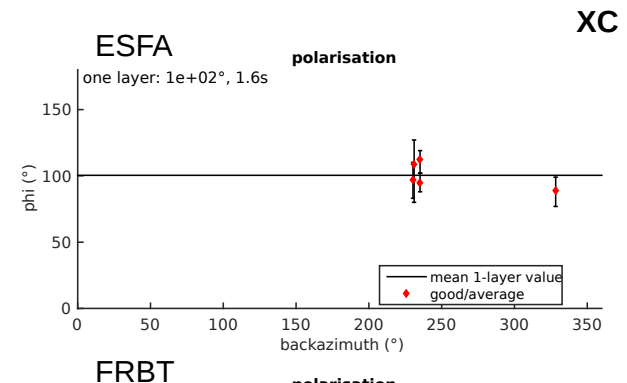

XC Network
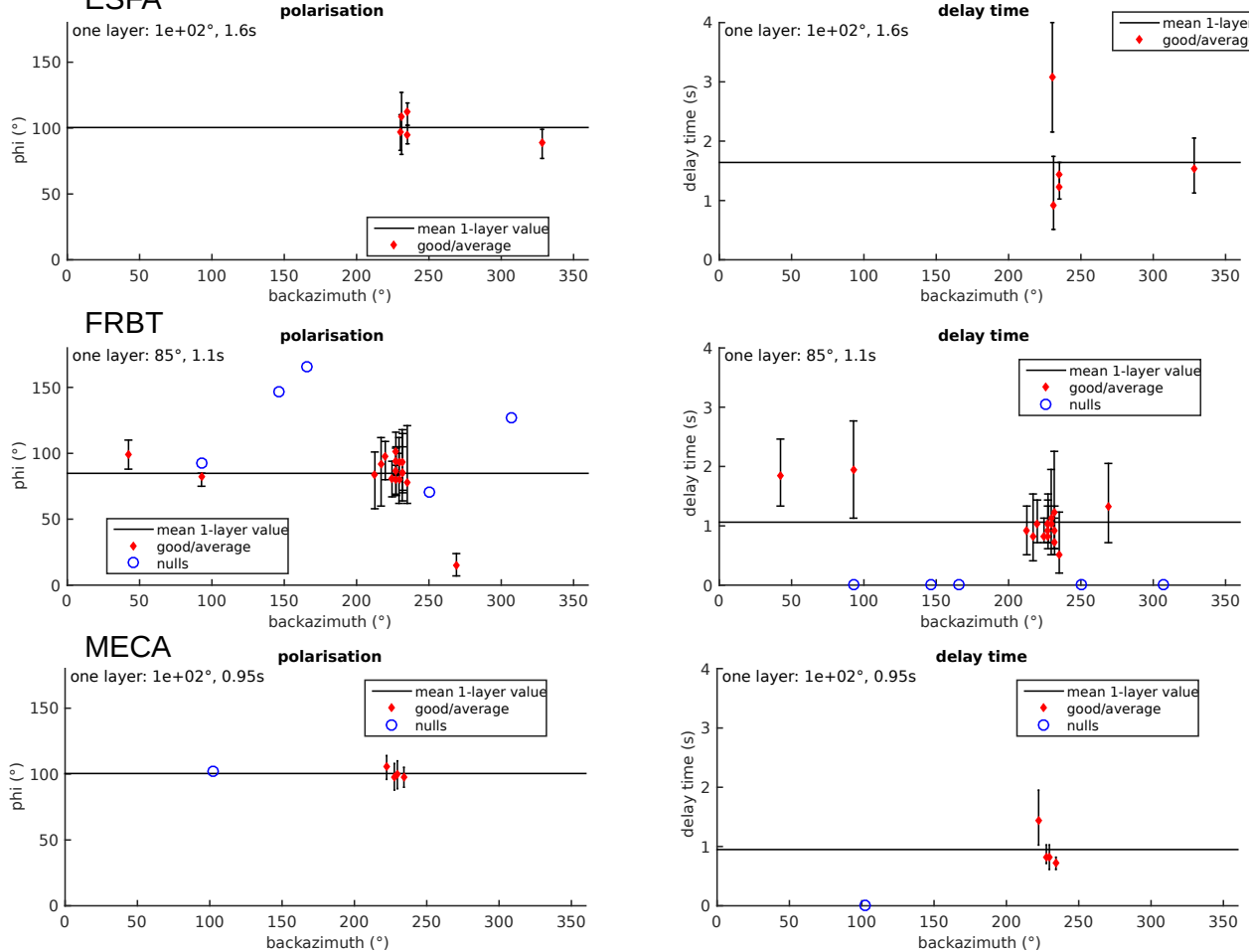

Fig. S 14: Individual measurements plotted with back-azimuth for stations ESFA, FRBT and MECA (XC network from the FAPESP "3-Basin Thematic Project"). 


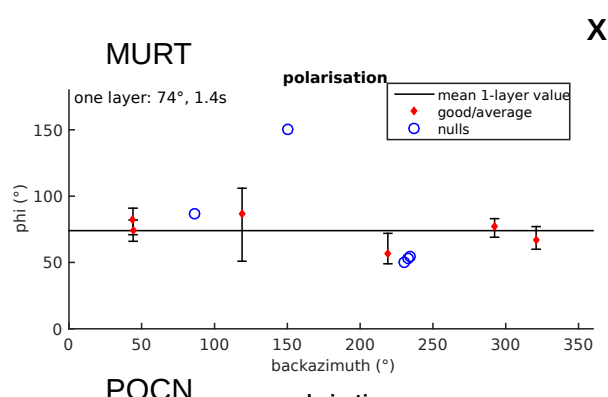

XC Network
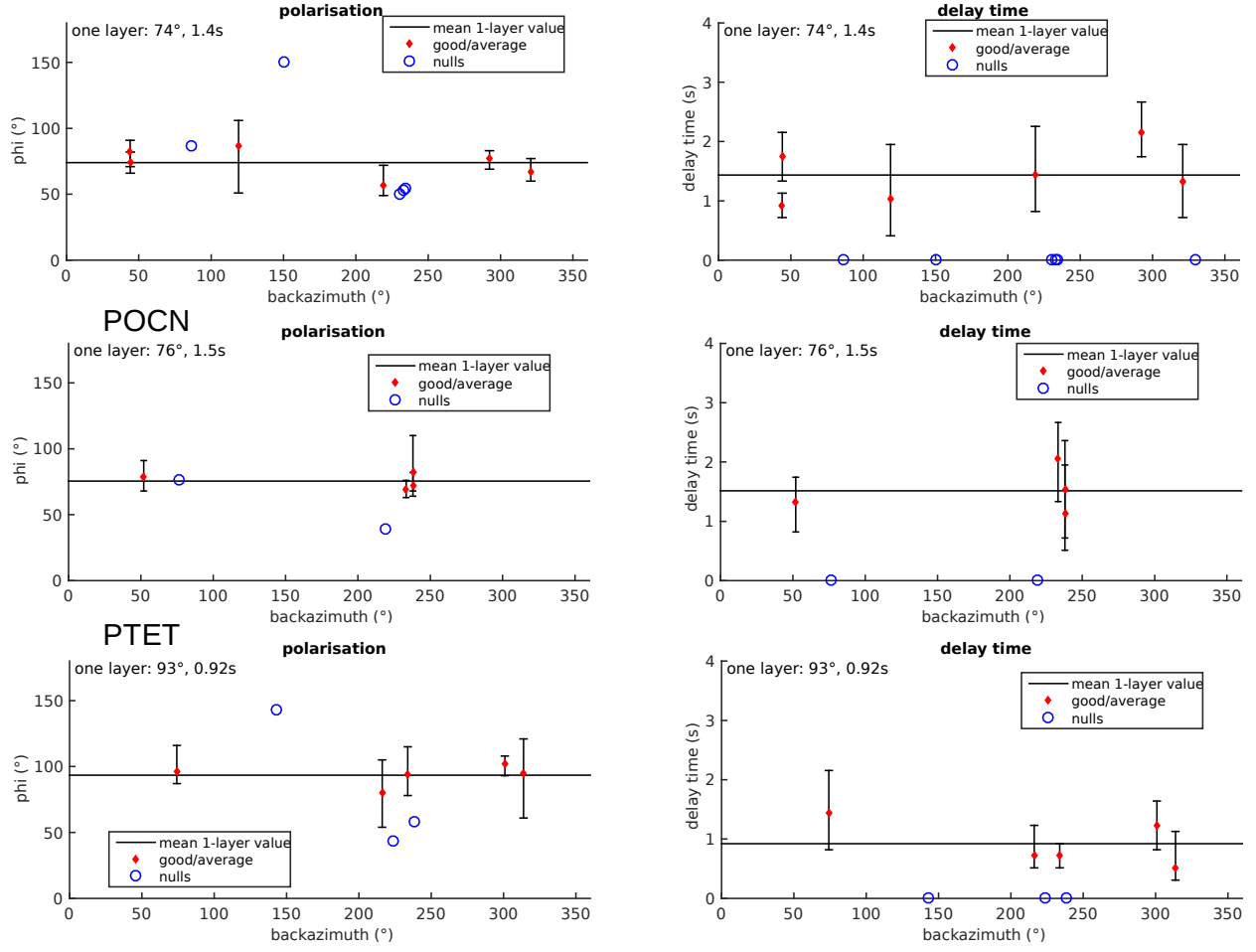

Fig. S 15: Individual measurements plotted with back-azimuth for stations MURT, POCN and PTET (XC network from the FAPESP "3-Basin Thematic Project").

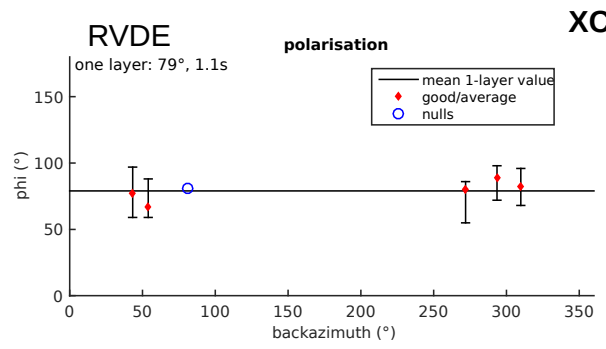

XC Network

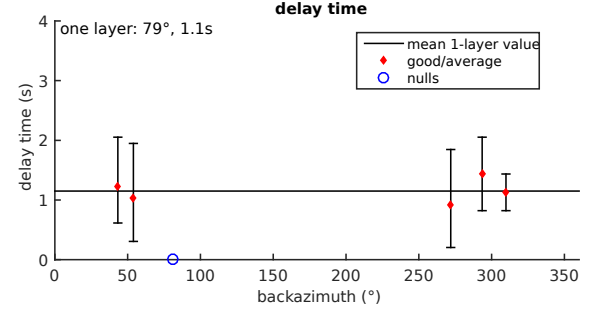

Fig. S 16: Individual measurements plotted with back-azimuth for stations RVDE (XC network from the FAPESP "3-Basin Thematic Project"). 


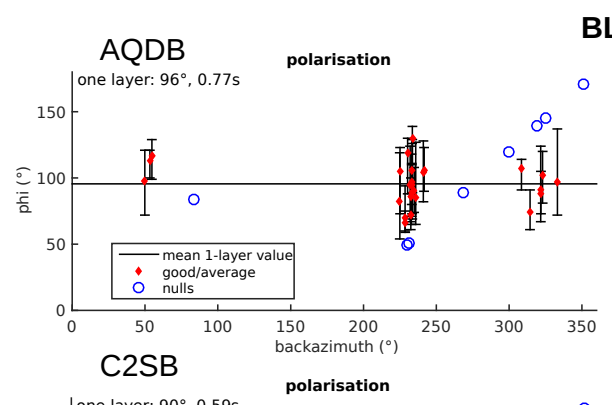

\section{BL Network}
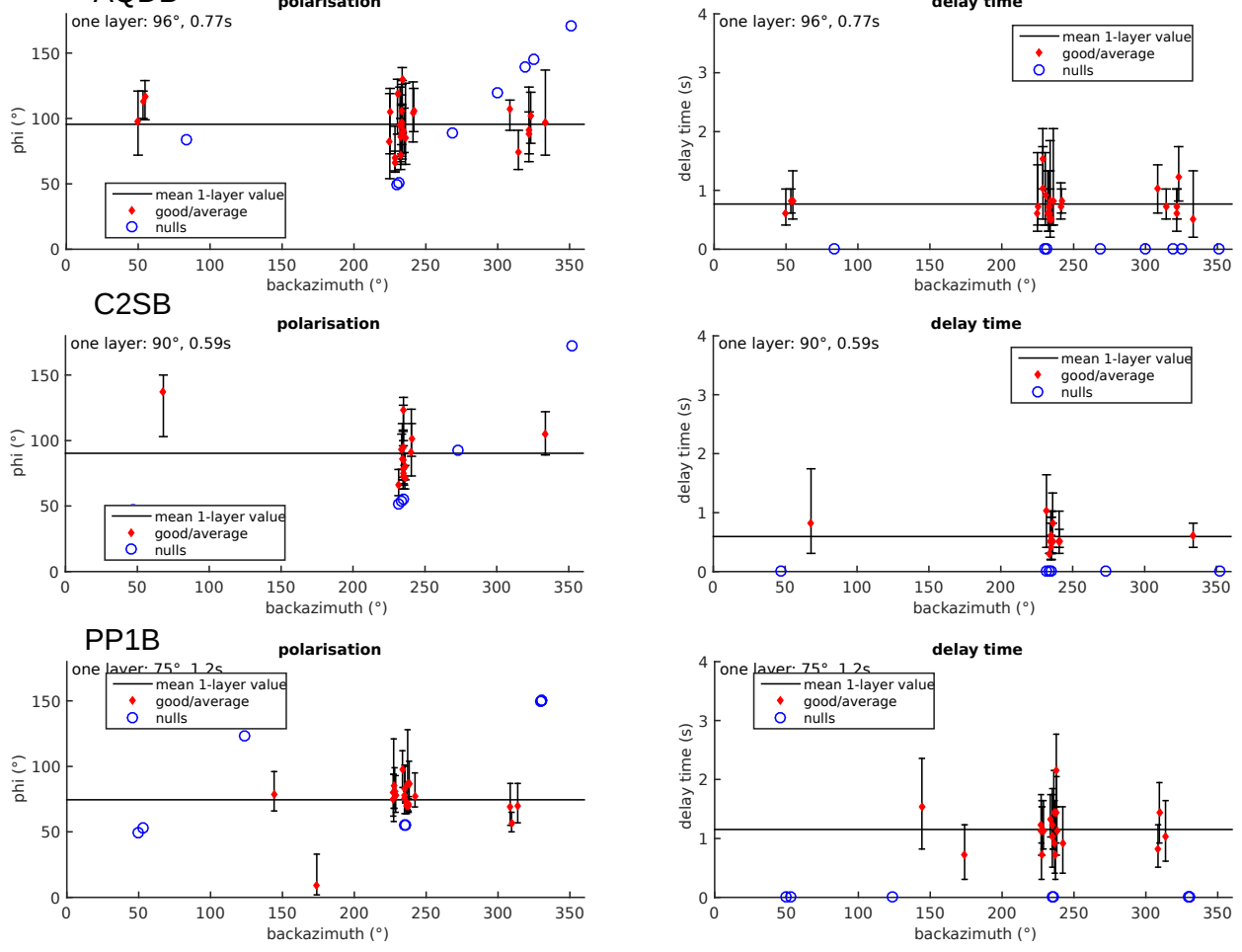

Fig. S 17: Individual measurements plotted with back-azimuth for stations AQDB, C2SB and PP1B (BL network from the RSBR). 

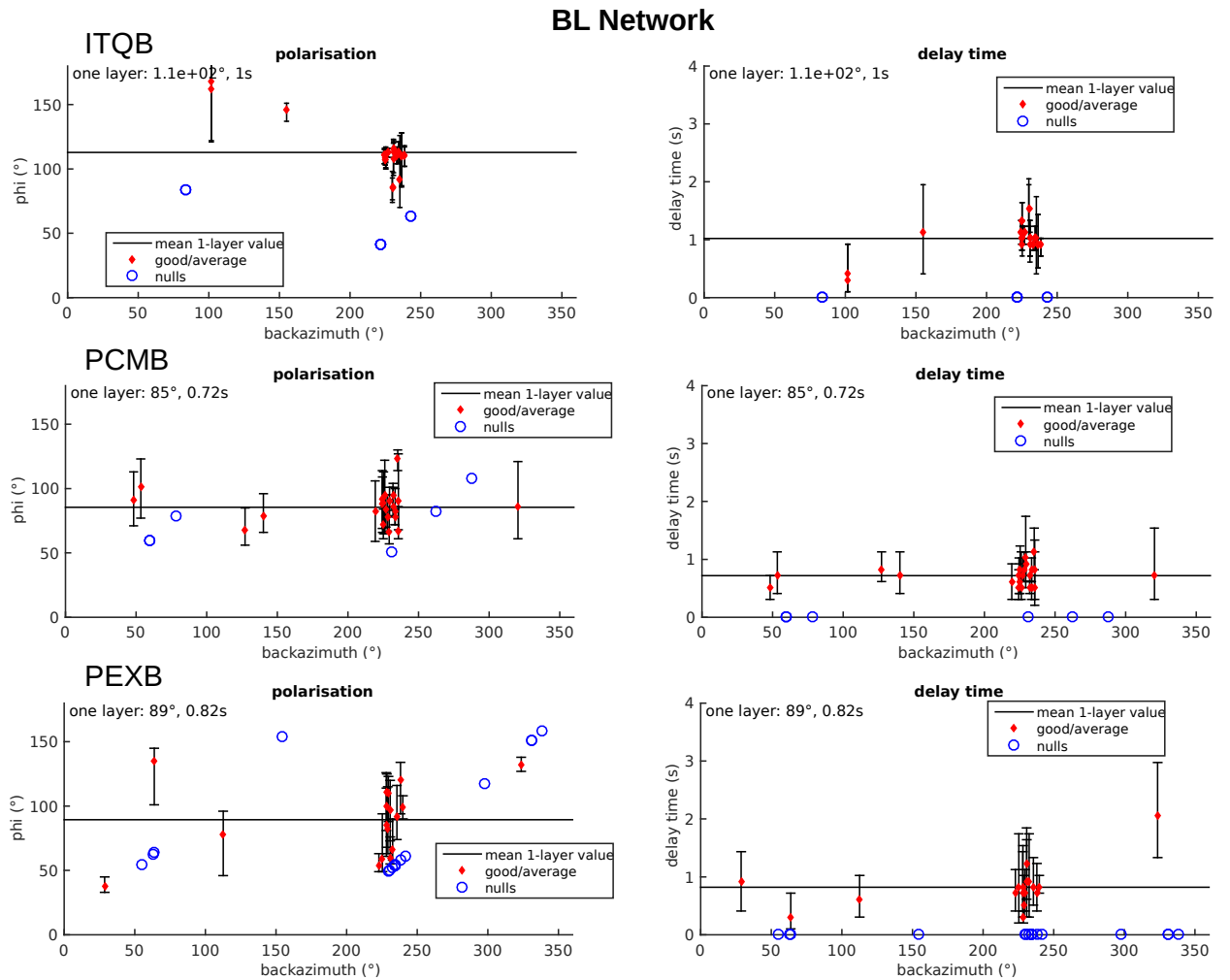

Fig. S 18: Individual measurements plotted with back-azimuth for stations ITQB, PCMB and PEXB (BL network from the RSBR). 

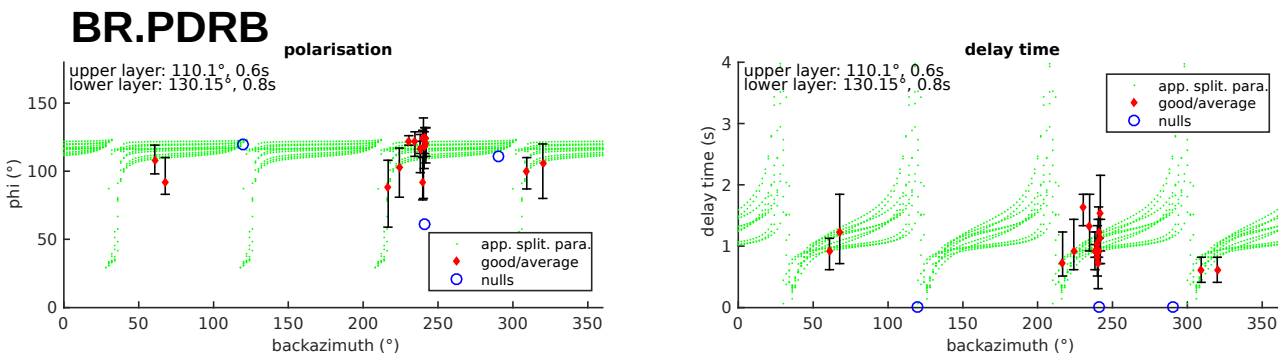

\section{BL.PTGB}
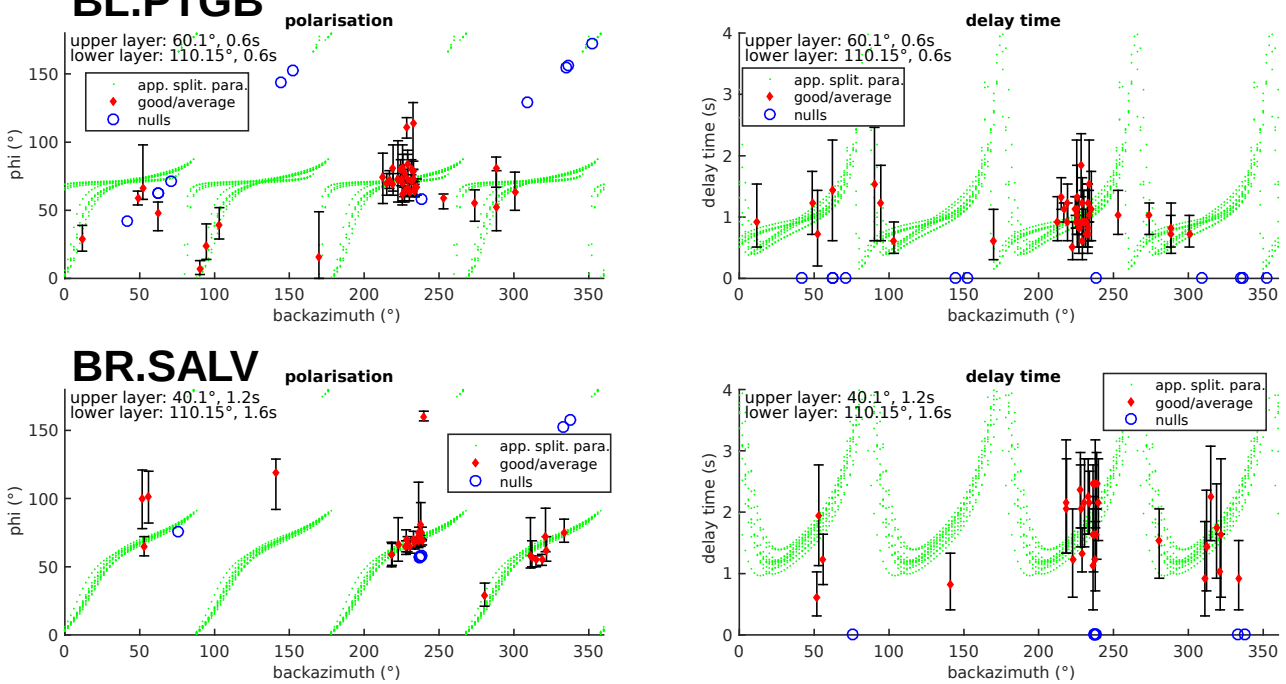

\section{XC.VBST}
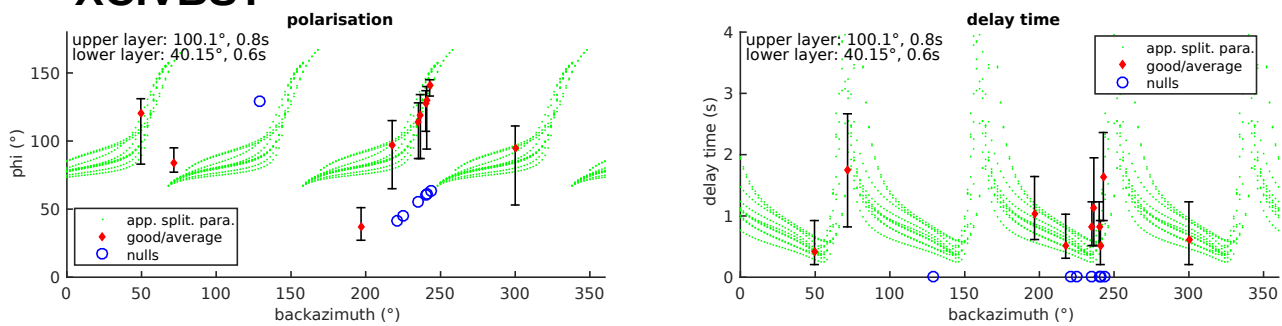

Fig. S 19: Stations where a 2 layer case was investigated. 


\subsection{Models at different depths}

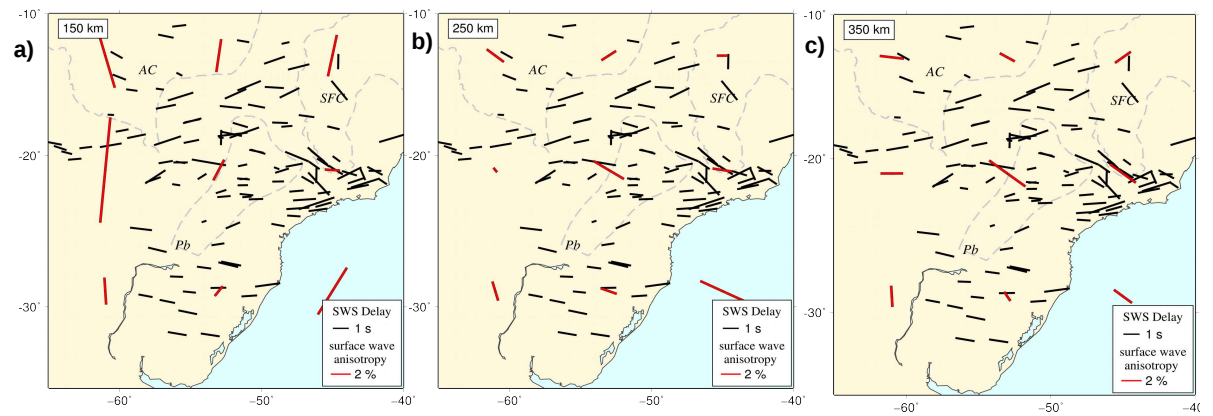

Fig. S 20: Surface wave anisotropy directions at different depths, compared to the SWS anisotropy directions. a) At $150 \mathrm{~km}$ depth; b) At $250 \mathrm{~km}$ depth; c) $350 \mathrm{~km}$ depth. 

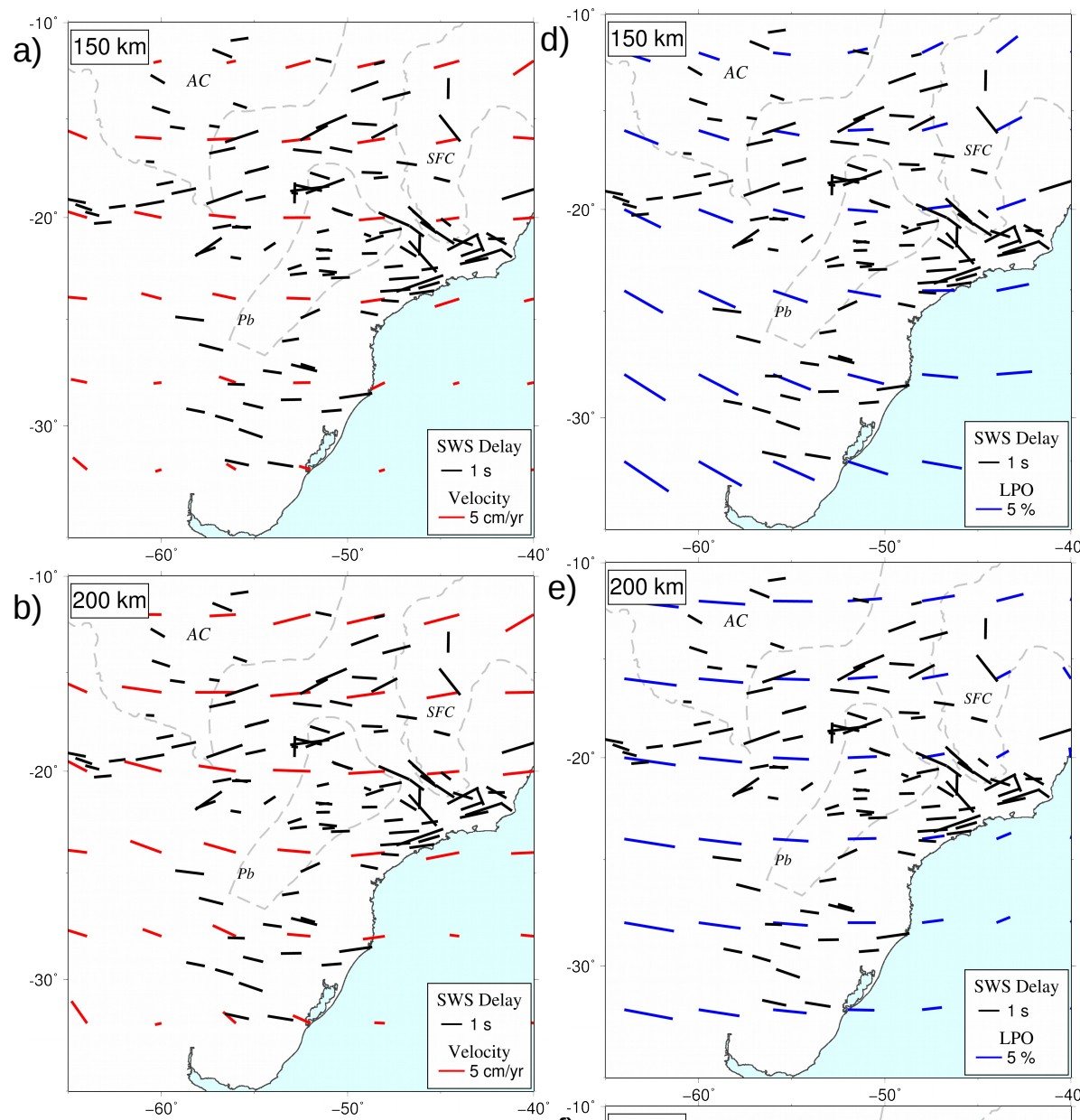

e)
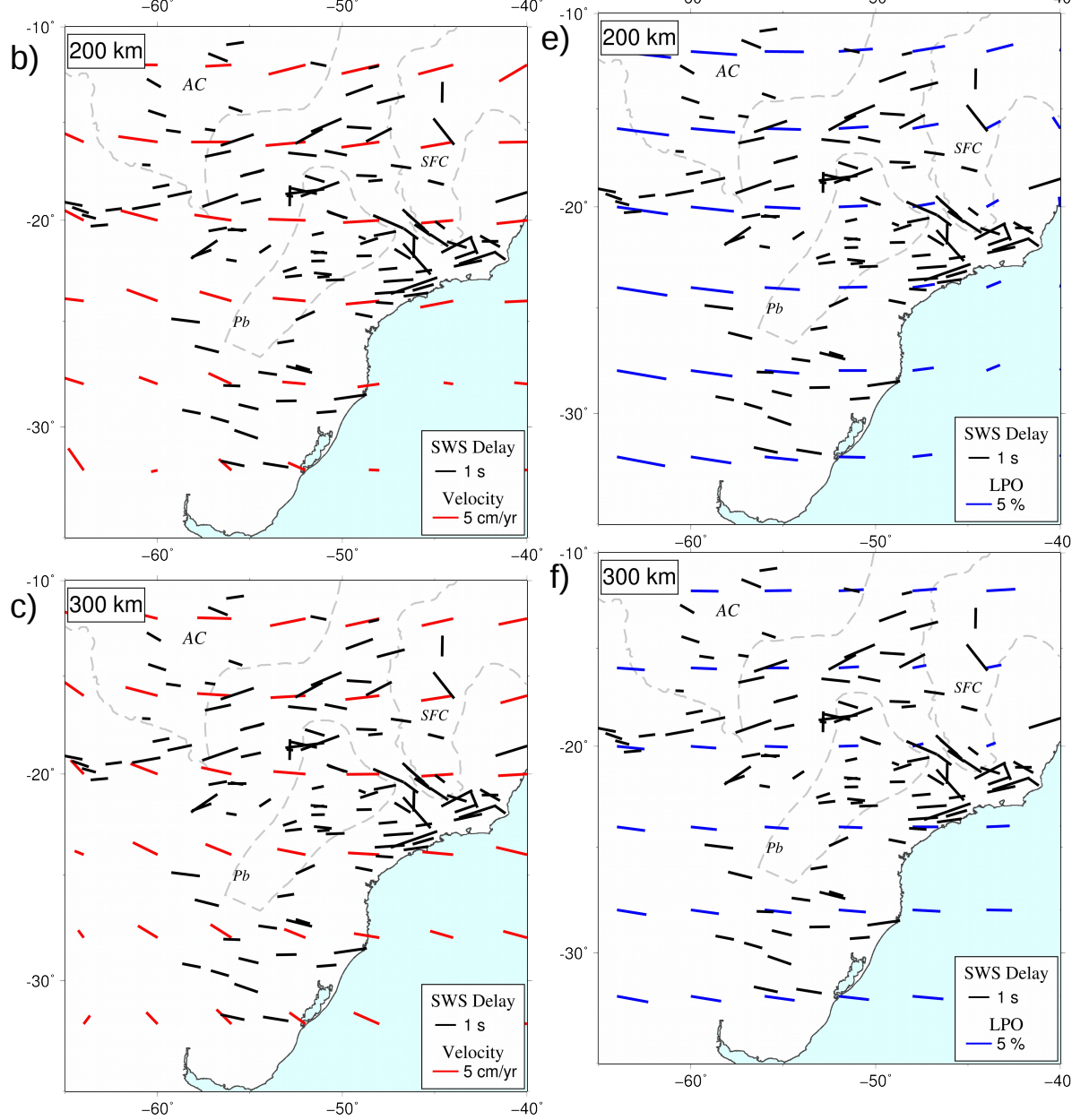

Fig. S 21: a), b) and c) are subduction induced mantle flow velocity directions at $150 \mathrm{~km}, 200 \mathrm{~km}$ and $300 \mathrm{~km}$ depth, respectively. d), e) and f) are LPO directions computed from TI axis also at at $150 \mathrm{~km}$, $200 \mathrm{~km}$ and $300 \mathrm{~km}$ depth, respectively. 

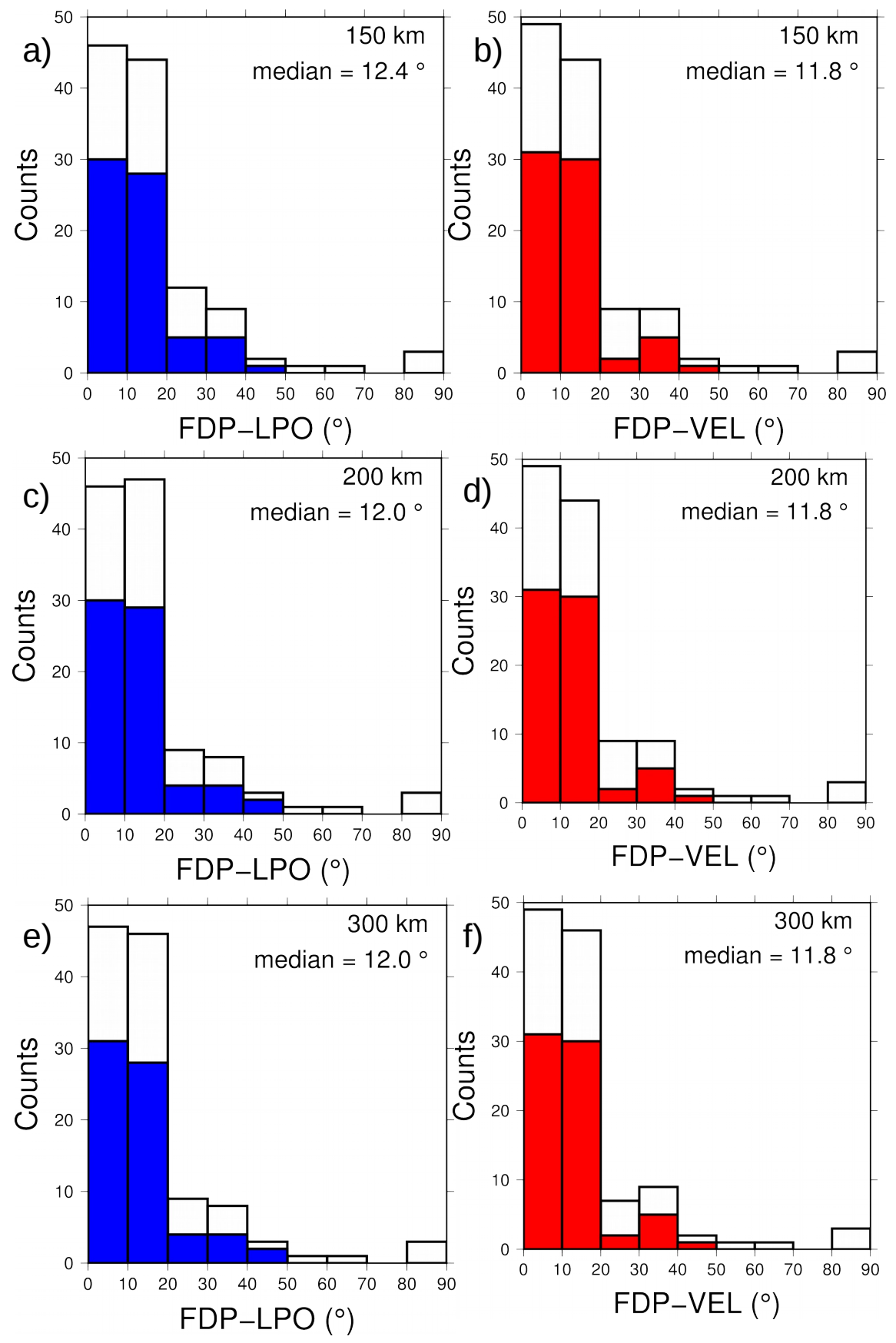

Fig. S 22: Histograms of the comparison of all station fast polarization orientations with LPO directions computed from TI axis also at $150 \mathrm{~km}, 200 \mathrm{~km}$ and $300 \mathrm{~km}$ depth, respectively. b), d) and f) are the comparison with subduction induced mantle flow velocity directions also at $150 \mathrm{~km}, 250 \mathrm{~km}$ and 300 $\mathrm{km}$ depth, respectively. Colored columns are more reliable values with measurements from 5 or more events, and white columns are all measurements. 


\section{Chapter 3}

\section{Additional Results and Discussion}

Beyond the results presented at Chapter 2, now we add 20 new measurements at the northern part of Brazil from $10^{\circ} \mathrm{S}$ to $5^{\circ} \mathrm{N}$ in an area poorly sampled before. The new measurements also have a general ENE-WSW pattern, with some stations deviating to a ESE-WNW orientation. Furthermore, stations in northwestern Brazil (not plotted here), and northeastern Brazil mainly have null results, as already observed by Bastow et al. (2015). We first compare the SWS fast orientations with the surface wave azimuthal global anisotropy orientations at $300 \mathrm{~km}$ depth from Debayle, Dubuffet, and Durand (2016), Figure 3.1.

There is some similarity between the orientations at the northern and western boundaries, with all SWS orientations tending to be ENE-WSW and the surface wave anisotropy orientations with a more accentuated NE-SW orientation. These areas have less influence of the lithospheric thickness variation caused by the cratons, and the surface wave anisotropy orientations reflect mainly the large scale mantle flow direction at $300 \mathrm{~km}$ depth. Therefore, the SWS orientations at these regions may be due only to upper mantle flow. At the central part of northern Brazil, the SWS orientations do not correlate with the surface wave anisotropy orientations, meaning that a smaller scale change in anisotropy is present. Figure 3.2 we see the main basement faults mapped at Brazilian territory by CPRM (Brazilian Geological Services). Beyond the general ENE-WSW orientations of the SWS measurements, a second pattern of orientations trending ESE-WNW is present (blue circles in Figure 3.2) which may correlate with some of the SW-NE 


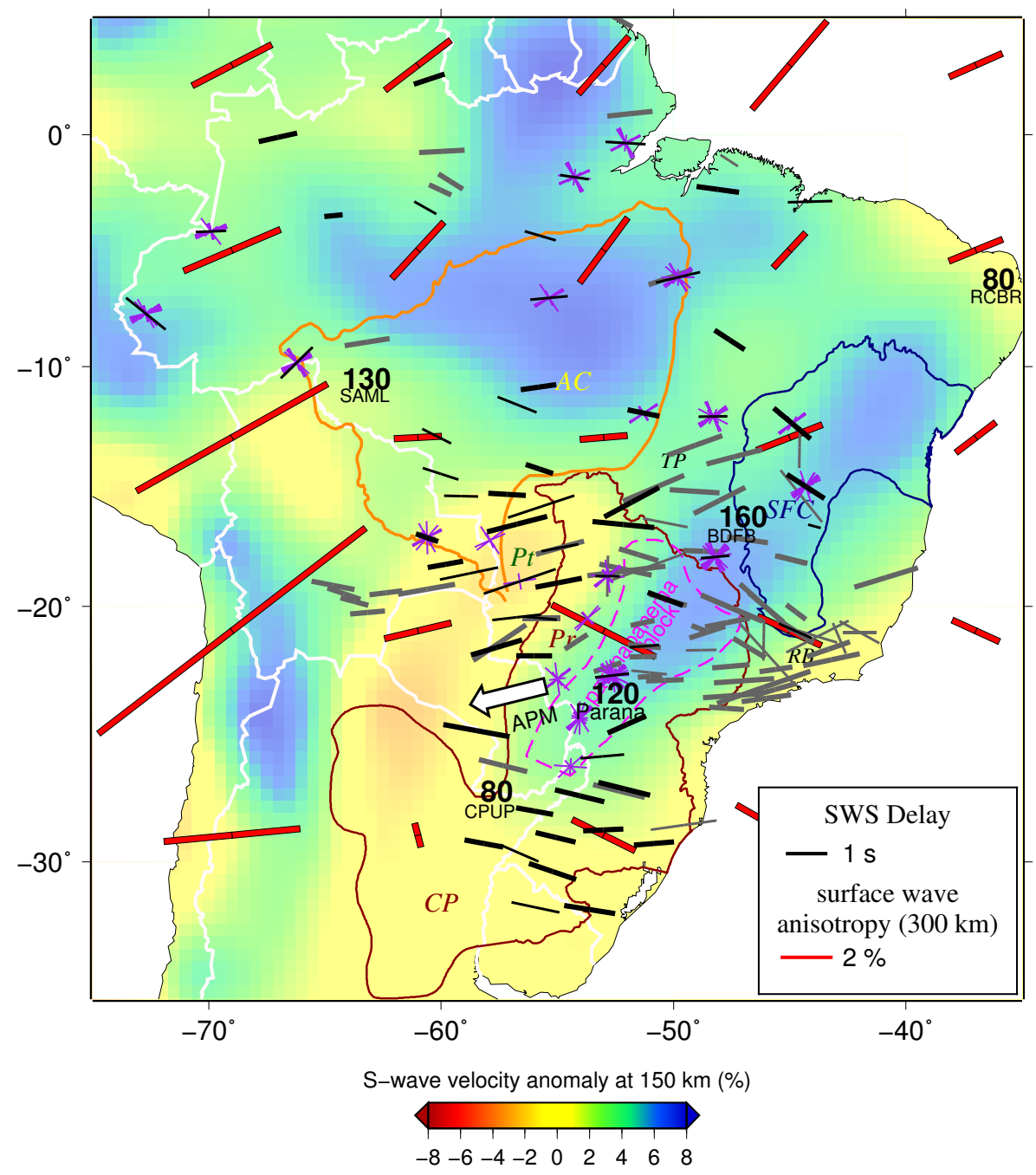

Figure 3.1: All SWS fast directions from this study (black bars) and other published results (gray bars). The bar lengths indicate delay time and good/average qualities of SWS are indicated by thick and thin bars. Red bars are surface wave azimuthal anisotropy directions at 300 $\mathrm{km}$ depth. Colors indicate S-wave velocity anomalies at $150 \mathrm{~km}$ depth from the surface-wave tomography model SL2013Sv. The white arrow indicates the absolute plate motion in the hotspot reference frame HS3-NUVEL1A. Colored contours are boundaries of major provinces. Null bars (purple bars) are plotted at stations where few or no measurements were found. Bold numbers denote lithosphere/asthenosphere depth from S-wave receiver functions.

major fault orientation of the basement.

In these areas, the SWS anisotropy directions may be due only to frozen anisotropy imprinted at the lithosphere, from past tectonic events, or they can be a compound effect of the asthenospheric anisotropy, generated by mantle flow, plus the lithospheric frozen anisotropy. Baptiste and Tommasi (2014) argues that small delays and null SWS measurements may result from vertical variations of seismic anisotropy, which could be the reason of the observed small delays and many null results in northern Brazil. 


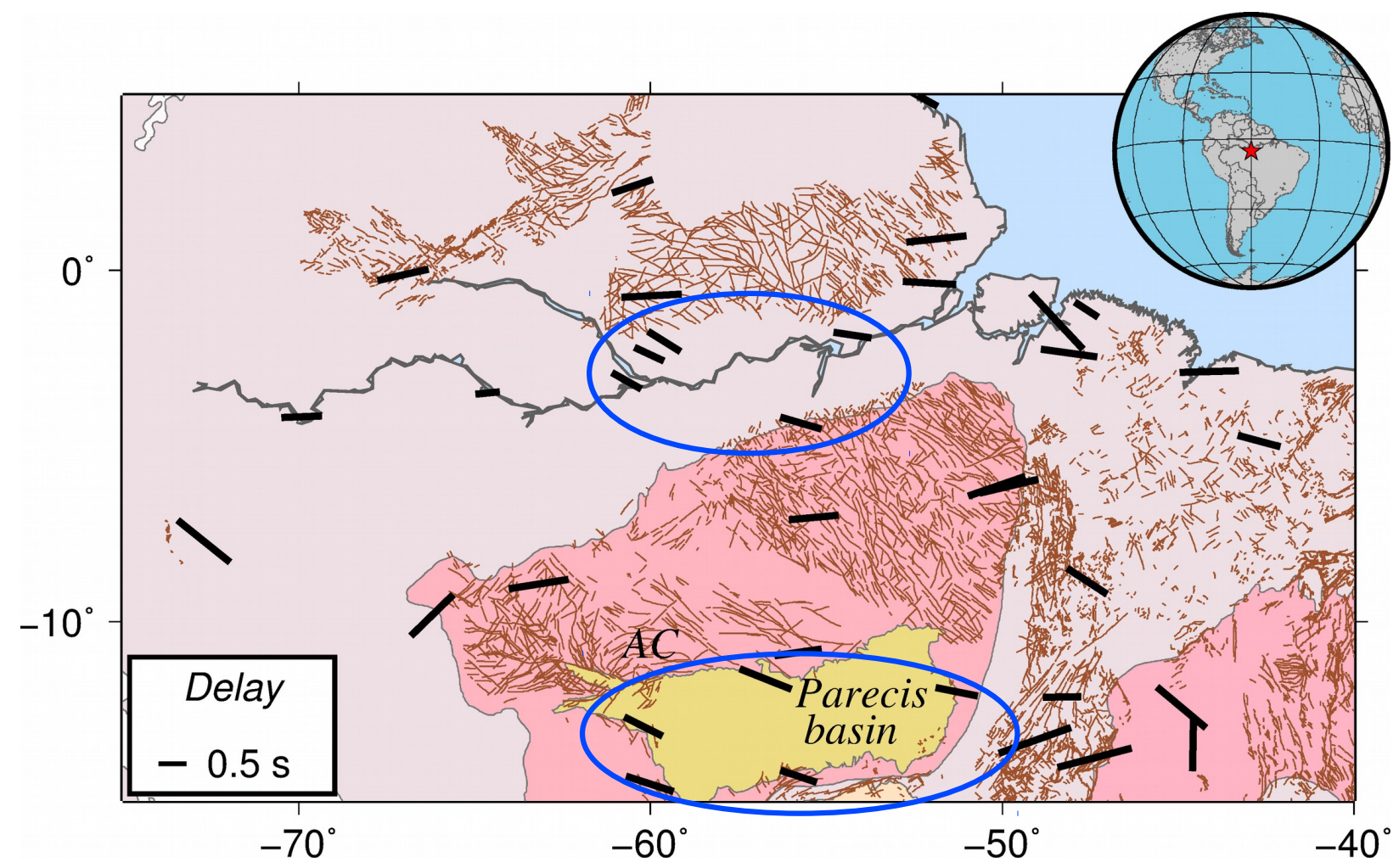

Figure 3.2: SWS orientations compared with the main faults mapped at Brazilian territory. Blue ellipses are the areas where the SWS measurements show a general ESE-WNE direction. In few stations there is a indicative of agreement of the SWS orientation with the direction of the fault alignment. AC: Amazon Craton.

\subsection{Comparison with Different Anisotropy Proxies}

In this section we compare all SWS measurements of this study with three different proxies of anisotropy: convection velocity, computed LPO directions from TI axis, and predicted SWS, all from the model of Hu, Faccenda, and Liu (2017), shown in Figure 3.3.

LPO and velocity models were already discussed at Chapter 2. To calculate the synthetic SKS splitting, Hu, Faccenda, and Liu (2017) use the software package FSTRACK from Becker et al. (2006). The code gathers the elastic tensors of all upper mantle aggregates and stack them into layers below the station. Synthetic seismograms are calculated for various azimuths and distances, and filtered to the XKS frequency band of 0.1 to $0.3 \mathrm{~Hz}$. Finally, the XKS splitting parameters are determined by the cross correlation method of Menke and Levin (2003).

We calculate the orientation difference of mantle velocity, LPO orientation and synthetic SWS 

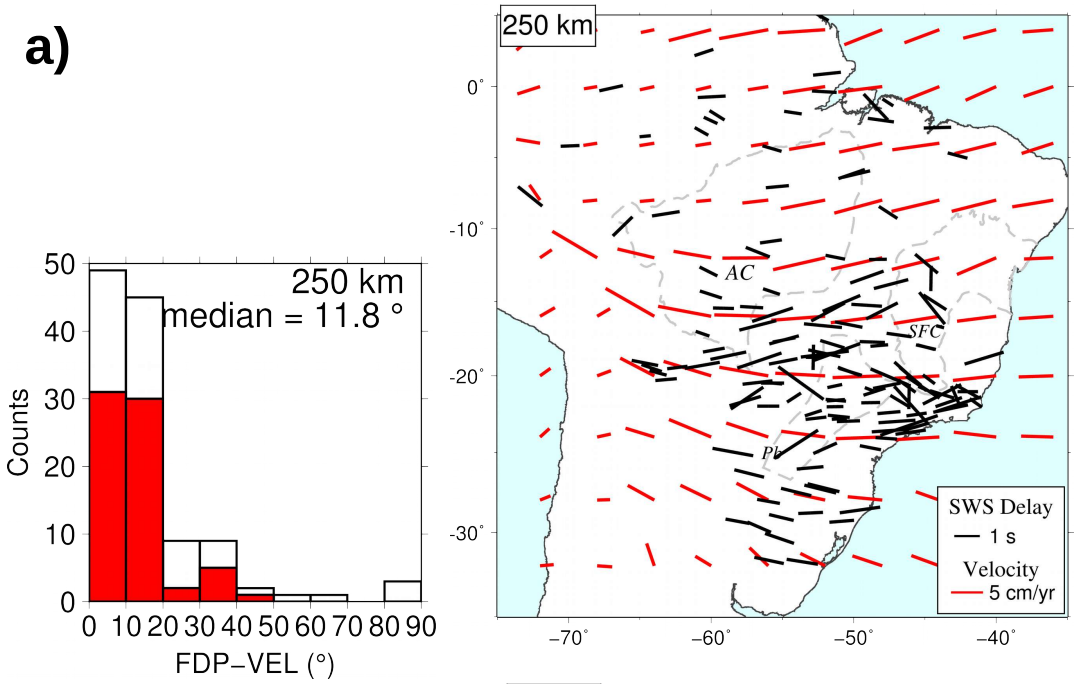

b)
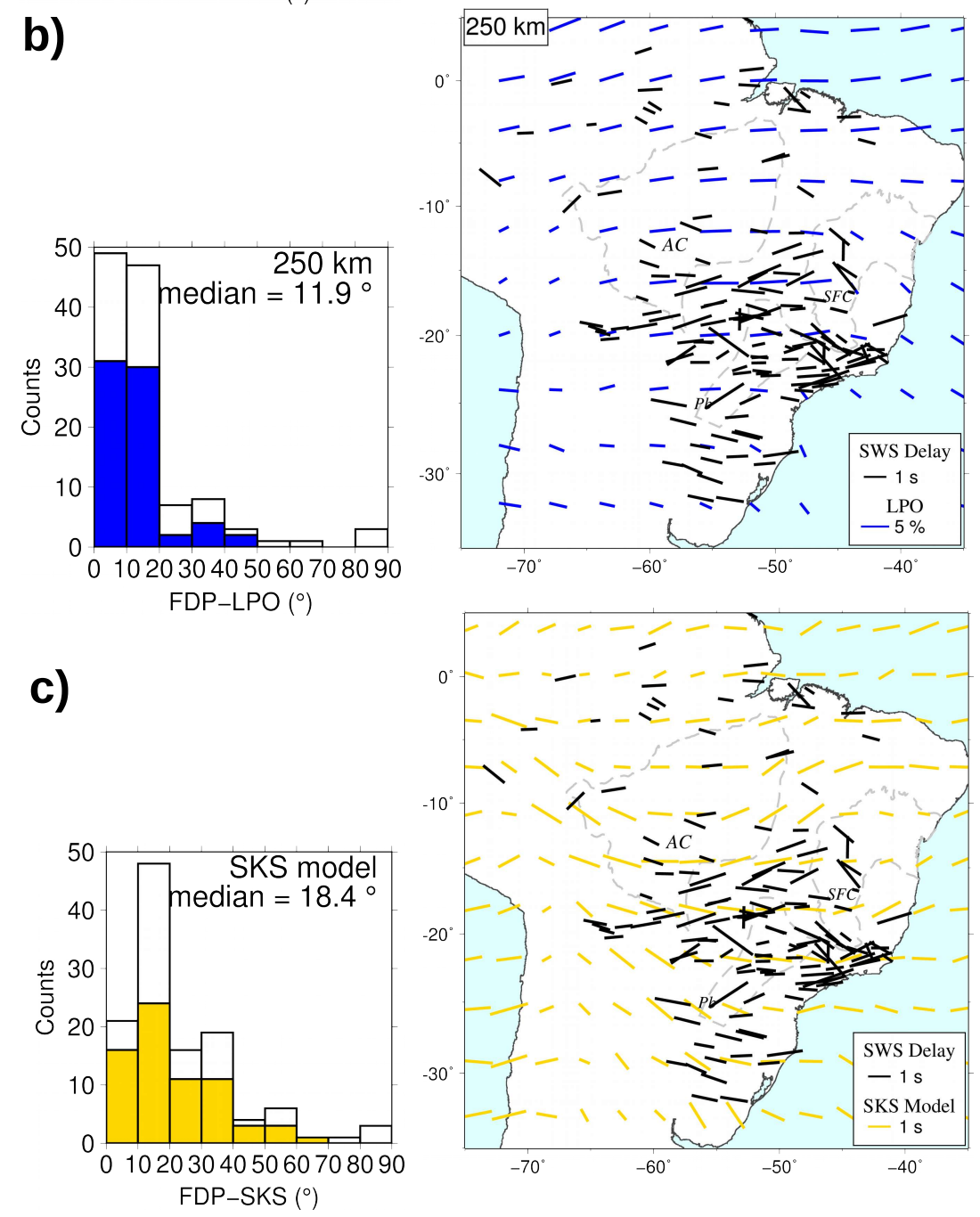

Figure 3.3: Upper mantle flow directions (a) and LPO directions computed from TI axis (b), both at $250 \mathrm{~km}$ compared with the observed fast-polarization orientations (black bars) and their respective histograms of the difference between the SWS direction and the model. (c) comparison of the observed SWS fast directions with the predicted SKS, with its respective histogram (Hu, Faccenda, and Liu, 2017) 
with all SWS measurements of this study in the histograms of Figure 3.3. The median misfit values are $11.8^{\circ}, 11.9^{\circ}$ and $18.9^{\circ}$ respectively. The addition of the new data did not make a big change in the median values of the difference between the SWS measurements and the velocity and LPO proxies. However we note that in the Amazon region, the SWS anisotropy orientations and delays correlate slightly better with the mantle velocity directions and intensities, compared with LPO (Figure 3.3 a,b). We also show that the synthetic SWS direction do not provide a good fit to the data (Figure 3.3 c), although it should be the best estimate, theoretically. Perhaps, this worse misfit suggests higher uncertainties in the calculation of the synthetic SKS fast directions in $\mathrm{Hu}$, Faccenda, and Liu (2017).

\subsection{Two Layer Anisotropy}

We now test the 2-layer anisotropy model at stations that showed larger variation of the anisotropy parameters with back-azimuth (Figure 3.4). Moreover, they had to exhibit a good back-azimuthal distribution, so that the $\pi / 2$ periodicity could be observed. Figure 3.5 shows the 1-layer and 2-layer anisotropy parameter found at each station. Black bars are the orientations of the lower layer of the 2-layer model, purple bars are the directions of the upper layer, and bars in green are the orientations of the 1-layer model. The length of the bars indicates the delay time. We want to compare whether these directions correlate with lithospheric frozen anisotropy, which can be related to the fault alignment trend observed at the surface, and with asthenospheric properties, such as mantle velocity and LPO alignment.

At station PDRB both models show a SW-NE orientation. However both the lower and upper layer have similar orientations of the nearby faults. At this station frozen anisotropy could have a larger contribution than asthesnospheric flow. This could be due to a thin asthenosphere below a thick craton. At station VBST the lower layer has the same orientation as the surface wave anisotropy and upper layer in the same orientation as the mantle flow. At station SALB the lower layer has a orientation close to the mantle velocity orientation, and the upper layer has the same orientation of the local fault trend. Finally, at station PTGB the lower layer 


\section{BR.PDRB}

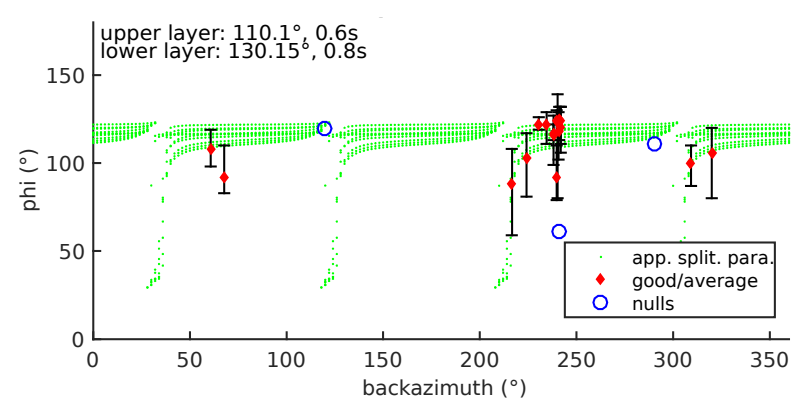

BL.PTGB

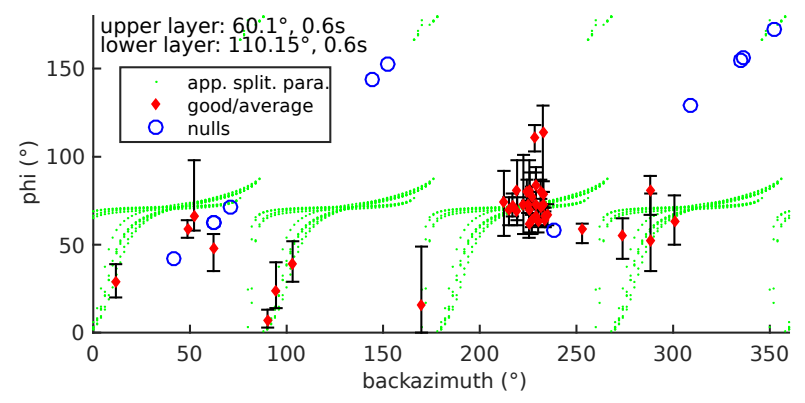

BR.SALB

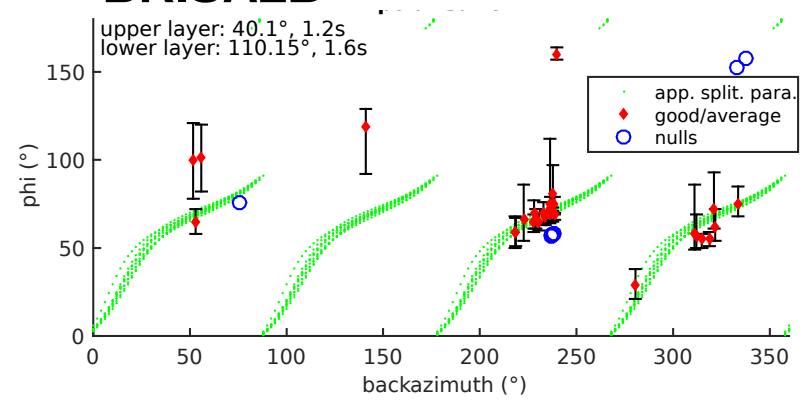

XC.VBST

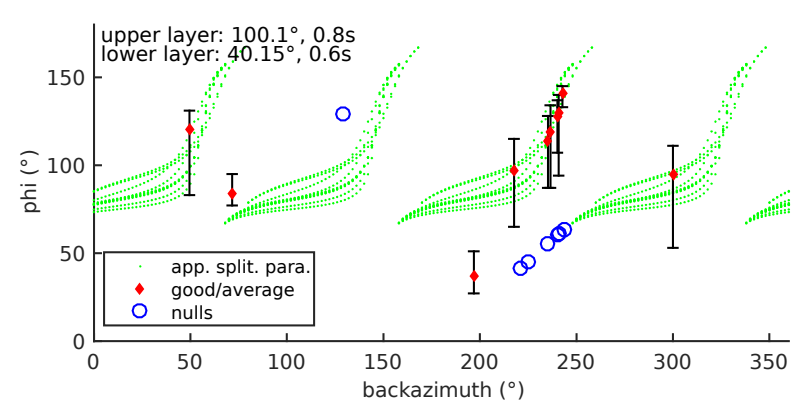

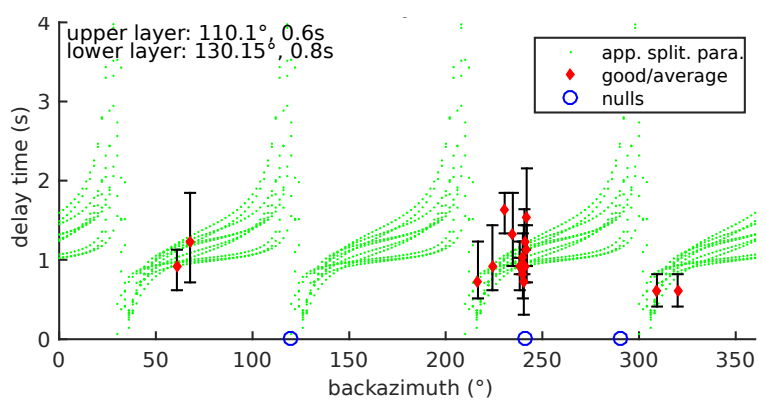
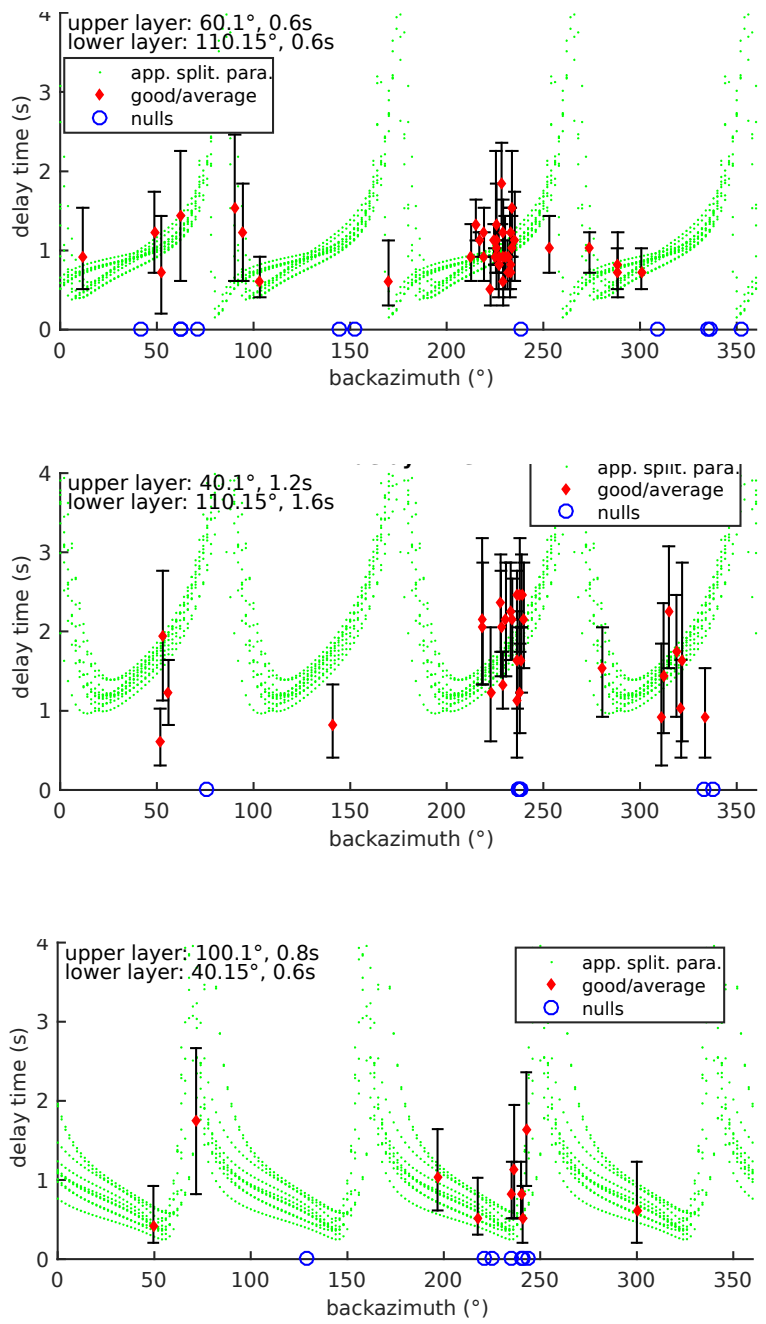

Figure 3.4: Two-layer anisotropy results at stations PDRB, PTGB, SALB and VBST plotted with back-azimuth. The curves in green are the 10 best fit models relating the 1 layer apparent parameters to the 2-layer parameters, by the method of Silver and Savage (1994).

orientation is also close to the mantle velocity orientation, but no clear fault trend can be correlated with the upper. These last two stations show some evidence of 2-layer of anisotropy

Differently from the data analyzed at Chapter 2, which showed no correlation with lithospheric 

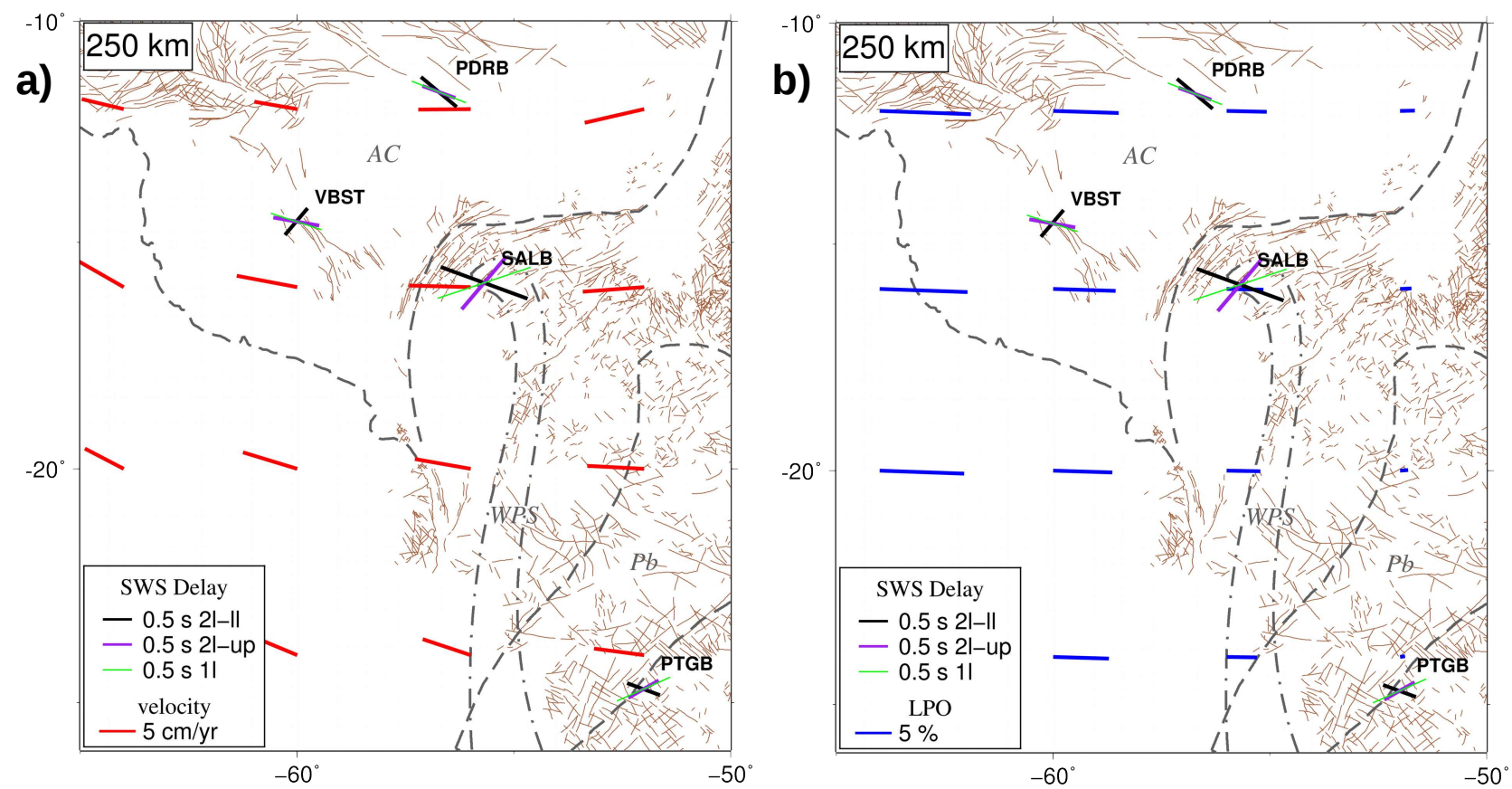

Figure 3.5: Stations where a 2-layer inversion was calculated compared with a) velocity directions and b) LPO from TI axis, both at $250 \mathrm{~km}$ depth, and main fault directions in brown. Black bars are anisotropy directions of the lower layer, purple bars are anisotropy directions of the upper layer and green bars are the 1-layer anisotropy directions. AC: Amazon craton; WPS: Western Parana Suture; Pb: Paranapanema block

structures (as shown by the comparison with the basement fault trends), now we have some indication of frozen lithospheric anisotropy at the central part of northern Brazil, with a general NW-SE trend. In addition, we now compare all the new data with the directions of mantle flow velocity, computed LPO and synthetic SKS from the model of Hu, Faccenda, and Liu (2017). The addition of the SWS measurements of the northern region did not significantly change the fit to the mantle flow velocities and computed LPO (median misfit of $\approx 12^{\circ}$, Figure 3.3). We also tested a 2-layer model for a few stations, and by comparing these results with different mantle models and basement fault directions we find that stations SALB and PTGB show some evidence of a 2-layer anisotropy, with the lower layer orientations having a better correlation with the mantle velocity directions. Altogether the Amazon region does not have enough stations with good measurements for a clear definition of the anisotropy pattern. More stations and data are necessary for a more conclusive interpretation. 


\section{Bibliography}

Baptiste, V. and A. Tommasi (2014). "Petrophysical constraints on the seismic properties of the Kaapvaal craton mantle root". In: Solid Earth. ISSN: 18699510. DOI: $10.5194 /$ se-545-2014.

Bastow, I. D. et al. (2015). "Upper mantle anisotropy of the Borborema Province, NE Brazil: Implications for intra-plate deformation and sub-cratonic asthenospheric flow". In: Tectonophysics. ISSN: 00401951. DOI: $10.1016 / \mathrm{j}$.tecto.2015.06.024.

Becker, T. W. et al. (2006). "Mantle flow under the western United States from shear wave splitting". In: Earth and Planetary Science Letters. ISSN: 0012821X. DOI: 10.1016/j.epsl. 2006.05 .010 .

Debayle, E., F. Dubuffet, and S. Durand (2016). "An automatically updated S-wave model of the upper mantle and the depth extent of azimuthal anisotropy". In: Geophysical Research Letters. ISSN: 19448007. DOI: 10.1002/2015GL067329.

Hu, J., M. Faccenda, and L. Liu (2017). "Subduction-controlled mantle flow and seismic anisotropy in South America". In: Earth and Planetary Science Letters. ISSN: 0012821X. DOI: $10.1016 / \mathrm{j}$. epsl.2017.04.027.

Menke, W. and V. Levin (2003). "The cross-convolution method for interpreting SKS splitting observations, with application to one and two-layer anisotropic earth models". In: Geophysical Journal International. ISSN: 0956540X. DOI: 10.1046/j.1365-246X.2003.01937.x.

Silver, P. G. and M. K. Savage (1994). "The Interpretation of Shear Wave Splitting Parameters In the Presence of Two Anisotropic Layers". In: Geophysical Journal International. DoI: 10.1111/j.1365-246X.1994.tb04027.x. 


\section{Chapter 4}

\section{Conclusion}

\subsection{Final Conclusions}

In this work we present new measurements of shear wave splitting in Brazil and some neighboring countries, in areas not well sampled before. In general, considering the previous and new results in the continental midplate South America, the fast polarization orientations have an average E-W trend, previously related with the absolute plate motion directions (HS3NUVEL1A). Our results show that the subduction-induced, time dependent flow model of $\mathrm{Hu}$ et. al., (2017), provides a much better explanation for the SWS observations, which is seen using three proxies: convection time dependent mantle velocity and computed LPO from TI axis at $250 \mathrm{~km}$ depth. We also compare the results with the computed SWS directions of $\mathrm{Hu}$ et. al., (2017), however those do not provide a good fit to the data. Most observed orientations are consistent with the flow around the Amazon craton, predicted by their model. We also support the existence of a cratonic block under the Paraná basin, the Paranapanema block, which diverts mantle flow. The small delay times observed in the Paranapanema block seem to be typical of other cratonic areas, such as the Amazon craton. 


\subsection{Summary of Achievements}

During these two years of M.Sc. research, several activities and achievements have been developed. Beyond the paper entitled "Mantle Anisotropy and Asthenospheric Flow Around Cratons in Southeastern South America" presented here as body of this dissertation, this work has been presented at two conferences. On the 21st of April of 2017 this work was presented as the poster "Asthenospheric Flow Around the Paraná Basin Cratonic Nucleus Measured with SKS splitting" at the "XXVII Reunión Científica de la Asociación Argentina de Geofísicos y Geodestas" in La Plata, Argentina, and was awarded as the best poster presentation of the Earth's Interior Thematic Section. And on the 14th of November of 2017 "Mantle Anisotropy And Asthenospheric Flow Around Cratons In Southeastern South America" was presented at the II Simpósio Brasileiro de Sismologia at João Pessoa, Brazil. Moreover, an abstract entitled "SKS Seismic Anisotropy Observations in Mid-Plate South America: Investigating Mantle Flow and Effects of Cratonic Keels" has been accepted at this year's Seismology of the Americas meeting at Miami, US.

\subsection{Future Work}

The Brazilian Seismographic Network now counts with a large number of stations and high amount of data. This dissertation can serve as an initial study of the anisotropy in the stable South American platform, and with more data availability and focus in this area, expanding on these findings will be crucial to our understanding of the region in depth.

Although a single horizontal layer of anisotropy is a common simplified hypothesis in shear wave splitting studies, one makes significant assumptions about the orientation and symmetry of anisotropy, while also simplifying the XKS ray paths as being vertically incident. Given the variability of the shear wave splitting measurements in this area, we can say that there are regions where a more detailed study, focusing on the analyses of other anisotropic models can reveal anisotropic structures not yet observed. The stations in Brazil and the stations of the temporary FAPESP "3-Basin" deployment provide a unique opportunity to test different 
models of anisotropy forming mechanisms in the vicinity of a cratonic margin. It is plausible to assume that there are both a lithospheric and an asthenospheric components to the upper mantle anisotropy. Therefore, a natural recommendation for future work is to expand the interpretations to these more complex anisotropy scenarios. Older stations with larger datasets should provide enough back-azimuthal coverage to effectively test the 2-layer hypothesis or even other more complex anisotropic structures. 


\section{Appendix A}

\section{Supplementary Material}

Table A.1: Complete list of the new XKS splitting results calculated with the average of all individual results. $\phi$ are fast polarization orientations and $\mathrm{d} \phi$ are the errors; $\delta t$ is splitting delay time and $\mathrm{d} \delta t$ are the errors; $\mathrm{N}$ is the number of measurements; null values represent stations where only null measurements were available. BR and BL networks are part of the Brazilian Seismographic Network (RSBR). XC is the temporary deployment of the "3 Basins" project.

\begin{tabular}{ccccccccc}
\hline \hline Net & Sta & Lat $\left(^{\circ}\right)$ & Lon $\left(^{\circ}\right)$ & $\phi\left(^{\circ}\right)$ & $d \phi\left(^{\circ}\right)$ & $\delta \mathbf{t}$ & $d \delta \mathbf{t}$ & $\mathbf{~ N}$ \\
\hline BL & AQDB & -20.48 & -55.70 & 95.5 & 15.7 & 0.77 & 0.23 & 26 \\
BL & BSCB & -21.00 & -44.76 & 113.9 & 18.0 & 0.87 & 0.42 & 22 \\
BL & C2SB & -18.77 & -52.84 & 90.3 & 19.6 & 0.59 & 0.18 & 15 \\
BL & CLDB & -10.87 & -55.80 & 81.8 & 8.4 & 0.86 & 0.21 & 38 \\
BL & CNLB & -29.31 & -50.85 & 85.4 & 11.8 & 0.98 & 0.24 & 33 \\
BL & ITAB & -27.23 & -52.13 & 104.1 & 11.0 & 1.29 & 0.33 & 48 \\
BL & ITQB & -29.66 & -56.63 & 113.6 & 17.8 & 1.02 & 0.26 & 27 \\
BL & ITRB & -19.70 & -50.36 & 110.6 & 17.3 & 0.90 & 0.29 & 40 \\
BL & PCMB & -21.61 & -51.26 & 85.5 & 12.6 & 0.72 & 0.17 & 22 \\
BL & PEXB & -12.11 & -48.30 & 89.2 & 24.7 & 0.70 & 0.20 & 14 \\
BL & PLTB & -31.76 & -53.60 & 99.1 & 11.1 & 1.24 & 0.29 & 53 \\
BL & PP1b & -17.60 & -54.88 & 79.2 & 9.7 & 0.91 & 0.22 & 13 \\
BL & PTGB & -24.72 & -52.01 & 65.8 & 20.9 & 1.01 & 0.29 & 40 \\
BL & TRCB & -22.79 & -52.64 & 83.5 & 21.2 & 0.83 & 0.32 & 26 \\
BR & ARAG & -15.71 & -51.81 & 61.6 & 32.4 & 1.50 & 0.48 & 5 \\
BR & BOAV & 2.40 & -60.52 & 71.5 & 8.8 & 0.79 & 0.18 & 4 \\
BR & CZSB & -7.73 & -72.70 & 129.0 & 0.0 & 1.23 & 0.00 & 1 \\
BR & ETMB & -9.82 & -66.21 & 45.5 & 34.6 & 1.08 & 0.07 & 2 \\
BR & IPMB & -17.98 & -48.21 & 85.0 & 16.6 & 0.69 & 0.24 & 23 \\
BR & ITTB & -4.37 & -55.73 & 106.4 & 30.8 & 0.78 & 0.45 & 13 \\
BR & JANB & -15.06 & -44.31 & 122.9 & 13.9 & 1.09 & 0.41 & 3 \\
BR & MACA & -3.16 & -60.68 & 119.6 & 17.4 & 0.62 & 0.14 & 13 \\
BR & MALB & -1.85 & -54.26 & 98.6 & 11.4 & 0.70 & 0.18 & 20 \\
BR & MC01 & -16.71 & -43.94 & 105.0 & 0.0 & 0.31 & 0.00 & 1 \\
BR & MCPB & -0.36 & -52.06 & 93.4 & 18.3 & 0.98 & 0.37 & 15 \\
\hline & & & & & Continued on & next & page \\
\hline
\end{tabular}


Table A.1 - continued from previous page

\begin{tabular}{|c|c|c|c|c|c|c|c|c|}
\hline Net & Sta & Lat $\left(^{\circ}\right)$ & Lon $\left(^{\circ}\right)$ & $\phi\left(^{\circ}\right)$ & $d \phi\left(^{\circ}\right)$ & $\delta \mathbf{t}$ & $d \delta \mathbf{t}$ & $\mathbf{N}$ \\
\hline $\mathrm{BR}$ & NPGB & -7.05 & -55.36 & 84.7 & 10.3 & 0.90 & 0.36 & 15 \\
\hline BR & PDRB & -11.61 & -56.73 & 111.8 & 12.7 & 1.01 & 0.30 & 17 \\
\hline BR & PRPB & -6.17 & -49.81 & 76.6 & 16.0 & 1.11 & 0.26 & 15 \\
\hline $\mathrm{BR}$ & PTLB & -15.45 & -59.14 & 91.3 & 26.7 & 0.82 & 0.20 & 24 \\
\hline BR & ROSB & -2.90 & -44.12 & 88.4 & 12.9 & 1.09 & 0.22 & 20 \\
\hline $\mathrm{BR}$ & SALB & -15.90 & -55.69 & 71.5 & 23.3 & 1.69 & 0.56 & 29 \\
\hline BR & SDBA & -12.41 & -44.90 & 130.1 & 41.7 & 1.16 & 0.63 & 9 \\
\hline $\mathrm{BR}$ & SGCB & -0.12 & -67.03 & 77.4 & 14.0 & 0.95 & 0.40 & 8 \\
\hline BR & SMTB & -8.86 & -47.59 & 123.2 & 13.9 & 0.86 & 0.31 & 7 \\
\hline $\mathrm{BR}$ & SNDB & -11.97 & -51.29 & 101.4 & 27.3 & 0.79 & 0.35 & 4 \\
\hline $\mathrm{BR}$ & TBTG & -4.19 & -69.91 & 87.8 & 21.3 & 0.75 & 0.21 & 15 \\
\hline $\mathrm{BR}$ & TEFE & -3.51 & -64.63 & 84.5 & 15.0 & 0.44 & 0.13 & 4 \\
\hline $\mathrm{BR}$ & TMAB & -2.37 & -48.10 & 97.9 & 15.9 & 1.03 & 0.30 & 4 \\
\hline $\mathrm{BR}$ & VILB & -12.95 & -60.20 & 116.9 & 37.1 & 0.79 & 0.24 & 13 \\
\hline $\mathrm{XC}$ & ALGR & -28.80 & -53.03 & 87.4 & 16.5 & 0.98 & 0.32 & 9 \\
\hline $\mathrm{XC}$ & ANTJ & -22.00 & -56.00 & 90.1 & 18.2 & 0.87 & 0.35 & 4 \\
\hline $\mathrm{XC}$ & AZCA & -28.08 & -55.98 & 100.2 & 14.4 & 0.91 & 0.32 & 7 \\
\hline $\mathrm{XC}$ & BBLB & -18.67 & -58.80 & 78.2 & 6.8 & 1.43 & 0.36 & 11 \\
\hline $\mathrm{XC}$ & BBRB & -18.28 & -59.81 & 79.8 & 9.8 & 0.87 & 0.19 & 8 \\
\hline $\mathrm{XC}$ & BBSD & -17.19 & -60.61 & 109.2 & 21.7 & 0.58 & 0.12 & 3 \\
\hline $\mathrm{XC}$ & $\mathrm{BDQN}$ & -20.45 & -56.75 & 83.5 & 19.1 & 1.18 & 0.51 & 2 \\
\hline $\mathrm{XC}$ & CRSM & -27.49 & -54.04 & 103.8 & 5.8 & 1.23 & 0.37 & 7 \\
\hline $\mathrm{XC}$ & DVLD & -16.64 & -52.16 & 95.6 & 10.2 & 1.51 & 0.42 & 8 \\
\hline $\mathrm{XC}$ & ESFA & -24.96 & -58.49 & 100.4 & 9.7 & 1.64 & 0.84 & 5 \\
\hline $\mathrm{XC}$ & FRBT & -25.98 & -53.06 & 84.9 & 19.2 & 1.06 & 0.37 & 17 \\
\hline $\mathrm{XC}$ & MECA & -29.30 & -58.17 & 100.5 & 3.8 & 0.95 & 0.33 & 4 \\
\hline $\mathrm{XC}$ & MURT & -21.66 & -57.61 & 73.4 & 11.9 & 1.29 & 0.33 & 5 \\
\hline $\mathrm{XC}$ & NBRS & -14.32 & -55.78 & 108.6 & 15.0 & 0.69 & 0.24 & 4 \\
\hline $\mathrm{XC}$ & PANT & -18.99 & -56.62 & 71.0 & 0.0 & 1.85 & 0.00 & 1 \\
\hline $\mathrm{XC}$ & POCN & -16.62 & -56.73 & 75.5 & 6.0 & 1.51 & 0.40 & 4 \\
\hline $\mathrm{XC}$ & PTET & -15.38 & -57.16 & 93.4 & 8.1 & 0.92 & 0.39 & 5 \\
\hline $\mathrm{XC}$ & RODS & -30.35 & -55.20 & 109.0 & 1.0 & 1.20 & 0.16 & 3 \\
\hline $\mathrm{XC}$ & RVDE & -19.03 & -54.94 & 79.0 & 8.0 & 1.15 & 0.20 & 5 \\
\hline $\mathrm{XC}$ & TBOT & -31.68 & -55.94 & 102.0 & 2.8 & 1.18 & 0.22 & 2 \\
\hline $\mathrm{XC}$ & UNIS & -29.07 & -55.07 & 103.5 & 74.9 & 0.99 & 0.38 & 6 \\
\hline $\mathrm{XC}$ & VBST & -14.53 & -60.02 & 108.0 & 30.1 & 0.92 & 0.47 & 10 \\
\hline
\end{tabular}

\section{A.1 Figures}




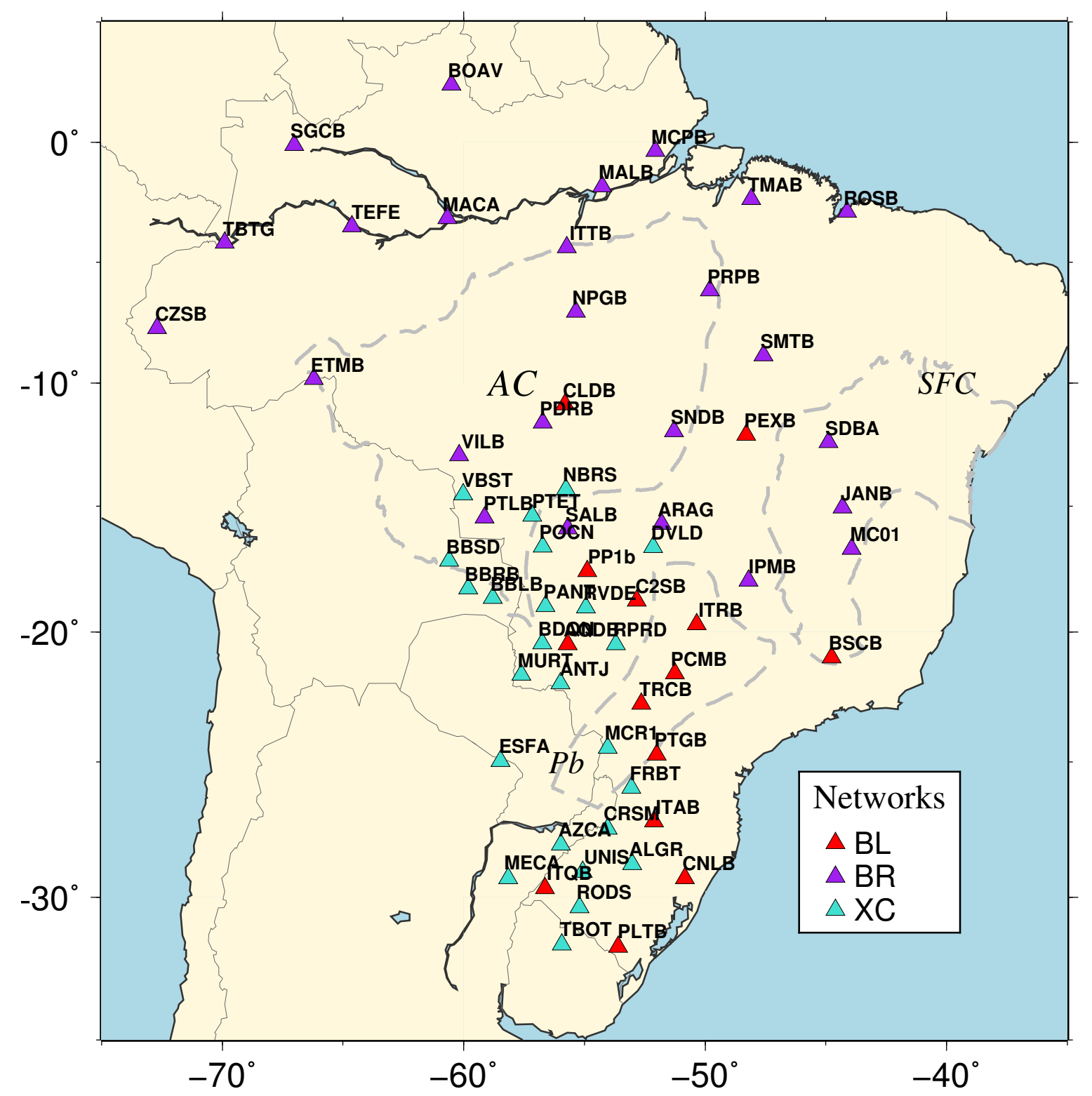

Figure A.1: Station names and their respective networks used in this paper. AC: Amazon craton; SFC: São Francisco craton; Pb: Paranapanema Block. 